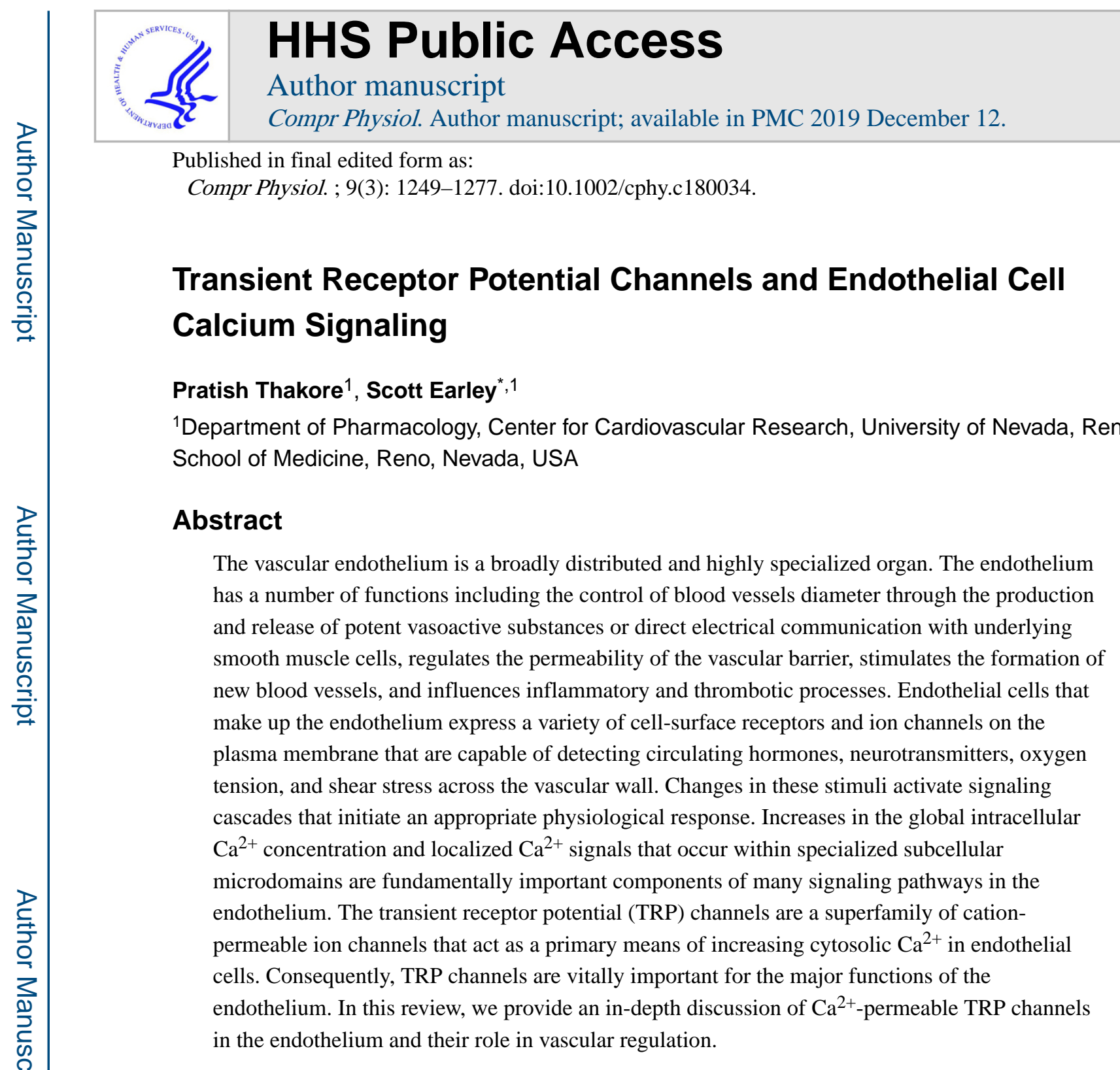

\title{
Introduction
}

The vascular endothelium is a large, spatially distributed organ that is formed by a monolayer of specialized endothelial cells lining the lumen of all blood vessels. The term "endothelium" first appeared in print in 1865 in a report from the Swiss anatomist Wilhelm His (6). Historically, the endothelium was described as an inert protective barrier between the contents of the vascular lumen and the interstitium. This changed in 1976, when Moncada and colleagues proposed a potential role for the endothelium as a source of potent vasoactive substances based on the discovery of a novel endothelium-derived prostanoid, later identified as prostacyclin, with antithrombotic and vasodilatory properties (186). A subsequent landmark study by Furchgott and Zawadzki(93) led to the discovery of nitric oxide (NO) as a critically important endothelium-derived vasodilator $(123,125)$. In the

*Correspondence to searley@med.unr.edu.

Disclosures

The authors have no conflicts of interest, financial or otherwise, to report. 
decades following these ground-breaking investigations, the importance of the endothelium in regulating vascular function has become firmly established. Importantly, endothelial dysfunction is a hallmark of many common cardiovascular diseases, such as hypertension and atherosclerosis, as well as inflammatory diseases, including systemic lupus erythematosus and rheumatoid arthritis.

The endothelium regulates the contractility of the underlying smooth muscle cells (SMCs), the permeability of the vascular wall, promotes the formation of new blood vessels, and prevents coagulation of blood. Optimal function of the endothelium is dependent on the ability of endothelial cells to detect a vast array of chemical and physical stimuli and engage appropriate intracellular signal transduction cascades to elicit suitable physiological responses. The endothelium is the only tissue in the body that maintains constant contact with the circulating blood. Because of this unique anatomical position, endothelial cells are able to detect circulating hormones and neurotransmitters, oxygen tension, and shear stress resulting from the flow of blood. The ability to detect these diverse stimuli is enabled by a large number of G-protein-coupled and enzyme-linked cell surface receptors and ion channels on the plasma membrane of endothelial cells. Consequently, the endothelium can be viewed as an intricate sensory system that is capable of sensing and integrating numerous inputs to achieve vascular homeostasis and adaptability.

This review explores the current literature on the roles of the transient receptor potential (TRP) superfamily of cation channels in the regulation of endothelial cell function, focusing on signaling pathways that are regulated by $\mathrm{Ca}^{2+}$ ions.

\section{Functions of the Endothelium}

\section{Endothelium-dependent vasodilation}

Stimulation of the vascular endothelium with specific agonists that signal through G-proteincoupled receptors (GPCRs) results in the generation of vasodilator substances that diffuse to and relax the underlying SMCs (Fig. 1). In addition to agonist-induced stimulation, increases in blood flow velocity and relaxation of the smooth muscle layer can occur in response to the laminar shear stress experienced by the vascular wall, a vasodilator response known as "flow-induced dilation" (60). From an in vivo perspective, endothelial-derived vasodilators offset the effects of tonic vasoconstrictor influences and serve to maintain the optimal balance for the appropriate intermediate level of smooth muscle contractility and arterial diameter ("vascular tone"). Prostacyclin $\left(\mathrm{PGI}_{2}\right)$, produced by cyclooxygenase (COX) enzymes (209), and NO, produced by endothelial nitric oxide synthase (eNOS)(93), were the first endothelium-derived vasodilators to be identified at the molecular level. However, agonist-induced, endothelium-dependent vasodilation persists during pharmacological inhibition of NOS and COX, demonstrating the existence of additional pathways. This response was initially credited to an unidentified substance termed "endothelium-derived hyperpolarizing factor" (EDHF), reflecting the fact that NOS- and COX-independent relaxation of SMCs was associated with hyperpolarization of the SMC plasma membrane (44). The precise identity of EDHF has been the subject of countless investigation by numerous laboratories. These studies have implicated multiple diffusible factors as candidate vasodilators, including $\mathrm{K}^{+}$ions (81); epoxyeicosatrienoic acids (EETs) $(40,88)$, a family of 
four regioisomers (5,6-EET, 8,9-EET, 11,12-EET, and 14,15-EET) generated from arachidonic acid by the action of cytochrome P450 (CYP) epoxygenase enzymes (40, 78, 83, 88 ); hydrogen peroxide $\left(\mathrm{H}_{2} \mathrm{O}_{2}\right)$; hydrogen sulfide $\left(\mathrm{H}_{2} \mathrm{~S}\right)$; C-type natriuretic peptide; and carbon monoxide, among others (82). In addition to these diffusible substances, direct propagation of membrane hyperpolarization from endothelial cells to SMCs through myoendothelial gap junctions has been shown to induce vasodilation. This is often referred to as endothelium-dependent hyperpolarization (EDH) to differentiate it from EDHF-type vasodilation mediated by diffusible substances (95).

\section{Vascular permeability and transfer of solutes and macromolecules}

The vascular endothelium forms a semipermeable barrier between the blood and the surrounding tissue that regulates the passage of solutes and macromolecules across the vascular wall. This permeability takes two forms: basal permeability at the level of capillaries, which mediates exchange of nutrients and gases, and permeability associated with inflammation, which occurs primarily at the level of post-capillary venules. Transcellular transportation involves the shuttling of molecules with molecular radii greater than $3 \mathrm{~nm}$ through the endothelial cell by caveolae via receptor-dependent or -independent mechanisms (182). An important signaling event in this pathway is Src-dependent tyrosine phosphorylation of caveolin-1, which initiates fission of the membrane-bound vesicle, resulting in endocytosis at the apical/luminal membrane, transmigration of the vesicle across the cell, fusion with the basolateral/abluminal membrane, and exocytosis $(121,158,237)$. Under basal conditions, tight and adherens junctions interact with the endothelial actin cytoskeleton, allowing mechanical coupling between adjacent endothelial cells and forming a restrictive barrier that prevents transport of macromolecules across the endothelial layer at cell-cell junctions (i.e., paracellular). Endothelial cell morphology also governs the adhesive force coupling adjacent cells. However, in response to certain receptor agonists, including histamine, serotonin, thrombin, and bradykinin, or under certain conditions, such as inflammation or angiogenesis, endothelial cells retract causing a reorganization of the cytoskeleton that allows passage of macromolecules via the paracellular route(54). Dysfunction of the endothelial barrier, for example during inflammation, leads to excessive plasma extravasation. When plasma extravasation exceeds both reabsorption into the blood stream and the ability of the lymphatic system to remove fluid, the result is edema formation in the surrounding tissue.

\section{Formation of the vascular network}

The endothelium plays a critical role in the development of the vascular network. The process by which a stable vasculature is created can be subdivided into three categories: vasculogenesis, angiogenesis, and arteriogenesis. Vasculogenesis refers to the process responsible for the formation of a primitive vascular network during embryonic development. In contrast, angiogenesis is the tightly regulated process by which new blood vessels form from pre-existing vessels. The turnover rate of quiescent endothelial cells is typically on the order of hundreds of days. However, in response to proangiogenic factors, such as vascular endothelial growth factor (VEGF), endothelial cells proliferate rapidly, exhibiting a turnover rate of less than 5 days (90). Destabilization of the basal lamina and surrounding extracellular matrix of the mature vessel is required for new endothelial cells to 
emigrate. Following this destabilization process, growth factors and chemoattractants promote the proliferation and migration of endothelial cells toward a target location. Arteriogenesis is the process by which newly formed blood vessels stabilize to form a mature blood vessel through recruitment of SMCs or pericytes and generation of an extracellular matrix.

\section{Leukocyte trafficking}

Interactions between circulating leukocytes and endothelial cells contribute to the immune response and wound repair. Under basal conditions, leukocytes do not adhere to the endothelium. However, following stimulation of endothelial cells, leukocytes rolling on the luminal surface of the endothelium establish close contact, beginning the recruitment process. This process is dependent on membrane localization of selectin family of adhesion molecules on both cell types. Rolling facilitates leukocyte activation in response to endothelium-derived chemokines. Leukocyte activation results in a conformational change in leukocyte integrins, which interact with their respective adhesion molecule ligands on endothelial cells, resulting in firm adhesion and arrest of rolling. Transendothelial migration of leukocytes occurs primarily through inter-endothelial junctions following disruption of tight and adherence junctions, but transcellular migration has also been observed (313).

\section{Thrombosis}

Quiescent endothelial cells release and express certain factors on their luminal surface that confer an anticoagulant quality. In contrast, the basal lamina, which may become accessible to blood components under certain conditions (see later), is strongly thrombogenic, as are endothelial cells stimulated with procoagulant factors. Thus, endothelial cells are important in regulating the equilibrium of thrombus formation.

NO and prostacyclin, which inhibit platelet adhesion and aggregation, are constitutively released by endothelial cells (223). 3-hydroxyoctadecadienoic acid, synthesized via lipoxygenase pathways in resting endothelial cells, inhibit platelet aggregation by acting as a negative regulator for the adhesion receptor vitronectin $(35,36)$. Membrane-bound ectonucleotidases on cell surface of endothelial cells metabolize ATP and ADP to prevent platelet activation $(191,289)$. The thrombin receptor thrombomodulin is also expressed on the surface of endothelial cells (226). Binding to this receptor converts thrombin, a highly potent procoagulant, to an anticoagulant enzyme that serves to activate protein $\mathrm{C}$, which halts the coagulation cascade. The cell surface of endothelial cells are enriched with heparinlike sulfated glycosaminoglycan molecules that bind and activate the thrombin inhibitor antithrombin (203).

Disruption of the continuity of the endothelium exposes the highly procoagulant basal lamina, allowing circulating platelets to adhere and initiate hemostasis. von Willebrand factor (vWf), a large, multimeric protein that is synthesized and stored within endothelial cells (129), plays a critical role in initial platelet recruitment and thrombus formation. Following release, vWf binds to exposed collagen, serving as a bridge between platelets and the exposed tissue, and a mediator of endothelial cell-platelet interactions $(33,289)$. Endothelial cells also synthesize platelet-activating factor (PAF), which further promotes 
platelet activation and adherence. Following initiation of coagulation, degranulation of activated platelets is predominantly responsible for further recruitment and aggregation of platelets. However, platelet-derived ADP, ATP, or serotonin can facilitate endothelium production of the arachidonic acid metabolite thromboxane A2, whereas platelet-derived thrombin upregulates vWf and tissue factor to further promote thrombogenesis (210). Once the blood clot has served its purpose, the endothelium induces fibrinolysis by converting inactive plasminogen to active plasmin through tissue-type plasminogen activator or urokinase-type plasminogen activator.

\section{$\mathrm{Ca}^{2+}$ as a Second Messenger in the Endothelium}

Free cytosolic $\mathrm{Ca}^{2+}$ ions are integral components of the signaling cascades that regulate many of the primary functions of endothelial cells, including the synthesis and release of vasoactive factors, control of permeability, cellular proliferation, and angiogenesis. The effects of $\mathrm{Ca}^{2+}$ are mediated by factors that directly associate with free $\mathrm{Ca}^{2+}$. Although some effector proteins contain intrinsic $\mathrm{Ca}^{2+}$ domains, such as the $\mathrm{C} 2$ domain or the EF-hand motif, in most cases, $\mathrm{Ca}^{2+}$ associated with the intermediate factor calmodulin, an EF-hand motif-containing $\mathrm{Ca}^{2+}$-binding protein, underlies $\mathrm{Ca}^{2+-}$ dependent regulation. Binding of $\mathrm{Ca}^{2+} /$ calmodulin to such effectors elicits a number of physiological effects, including eNOSdependent production of NO (39).

Endothelial cells do not express voltage-dependent $\mathrm{K}^{+}, \mathrm{Ca}^{2+}$, or $\mathrm{Na}^{+}$ion channels and thus are nonexcitable cells. In such cells, changes in intracellular $\mathrm{Ca}^{2+}$ concentration result from activation of GPCRs that signal through $\mathrm{G}_{\mathrm{q} / 11}$-type $\mathrm{G}$-proteins $\left(\mathrm{G}_{\mathrm{q}} \mathrm{PCRs}\right)$ or responses to mechanical stimuli, with shear stress being the prime example in the endothelium. $\mathrm{G}_{\mathrm{q}} \mathrm{PCR}$ mediated increases in intracellular $\mathrm{Ca}^{2+}$ occur in a biphasic manner, reflecting an initial release of $\mathrm{Ca}^{2+}$ from intracellular stores, primarily from inositol 1,4,5-trisphosphate $\left(\mathrm{IP}_{3}\right)$ on the endoplasmic reticulum (ER) membrane, and subsequent influx of $\mathrm{Ca}^{2+}$ from the extracellular space through integral plasma membrane ion channels $(38,298)$. The ER accounts for approximately $75 \%$ of the $\mathrm{Ca}^{2+}$ reserves of endothelial cells, while the remaining $25 \%$ is contained within mitochondria (283). Increases in intracellular $\mathrm{Ca}^{2+}$ are typically associated with membrane hyperpolarization due to activation of intermediate- and small-conductance $\mathrm{Ca}^{2+}$-sensitive $\mathrm{K}^{+}$channels (IK and SK, respectively) $(38,175)$. GPCR activation may also facilitate entry of $\mathrm{Ca}^{2+}$ through receptor-operated channels. Depletion of $\mathrm{Ca}^{2+}$ reserves in the ER, either through $\mathrm{G}_{\mathrm{q}}$ PCR stimulation or inhibition of the $\mathrm{Ca}^{2+}$ pumps responsible for $\mathrm{Ca}^{2+}$ re-uptake into the ER, promotes a rise in intracellular $\mathrm{Ca}^{2+}$ through store-operated channels, a process known as store-operated $\mathrm{Ca}^{2+}$ entry (SOCE).

\section{Heterogeneity of the Endothelium}

The endothelium exhibits differences in cellular morphology, protein expression, and function between tissues, segments of the vascular network within the same organ, and among adjacent endothelial cells in a single artery (153). For example, functional IK and SK channels are present endothelial cells from mouse cerebral arteries and arterioles (151) but are absent from cerebral capillary endothelial cells (168). Another illustration is provided by high-resolution $\mathrm{Ca}^{2+}$ imaging experiments demonstrating that individual endothelial cells 
within the intact endothelium exhibit diffing sensitivity to carbachol and adenosine triphosphate (153). Phenotypic heterogeneity of the endothelium is thought to be a consequence of transcription factor-dependent gene expression in response to the local microenvironment as well as epigenetic modification (5). Transcriptional plasticity limits the utility of cell culture methodology for studying endothelial cell function, as illustrated by a study comparing the transcriptional profile of freshly isolated and cultured porcine coronary and iliac artery endothelial cells. Differences in gene expression between native endothelial cells isolated from the two vascular beds were largely absent from cell exposed to culture conditions $(37,334)$. These findings are supported by a study from Lacorre et al. reporting a loss of $50 \%$ of vascular bed-specific genes of human tonsil endothelial cells when cultured in vitro (148). Adaptation to cell culture conditions could account for discrepancies between observations made in vitro compared with native endothelial cell and in vivo studies discussed later in this review.

\section{The TRP Superfamily of Cation Channels}

TRP channels were discovered during investigations of Drosophila phototransduction mutants that could see normally in dim light, but behaved as if blind under bright light(58). Subsequent bioinformatic studies revealed the presence of several conserved genes encoding TRP channel proteins in many other organisms, including mammals. Mammalian genomes were found to encode 27 or 28 (depending on species) individual genes encoding distinct TRP subunits, which together constitute the TRP superfamily. The TRP genes and their products have been assigned to six subfami-lies based on sequence homology: ankyrin (TRPA), canonical (TRPC), vanilloid (TRPV), melastatin (TRPM), mucolipin (TRPML), and polycystin (TRPP) (55). TRPC2, important for pheromone sensing in rodents (171), is a nonexpressed pseudogene in humans (326). Transcriptional splice variants have been described for almost all individual TRP proteins (295).

The terminology used for the TRPP subfamily is confusing and requires clarification. Polycystin-1 protein encoded by the PKD1 gene is often referred to as TRPP1. However, $P K D 1$ encodes a protein with 11 transmembrane domains that does not form an ion-channel and is unrelated to TRP channels (308). Further, TRPP2, TRPP3, and TRPP5 have been described as products of the $P K D 2$ (polycystic kidney disease 2) gene, $P K D 2 L 1$ (polycystic kidney disease 2-like1) gene and PKD2L2 (polycystic kidney disease 2-like 2). In this review, TRPP1 refers to $P K D 2$, TRPP2 for PKD2L1, and TRPP3 for PKD2L2.

Additional reviews on TRP channels can be found elsewhere $(74,89,197)$.

\section{TRP Channel Structure}

Electron cryo-microscopy (cryo-EM) (162) has been used to reveal the protein structures of many TRP channels at near-atomic resolution (3-4 ̊), providing unique insights into channel function and regulation. These studies show that the transmembrane core region of all TRP channels are similar in overall structural organization to voltage-gated $\mathrm{K}^{+}\left(\mathrm{K}_{\mathrm{V}}\right)$ channels (167). Fully assembled TRP channels are composed of four subunits symmetrically arranged around a central ion-permeable pore. Each TRP subunit contains six trans- 
membrane a-helix domains (S1-S6) and a re-entrant pore loop between the S5 and S6 domains. Distinctive intracellular domains present on the $\mathrm{N}$ - and C-termini outside of this core pore-forming region characteristic of each TRP subfamily impact regulation and protein-protein interactions.

TRPV1, the first full-length TRP channel structure to be reported at high-resolution, typifies the TRPV subfamily $(41,163)$. Six ankyrin repeat domains are present at the intracellular Nterminus followed by a linker region that is close to an a-helix forming part of the intracellular pre-S1 domain. The TRP domain, a 23 to 25 amino acid region that is conserved in many members of the TRP superfamily, is present on the C-terminal side of the pore-forming region, immediately distal to the S6 domain. The function of the TRP domain has not been definitively established, but it has been proposed to be involved in subunit assembly or allosteric regulation of channel activity. The overall structure of TRPV2 channels determined by cryo-EM is nearly identical to that of TRPV1, with subtle differences in the selectivity filter $(124,341)$. X-ray crystallography and cryo-EM structures of TRPV4 channels from Xenopus tropicalis also reveal a shared structural organization with TRPV1 and TRPV2 (63). A unique structural feature of TRPV4 channels is the organization of the S1-S4 domain, which is rotated $90^{\circ}$ compared with that in TRPV1 (63). In addition, the selectivity filter of TRPV4 is in an expanded configuration compared with that in TRPV1, possibly accounting for differences in the selectivity for monovalent compared with divalent cations between the two channels (63). The cryo-EM structures of the highly $\mathrm{Ca}^{2+}$-selective channels, TRPV5 and TRPV6, demonstrate that these channels share the overall organization that is common to all TRPV subfamily members $(122,231)$. Unique features of these channels include the a-helical linker region between the S4 and S5 transmembrane domains, which is unstructured in TRPV6 (231). In addition, differences in the cation binding sites of the selectivity filter account for the conspicuous $\mathrm{Ca}^{2+}$ selectivity of TRPV5 and TRPV6 compared with TRPV1 and TRPV2 channels (231).

A high-resolution cryo-EM structure of the human TRPA1 channel has also been reported (208). The defining structural feature of TRPA1 is an array of 16 ankyrin repeat domains at the $\mathrm{N}$ terminus. Structural analyses also show that specific cysteine and lysine residues (Cys 621, Cys 641, Cys 665, and Lys 710), which are necessary for channel activation by electrophilic compounds, are located in a pre-S1 a-helix located within a solvent-accessible pocket that lies just below the plasma membrane. The pore loop domain between S5 and S6 contains two a-helix domains, and a TRP domain immediately follows S6. A coiled-coil domain, which is proposed to stabilize subunit interactions (208), is present at the Nterminus. Compared with TRPV1, the intracellular region of assembled TRPA1 channels adopts a more compact configu-ration. In addition, the outer pore region of TRPA1 contains two pore helices in contrast with TRPV1, which contains a single helix in this region.

Several studies have reported the full-length structure of the monovalent-cation-selective TRPM4 channel from humans and mice at high resolution $(16,72,103,309)$. The $\mathrm{N}$ terminus of this channel encodes four melastatin homology regions (MHRs)—unique domains that are highly conserved among TRPM subfamily members $(16,309)$. It is proposed that part of the MHRs in TRPM4 form a nucleotide-binding domain (NBD) that is responsible for ATP-dependent regulation of the channel (103). The MHRs are also 
proposed to contain a binding pocket for decavanadate (309), a compound that potentiates TRPM4 channel activity (199). The MHRs contain two ankyrin repeat domains that separate the NBD from a region composed of 12 linker helical domains preceding a pre-S1 helix. The TRP domain adjacent to S6 is atypical and is composed of two helices, one of which forms part of a re-entrant loop. The intracellular C-terminus contains a stretcher helical domain and a coiled-coil helix. The structure of the cold- and menthol-sensing channel, TRPM8, from the collared flycatcher is remarkably similar to that of TRPM4, although the pore diameter is slightly larger (328). The difference in pore diameter compared with the TRPM4 channel may account for the differences in permeability of divalent cations between these channels. The structure of TRPM2 from Nematostella vectensis has also been reported and shown to have an organization similar to that of TRPM4 and TRPM8, with a few notable differences (337). The C-terminus of TRPM2 contains a NUDT9-homology domain that binds ADP-ribose and is involved in regulation of channel activity. In addition, the ionic pore of TRPM2 channels has a large diameter and a greater negative surface charge compared with that of TRPM4, possibly accounting for the larger unitary conductance and higher permeability of TRPM2 for divalent cations. TRPM7, important for $\mathrm{Mg}^{2+}$ homeostasis, shares its overall organization with that of other TRPM channels (71), but also contains a kinase domain at the C-terminus (323). Notably, a single amino acid difference in the selectivity filter of TRPM7 $\left({ }^{1045} \mathrm{FGE}^{1047}\right)$ compared with that of TRPM4 $\left({ }^{975} \mathrm{FGQ}^{977}\right)$ likely imparts the permeability of TRPM7 to divalent cations (71).

High-resolution structures of TRPC3, TRPC4, and TRPC6, members of the canonical TRP subfamily, have been reported $(17,70,85,272,292)$. TRPC channels share a similar overall structural organization that includes four ankyrin repeat domains and several linker helical domains in the $\mathrm{N}$-terminus immediately prior to the pre-S1 helix. A pre-S1 "elbow" domain embedded within the lipid bilayer is present in all TRPC channel subtypes and may contribute to lipid-dependent channel activation $(85,272,292)$. The S3 domain of TRPC3 and TRPC6 is longer than that of TRPV, TRPA1, and TRPM, and may serve as a binding site for extracellular molecules (85). Intracellular rib and vertical helix domains, which form an inverted " $\mathrm{L}$ " shape, are present at the C-terminus immediately following the TRP domain region.

The TRPML and TRPP subfamilies form the group II TRP channels (287). Cryo-EM characterizations of the structures of these channels indicate an overall architecture similar to that of other TRP channels, but with the inclusion of a large extracellular polycystinmucolipin domain (PMD; also referred to as the TOP domain) between the S1 and S2 transmembrane domains $(46,101,116,157,236,242,263,306,336,338)$. It has been proposed that the PMD acts as a physical cover of the pore that can interact with extracellular factors to regulate channel activity (242). The structures of TRPP1 (PKD2) and TRPP2 (PKD2L1) channels are remarkably similar, with differences in the selectivity filter that account for differences in monovalent versus divalent ion permeability.

All TRP subtypes, with the possible exception of TRPC1 (256), appear to form functional homomeric cation channels. In addition, multiple TRP subtypes can form heteromeric channels composed of two (or even three) related types in various cell types in vivo. Formation of heteromeric channels is best characterized for TRPC channels. TRPC1 can 
form heteromeric channels with TRPC3, TRPC4, TRPC5, TRPC6, and TRPC7; TRPC4 and TRPC5 can heteromultimerize with each other; and combinations of TRPC3, TRPC6, and TRPC7 can form heteromeric channels. Other arrangements include channels composed of the closely related sub-types TRPV5 and TRPV6, TRPM6 and TRPM7 (156), and TRPML1 and TRPML3. There is less evidence supporting interactions between channels from different subfamilies, although formation of TRPC1/TRPV4 heteromeric channels in the endothelium (172) and TRPV1/TRPA1 channels in sensory nerves, and other combinations, has been reported. Notably, heteromeric channels display conduction properties and regulatory mechanisms that are distinct from those of homomeric channels.

\section{TRP Channel Currents}

All TRP channels conduct cations and are impermeable to anions, but the relative permeability of specific superfamily members to different types of cations varies widely. TRPM4 and TRPM5 channels are selective for monovalent cations and are essentially impermeable to divalent cations $(118,149,198,219)$, whereas TRPV5 and TRPV6 channels are highly selective for $\mathrm{Ca}^{2+}$ ions compared with $\mathrm{Na}^{+}$ions $\left(\mathrm{P}_{\mathrm{Ca}}: \mathrm{P}_{\mathrm{Na}} \sim 100: 1\right)(200,288,332)$. The remaining TRP channels conduct mixed currents composed of monovalent (primarily $\mathrm{Na}^{+}$and $\mathrm{K}^{+}$) and divalent (primarily $\mathrm{Ca}^{2+}$ ) cations. The specific fractional composition of these mixed cationic currents establishes the physiological effects of channel activity on cellular function. For example, TRPA1, which conducts the highest fractional $\mathrm{Ca}^{2+}$ current of all the TRP channels (with the exception of TRPV5 and TRPV6) (97, 135), can increase global intracellular $\left[\mathrm{Ca}^{2+}\right]$ and/or generate $\mathrm{Ca}^{2+}$ microdomain at the mouth of the channel to initiate $\mathrm{Ca}^{2+}$-sensitive signaling pathways. In contrast, TRPC subfamily members conduct current with a small $\mathrm{Ca}^{2+}$ fraction. Under physiological conditions, the resting membrane potential of endothelial cells in intact blood vessels is hyperpolarized relative to the $\mathrm{Na}^{+}$ equilibrium potential $\left(\mathrm{E}_{\mathrm{Na}}=+60 \mathrm{mV}\right)$ and depolarized relative to the $\mathrm{K}^{+}$equilibrium potential $\left(\mathrm{E}_{\mathrm{K}}=-88 \mathrm{mV}\right)$, and TRPC channels primarily conduct inward $\mathrm{Na}^{+}$currents. Interestingly, the relative permeability of $\mathrm{K}^{+}$ions can influence the fractional $\mathrm{Ca}^{2+}$ composition of TRP channel currents in physiological ionic gradients (114). For example, where the permeability of TRP channels to $\mathrm{Na}^{+}$and $\mathrm{K}^{+}$ions is similar $\left(\mathrm{P}_{\mathrm{K}}=\mathrm{P}_{\mathrm{Na}}\right)$, the reversal potential of the monovalent portion of the current is $\sim 0 \mathrm{mV}$ because no concentration gradient exists between total monovalent cations; thus, the fractional $\mathrm{Ca}^{2+}$ current is determined by the $\mathrm{P}_{\mathrm{Ca}}$ of the conducting channel. However, if $\mathrm{P}_{\mathrm{Na}}>\mathrm{P}_{\mathrm{K}}$, the reversal potential for the monovalent fraction is depolarized (compared with the case of $\mathrm{P}_{\mathrm{K}}=$ $\mathrm{P}_{\mathrm{Na}}$ ), which reduces the driving force for $\mathrm{Ca}^{2+}$ influx and diminishes the $\mathrm{Ca}^{2+}$ fraction of the current. Conversely, if $\mathrm{P}_{\mathrm{K}}>\mathrm{P}_{\mathrm{Na}}$, the cationic reversal potential is more hyperpolarized and the driving force for $\mathrm{Ca}^{2+}$ influx is increased. Differential $\mathrm{K}^{+}$permeability may explain why the $\mathrm{Ca}^{2+}$ fraction of TRPV4 currents is greater compared with TRPC6 currents under physiological conditions, despite a similar $\mathrm{P}_{\mathrm{Ca}}: \mathrm{P}_{\mathrm{Na}}$ ratio, established using ion-substitution methods $(114,119,258)$.

Spatially distinct $\mathrm{Ca}^{2+}$ signals representing $\mathrm{Ca}^{2+}$ influx through single TRP channels or clusters of functionally coupled channels can be recorded from cells loaded with $\mathrm{Ca}^{2+}$ indicators dyes, such as Fluo-4-AM (96), or in cells from animals expressing genetically encoded $\mathrm{Ca}^{2+}$ biosensor proteins, such as GCaMP (130), using fluorescence microscopy 
techniques. This approach has been used to record the activity of TRP channel subtypes that conduct mixed currents with the highest $\mathrm{Ca}^{2+}$ fraction: TRPV4, TRPV3, TRPV1, and TRPA1. These optically detected $\mathrm{Ca}^{2+}$ signals are generically referred to as "sparklets" (297), and are further defined by the name of the conducting channel (e.g., "TRPV4 sparklets"). TRP channel sparklets have been recorded from endothelial cells using spinning disc confocal microscopy and total internal reflection fluorescence (TIRF) microscopy (267). The ability of TIRF microscopy to detect fluorescent $\mathrm{Ca}^{2+}$ signals at the plasma membrane is based on the generation of a low-energy evanescent illumination field when excitation light is reflected away from a glass surface supporting the cells under investigation. The low-energy TIRF field illuminates to a depth of only $~ 100 \mathrm{~nm}$, producing an excellent signal-to-noise ratio. TRPV3, TRPV4, and TRPA1 sparklets have been recorded from the endothelium using TIRF microscopy $(215,266,267)$. The thin morphology of endothelial cells $(\sim 0.3 \mu \mathrm{m})$ facilitates recording of transient subcellular $\mathrm{Ca}^{2+}$ signals using confocal imaging. This method has been used to record TRPV4 sparklets in intact arteries isolated from mice expressing GCaMP Ca ${ }^{2+}$ biosensors exclusively in the endothelium $(253,254)$. In these studies, TRPV4 sparklet amplitudes were shown to display a quantal distribution and exhibit cooperative gating, suggesting that the endothelial TRPV4 channel is present as a four-channel metastructure (253). This coupled gating arrangement amplifies the initial $\mathrm{Ca}^{2+}$ signal created by TRPV4 channel activation and, combined with the biophysical properties of the channel, which favor $\mathrm{Ca}^{2+}$ influx, produces large-amplitude $\mathrm{Ca}^{2+}$ signals in the endothelium. An elegant study from the Santana laboratory that used a combination of TIRF microscopy and patch-clamp electrophysiology to quantify these signals demonstrated that, although the basal channel activity was low, the $\mathrm{Ca}^{2+}$ signal mass of a single TRPV4 sparklet was $~ 100$-fold greater than that of a CaV 1.2 L-type $\mathrm{Ca}^{2+}$ channel sparklet (184). The modal amplitudes of TRPA1 and TRPV3 sparklets are twofold to threefold greater than those of TRPV4 sparklets (215), suggesting that all of these channels can act as a significant point source of $\mathrm{Ca}^{2+}$ influx capable of generating high local intra-cellular $\mathrm{Ca}^{2+}$ concentrations, an essential feature underlying the concept of $\mathrm{Ca}^{2+}$ microdomains. Although the amplitude of individual TRP channel sparklets is large, the total number of active sites per cell is surprisingly low. For example, both Sonkusare et al. (253) and Sullivan et al. (266) showed that only a few TRPV4 sparklets (approximately 3-8 sites/cell) are active in individual endothelial cells during maximal agonist stimulation. The biophysical and pharmacological properties of endothelial TRP channels are summarized in Table 2 .

\section{Functional Roles of TRP Channels in the Vascular Endothelium}

Multiple TRP channel subunits have been reported to be expressed in endothelial cells (265). However, only 11 of these have been reported to have a functional role (summarized in Table 1).

\section{TRP channels and endothelial cell store-operated $\mathrm{Ca}^{2+}$ entry}

SOCE is a specialized $\mathrm{Ca}^{2+}$ influx pathway initiated by the depletion of intracellular $\mathrm{Ca}^{2+}$ from stores within the ER (250). This mechanism is thought to provide a means to rapidly replenish the empty $\mathrm{Ca}^{2+}$ stores and maintain elevated levels of free cytosolic $\mathrm{Ca}^{2+}$. A 
landmark study using unbiased high-throughput siRNA screens discovered that two proteins, stromal interacting protein 1 (STIM1) and the $\mathrm{Ca}^{2+-}$ selective plasma membrane ion channel Orai1, are required for SOCE (290). Extensive work characterizing the properties of STIM1 has demonstrated that STIM1 is a transmembrane protein with a $\mathrm{Ca}^{2+}$-binding EF-hand domain exposed within the ER and an Orail-interacting domain within the cytosol $(62,251)$. Upon $\mathrm{Ca}^{2+}$ store depletion, the interaction between the EF hand domain and free $\mathrm{Ca}^{2+}$ within the ER is reduced, resulting in the redistribution of STIM1 dimers into clusters. These clusters form peripheral coupling sites between the ER and plasma membrane that engage Ora1 channels, which in turn mediate extracellular $\mathrm{Ca}^{2+}$ influx (300).

Many early studies supported the concept that TRPC channels are necessary for SOCE in endothelial cells. For example, SOCE involving TRPC1 (32) and TRPC4 (91) channels has been implicated in endothelium-dependent vasodilation (91) and increases in microvascular permeability $(53,280,314)$. A study by Cioffi et al. provided evidence that heteromeric channels containing TRPC4 and TRPC1 subunits are present in cultured rat pulmonary artery endothelial cells and directly interact with Orai1, and further showed that Oria1 activity is necessary for the formation of inter-endothelial cell breaches (53). Investigations by Sundivakkam et al. demonstrated that STIM1 interacts with TRPC1 and TRPC4 to form a store-operated channel in cultured endothelial cells (268). However, the potential involvement of TRP channels in SOCE has become a matter of controversy $(217,249)$. The original shotgun siRNA screening study that identified STIM1 and Orai1 as obligatory components of SOCE also demonstrated that SOCE was not affected by down-regulation of TRP channels (290). Strong evidence from several laboratories further supports the concept that endothelial cell SOCE can occur without TRPC1, TRPC4, or TRPC6 expression $(1,243,284)$. One report indicates that $\mathrm{Ca}^{2+}$ release from internal stores persists in Purkinje neurons from TRPC1/C4/C6 triple-knockout mice, suggesting that these channels are not required for the SOCE-dependent maintenance of intracellular stores (110). Abdullaev et al. reported that knockdown of either TRPC1 or TRPC4 in cultured human umbilical vein endothelial cells (HUVECs) had no effect on SOCE or the $\mathrm{Ca}^{2+}$ release-activated $\mathrm{Ca}^{2+}$ current, and speculated that evidence for TRPC channel involvement in SOCE may be an artifact of the patch-clamp conditions employed in some studies, which may have resulted in phospholipase C (PLC)-mediated activation of TRPC channels downstream of store depletion (1).

Thus, these discrepancies may reflect methodological issues. The majority of studies supporting a role for TRPC channels in SOCE-mediated $\mathrm{Ca}^{2+}$ influx were performed using cultured endothelial cells or overexpression systems. Although the effects of culture conditions on the phenotypic properties of endothelial cells, notably including TRPC1 and TRPC4 expression, were not investigated in these studies, it is possible that such phenotypic transformations might have influenced SOCE and permeability regulation. This possibility is supported by a report from Bergdahl et al. demonstrating that culture conditions significantly increase TRPC1 and TRPC6 expression and SOCE in SMCs (26). A study by DeHaven et al. questioned the ability of TRPC channels to interact with either STIM1 or Orai1, and concluded that STIM1/Orai1 and TRPC signaling occur independently of each another and are not localized to the same microdomains (61). It should be noted that this 
latter study was conducted using cultured HEK cells, thus the direct applicability of these findings to endothelial cells is unclear and will require additional investigation.

\section{TRP channels and endothelium-dependent vasodilation}

The specific $\mathrm{Ca}^{2+}$-influx mechanisms associated with endothelium-dependent vasodilation were unknown until the discovery of TRP channels (196). Here, we review evidence supporting the involvement of TRPA1, TRPV4, TRPV3, TRPV1, TRPC1, TRPC3, TRPC4, TRPC5, and TRPP1 channel activity in endothelium-dependent vasodilation.

TRPA1-TRPA1 channels have a large unitary conductance ( $98 \mathrm{pS})$ (192), are more permeable to $\mathrm{Ca}^{2+}$ than $\mathrm{Na}^{+}\left(\mathrm{P}_{\mathrm{Ca}}: \mathrm{P}_{\mathrm{Na}}=7.9\right)(135)$, and conduct mixed cation currents with a high $\mathrm{Ca}^{2+}$ fraction. TRPA1 channels are activated by electrophilic compounds, including dietary molecules, such as allicin, a pungent compound found in garlic (173); allyl isothiocyanate (AITC), a derivative of mustard oil (19); and cinnamaldehyde from cinnamon (128). TRPA1 is present in sensory neurons, where it acts as a receptor for these pungent substances. This channel may also be activated by noxious cold (257), but this has been disputed $(22,131)$.

Recent studies demonstrate that TRPA1 channel activity contributes to vascular regulation (for review, see (73)). Activation of TRPA1 in perivascular nerves was shown to evoke dilation of rat mesenteric arteries through a signaling pathway that ultimately promoted the release of the neuropeptide, calcitonin gene-related peptide (CGRP) (23). Noxious cold has been shown to modulate blood flow within the mouse hindpaw in a manner that is dependent on TRPA1 activity(15). Although the precise cellular location of TRPA1 was not determined in this latter study, the increase in blood flow was thought to occur through activation of TRPA1 in sensory neurons. An in vivo study demonstrated that systemic TRPA1 activation results in a profound hypotensive response that was attributed to stimulation of TRPA1 in sensory neurons (218). However, basal blood pressure did not differ between control and global TRPA $1^{-/}$mice (30), suggesting that TRPA1 activity is not involved in the regulation of systemic blood pressure.

Work from Earley and colleagues indicated that TRPA1 channels are present in endothelial cells of cerebral arteries of rodents and humans (75), but are not detectable in mesenteric, coronary, dermal, or renal arteries (267). TRPA1 activation with AITC was shown to induce endothelium-dependent dilation and SMC membrane hyperpolarization in pressurized mouse cerebral arteries, an effect that was blocked by the selective TRPA1 antagonist, HC-030031 (75). AITC-induced responses were unaffected by NOS and COX inhibition, but were diminished by inhibition of IK, SK and inwardly-rectifying $\mathrm{K}^{+}\left(\mathrm{K}_{\mathrm{IR}}\right)$ channels, suggesting that TRPA1 mediates dilation through an EDH mechanism (75). Furthermore, TRPA1 channels were found to colocalize with IK channels and were abundant at myoendothelial projections (MEPs), sites of close contact between endothelial cells and SMCs, in the cerebral endothelium (75). Qian et al. further characterized the TRPA1dependent dilation of isolated rat cerebral arteries, demonstrating that activation of TRPA1 produced large, dynamic $\mathrm{Ca}^{2+}$ signals in the endothelium of cerebral arteries that were generated by $\mathrm{IP}_{3}$ receptor $\left(\mathrm{IP}_{3} \mathrm{R}\right)$-mediated release of $\mathrm{Ca}^{2+}$ from the ER (221). The 
amplitude, spatial spread, and duration of these $\mathrm{Ca}^{2+}$ signals were distinct from those of other types $\mathrm{Ca}^{2+}$ signals, including TRPA1 sparklets and $\mathrm{Ca}^{2+}$ pulsars. In addition, these large-amplitude $\mathrm{Ca}^{2+}$ signals were shown to be associated with a TRPA1 channel activitydependent vasodilatory response (221).

It is unlikely that TRPA1 channel activity in the cerebral vasculature is regulated by AITC or allicin under physiological conditions. TRPA1 channels are activated by reactive oxygen species (ROS) such as $\mathrm{H}_{2} \mathrm{O}_{2}$, as well as by ROS-derived metabolites generated by peroxidation of $\omega 6$ polyunsaturated fatty acids, including 4-hydroxy-2-nonenal (4-HNE), 4oxononenal (4-ONE), and 4-hydroxylhexenal (4-HHE) (10,286). Sullivan et al. demonstrated that TRPA1 sparklets induced by AITC can be recorded from cerebral artery endothelial cells. The modal amplitude of unitary TRPA1 sparklets was approximately twice that of TRPV4 sparklets, due to the larger unitary conductance and $\mathrm{Ca}^{2+}$ fraction of currents conducted by TRPA1 (267). Moreover, TRPA1 was found to colocalize with the ROSgenerating enzyme NOX2 (NADPH oxidase isoform 2) in the endothelium of isolated cerebral arteries; notably, stimulation of NOX2 was shown to increase the frequency of TRPA1 sparklets and induce dilation (267). These responses were dependent on the generation of extracellular $\mathrm{H}_{2} \mathrm{O}_{2}$ and hydroxyl radicals and the subsequent production of lipid peroxidation products, which activate TRPA1 channels. Thus, ROS and ROS metabolites appear to be endogenous agonists of TRPA1 in the cerebral endothelium. These results suggest TRPA1 channels are important for cerebral vascular regulation during pathophysiological conditions associated with increased ROS production and oxidative stress. Further support for this concept was provided by a report by Pires and Earley showing that activation of TRPA1 channels in the cerebral endothelium by mitochondrial ROS dilated mouse cerebral pial arteries and parenchymal arterioles in response to hypoxia (214). This study also demonstrated that activation of TRPA1 channels in the cerebral endothelium reduced infarct volume following ischemic stroke (214).

TRPV4-TRPV4 channels are more permeable to $\mathrm{Ca}^{2+}$ than $\mathrm{Na}^{+}$ions $\left(\mathrm{P}_{\mathrm{Ca}}: \mathrm{P}_{\mathrm{Na}}=\sim 6: 1\right)$ (258) and conduct a mixed cation current with a moderately high $\mathrm{Ca}^{2+}$ fraction. The channel is activated by cell swelling induced by hypotonic conditions (164) as well as by several chemical agonists $(279,301)$. TRPV4-mediated currents exhibit slight outward rectification, and are reported to have a unitary conductance of $\sim 30-60 \mathrm{pS}$ at $-60 \mathrm{mV}$ and $\sim 88-100 \mathrm{pS}$ at $+60 \mathrm{mV}(258,301,303)$. The availability of the selective, small-molecule agonists 4a-PDD (301) and GSK1016790A (279), and inhibitors RN-1732 (293) and HC-067047 (84), have enabled extensive characterization of the role of TRPV4 channels in endothelium-dependent vasodilation.

Nilius and colleagues provided the first functional evidence of TRPV4 channels in the endothelium of systemic arteries, demonstrating that TRPV4 channels are present in freshly isolated mouse aortic endothelial cells and could be activated by the phorbol compound $4 a-$ PDD (301), heat $\left(25-43^{\circ} \mathrm{C}\right)(303)$, and epoxyeicosatrienoic acids (EETs) (302). A subsequent study by Vriens and colleagues established that EETs generated by the CYP2C9 epoxygenase isoform could activate TRPV4 in an autocrine manner in cultured mouse aortic endothelial cells (294). This finding suggested that endogenous production of EETs has autocrine and paracrine effects that facilitate $\mathrm{Ca}^{2+}$ entry through TRPV4 channels. A report 
from Earley et al. demonstrated that exogenous application of 11,12-EET induced dilation of isolated pressurized mesenteric arteries from wild-type mice, but not TRPV4 ${ }^{-/-}$mice (79). This study further demonstrated that TRPV4 activation induced hyperpolarization of the surrounding SMCs that was sensitive to inhibition of endothelial cell IK and SK channels and SMC large-conductance $\mathrm{Ca}^{2+}$-activated $\mathrm{K}^{+}(\mathrm{BK})$ channels, but was not affected by NOS or COX inhibition. Interestingly, approximately $50 \%$ of this response was retained following mechanical disruption of the endothelium, indicating that TRPV4 channels present on both endothelial cells and SMCs contribute to the dilation induced by the application of EETs (79). Consistent with this, several other studies have shown that activation of TRPV4 channels in cerebral artery SMCs causes dilation $(77,184,270)$. It appears that TRPV4 channels stimulate dilation by functionally coupling with $\mathrm{Ca}^{2+}$-activated IK and SK channels in rat cerebral endothelial cells and with ryanodine receptors in SMCs (77). In this latter study, activation of SMC TRPV4 channels by EETs was shown to induce dilation by stimulating ryanodine receptor activity through a $\mathrm{Ca}^{2+}$-induced $\mathrm{Ca}^{2+}$-release (CICR) mechanism, with subsequent activation of BK channels and hyperpolarization of the SMC membrane potential. Interestingly, endothelial BK channels have also been implicated in dilatory responses through an entirely different mechanism. Naik et al. reported that endothelium-dependent dilation of rat mesenteric arteries in response to the hydrogen sulfide $\mathrm{H}_{2} \mathrm{~S}$ donor NaHS was sensitive to blockade of TRPV4 and BK channels (193). A related study showed that acetylcholine ( $\mathrm{ACh}$ )-induced dilation of mesenteric arteries isolated from rats subjected to hypoxia (0.5 ATM) for $48 \mathrm{~h}$ was diminished by block of TRPV4 channels (194). Further, dilation of arteries from hypoxic rats in response to the selective TRPV4 agonist GSK1016790A could only be inhibited by simultaneous block of IK, SK, and BK channels (194). However, the presence of functional BK channels in native endothelial cells has been disputed based on patch-clamp electrophysiological studies, which failed to find BK currents in native endothelial cells (150). This view is currently held by most investigators working in this area.

TRPV4 channels are also localized to the endothelium of pulmonary arteries. The TRPV4 agonist GSK1016790A was shown to induce an endothelium-dependent relaxation of rat pulmonary artery rings that was sensitive to inhibition of TRPV4 with the selective antagonist HC-067047 and blockade of IK and SK channels (264). A similar study reported that GSK1016790A-induced dilation of rat pulmonary arteries was dependent on NOS activity, as well as EDHF or EDH mechanisms (3). A recent report proposed that increased NO production following TRPV4 activation in pulmonary arteries not only dilates the underlying smooth muscle layer, but also is involved in a negative feedback loop that reduces TRPV4 activity through protein kinase G-mediated TRPV4 phosphorylation (178). Interestingly, this signaling cascade was not found to operate in mesenteric arteries, a vascular bed in which these authors proposed that TRPV4 activation is not associated with NO production (178). However, ACh-induced relaxation of rat pulmonary artery rings was not affected by TRPV4 inhibition with two different antagonists (HC-067047 and RN-1734), suggesting that TRPV4 channels are not involved in muscarinic agonist-induced relaxation in this vascular segment (264). In agreement with these findings, Pankey et al. showed that the reduction in pulmonary arterial pressure of rats in response to intravenous (i.v.) administration of ACh was unaffected by systemic administration of the TRPV4 antagonist 
GSK2193874 (204). Interestingly, Ke et al. reported that endothelial TRPV4 stimulation with the agonist GSK1016790A significantly increased pulmonary vascular resistance in isolated perfused lungs (136). Activation of smooth muscle TRPV4 in the absence of endothelial signaling may also contribute to increased pulmonary artery pressure (204). Overall, these studies suggest that, although pharmacological stimulation of TRPV4 in the pulmonary artery endothelium can cause endothelium-dependent dilation, the physiological role of this channel in the regulation of the pulmonary vasculature remains unclear.

Multiple studies have implicated TRPV4 in endothelium-dependent relaxation of systemic arteries in response to muscarinic $(59,227,333)$ and purinergic receptor (178) stimulation. Saliez et al. reported that EDHF/EDH- and NO-dependent relaxation of mesenteric arteries following carbachol application was attenuated in isolated mesenteric arteries from TRPV4 $^{-/}$mice compared with those from wild-type animals (227). Interestingly, they further demonstrated that TRPV4 is localized in distinct subcellular microdomains with caveolin-1 and connexins. A study by Goedicke-Fritz and colleagues further suggested compartmentalization of TRPV4, and demonstrated that the channel is spatially coupled to caveolin-1 and SK channels, but interestingly not to IK channels (98). Gutterman and colleagues confirmed that ACh-induced dilation was blunted in isolated pressurized mesenteric arteries from TRPV4 ${ }^{-1-}$ mice and further demonstrated that $\mathrm{Ca}^{2+}$ influx and NO production induced by $\mathrm{ACh}$ in endothelial cells of freshly isolated mesenteric and carotid arteries from TRPV4 ${ }^{-/}$mice was diminished compared with that in wild-type controls (333). Receptor-dependent activation of TRPV4 has been noted in other vascular beds as well, including by Senadheera et al., who showed that blockade of TRPV4 with RN-1734 blunts ACh-induced dilation of rat uterine radial arteries (239). Working with freshly isolated rat cerebral pial arteries, Marrelli and colleagues found that activation of purinergic receptors with UTP stimulated $\mathrm{Ca}^{2+}$ influx in the endothelium and induced a subsequent vasodilation that was attenuated by inhibition of phospholipase $\mathrm{A}_{2}\left(\mathrm{PLA}_{2}\right)$, which liberates arachidonic acid from the plasma membrane, and by the non-selective TRPV antagonist ruthenium red (177). These data suggest that arachidonic acid generation activates TRPV4mediated $\mathrm{Ca}^{2+}$ influx, most likely through the production of EETs, leading to dilation through EDHF or EDH mechanisms. The Nelson laboratory showed that muscarinic receptor activation increases TRPV4 sparklet activity and causes dilation of mouse mesenteric arteries, effects that are blunted by blocking IK and SK channels, providing evidence that muscarinic receptor signaling-induced TRPV4 sparklets activate an EDH vasodilator pathway (253). A recent study by Harraz and colleagues revealed a potentially novel mechanism for activation of TRPV4 channels in endothelial cells downstream of $\mathrm{G}_{\mathrm{q}}$ PCRs (109). This study showed that TRPV4 channels in freshly isolated mouse brain capillary endothelial cells are tonically inhibited by phosphatidylinositol 4,5-bisphosphate $\left(\mathrm{PIP}_{2}\right)$ in the plasma membrane. Activation of $\mathrm{G}_{\mathrm{q}}$ PCRs and subsequent hydrolysis of PIP 2 by phospholipase $\mathrm{C}$ relives this inhibition and activates TRPV4 channel activity. These finding provide a universal mechanism for activation of TRPV4 channels downstream of $\mathrm{G}_{\mathrm{q}} \mathrm{PCRs}$. A recent study Hong et al. implicated TRPV4 in heterocellular communication between SMCs and endothelial cells of isolated small mouse mesenteric arteries (120). They proposed that stimulation of $\mathrm{G}_{\mathrm{q}} \mathrm{PCR}$ signaling pathways following adrenergic or thromboxane A2 receptor activation stimulates endothelial TRPV4 sparklets within MEPs to inhibit phenylephrine- 
induced contraction (120). The authors hypothesized that, upon $\mathrm{G}_{\mathrm{q}}$ activation, $\mathrm{IP}_{3}$ translocates from SMCs to the endothelium via gap junctions to activate TRPV4, thereby serving as a negative feedback pathway that counteracts agonist-induced contraction. However, Senadheera et al. were unable to detect TRPV4 expression within gaps in the internal elastic lamina (IEL) of uterine arteries from control or pregnant rats (239), suggesting that signaling mechanisms and cellular localization patterns of TRPV4 may be specific to particular vascular beds.

Dora and colleagues proposed a mechanism in which $\mathrm{Ca}^{2+}$ signaling through TRPV4 triggers CICR from the ER(18). They demonstrated that TRPV4 channels form clusters within MEPs of rat cremaster and mesenteric arteries that are spatially coupled with $\mathrm{Ca}^{2+}$ release sites on the ER. Interestingly, the frequency of spontaneous $\mathrm{Ca}^{2+}$ release from the ER was low at physiological pressures $(80 \mathrm{mmHg})$, but was increased by reducing the intraluminal pressure to less than $50 \mathrm{mmHg}$, an effect that was blunted by TRPV4 inhibition. TRPV4 antagonism was also shown to produce a modest increase in spontaneous myogenic tone development at low levels of intraluminal pressure (20 and $40 \mathrm{mmHg}$ ) (18), suggesting that this channel mediates an $\mathrm{ER} \mathrm{Ca}^{2+}$-release-dependent mechanism that induces vasodilation at low levels of intraluminal pressure. The authors proposed that $\mathrm{Ca}^{2+}$ influx through TRPV4 channels at low intraluminal pressures is amplified by $\mathrm{Ca}^{2+}$ release from $\mathrm{IP}_{3} \mathrm{Rs}$ on the ER and serves to generate large-amplitude $\mathrm{Ca}^{2+}$ signals, which in turn activate EDH to suppress myogenic constriction (18). Because this mechanism operates at subphysiological levels of intraluminal pressure, its relevance is not immediately apparent. It is plausible that activation of endothelial cell TRPV4 channels at low intraluminal pressure contributes to a precipitous drop in blood pressure, for example during hypovolemic shock.

Patch-clamp experiments in immortalized cell lines have shown that TRPV4 currents can be induced by exposing cells to hypotonic conditions, which cause swelling and stretching of the plasma membrane (164). These observations have led to the hypothesis that TRPV4 channels are mechanosensitive and may act as sensors of blood flow and shear stress in the endothelium and play a role in mediating flow-induced vasodilation. In support of this concept, Kohler and colleagues reported that dilation of rat gracilis arteries following exposure to the TRPV4 agonist 4a-PDD or application of shear stress was attenuated by the non-selective TRPV blocker ruthenium red (144). Interestingly, flow-induced dilation was attenuated by NOS inhibition, whereas 4a-PDD-induced dilation was unaffected by NOS inhibition, but was sensitive to IK and SK channel blockade (144). A follow-up study from this group provided additional support for this hypothesis, demonstrating that shear stressinduced dilation was absent in carotid arteries of TRPV4 ${ }^{-/-}$mice, while vasodilation in response to agonist stimulation was unchanged (111). Additional studies have reported that flow-induced dilation of mouse mesenteric arteries is significantly attenuated in arteries from TRPV4 ${ }^{-/-}$mice and that flow-dependent $\mathrm{Ca}^{2+}$ influx in cultured human coronary artery endothelial cells is dependent on TRPV4 (183). Flow-induced dilation of human coronary arteries is blunted by ruthenium red, the selective TRPV4 blocker RN-1732, and by small interfering RNA (siRNA)-mediated knockdown of TRPV4 expression (34). In cultured HUVECs, shear stress was reported to increase TRPV4 translocation to the plasma membrane (21) within distinct microdomains associated with caveolin and SK channels (170). However, a recent study by Darby et al. using an ex vivo preparation of rat cremaster 
arterioles suggested that shear stress sensitizes TRPV4 channels independent of any effects on its cellular localization (59). Arterioles conditioned to shear stress are more sensitive to relaxation produced the TRPV4 agonist GSK1016790A (59). The authors of this latter study further demonstrated that TRPV4 antagonism significantly impaired ACh-induced dilation in shear-exposed arterioles, but not in arterioles that did not experience shear stress(59). Collectively, these observations provide evidence for a role of TRPV4 channels in shear stress-induced responses in ex vivo models.

Further investigations on the mechanosensitivity of TRPV4 demonstrated that these channels are not directly activated by suction applied to the plasma membrane of transfected HEK-293 cells in cell-attached patch-clamp experiments (258), suggesting that these channels lack intrinsic mechanosensitivity. In fact, several studies now support the concept that activation of TRPV4 channels during cell swelling occurs indirectly as the result of force-sensitive signaling pathways. Loot et al. proposed that EETs link TRPV4 activation to the flow-sensor function, as evidenced by the fact that inhibition of CYP epoxygenases, which are responsible for EETs production, attenuated flow-induced dilation of mouse carotid arteries (169). These findings are further supported by reports that cell-swelling induced activation and $\mathrm{Ca}^{2+}$ entry through TRPV4 channels are blocked by inhibition of CYP2C9 in cultured mouse aortic endothelial cells (294) and that flow-induced dilation of mouse carotid arteries is impaired by inhibition of $\mathrm{PLA}_{2}$ (111). Collectively, these studies support a mechanism in which shear indirectly activates TRPV4 through PLA -mediated $^{-}$ liberation of AA and its subsequent conversion to EETs by CYP2C9. However, the nature of the endothelial cell flow sensor responsible for initiation of this pathway has not yet been identified. A potential candidate is the angiotensin II (Ang II) type 1 receptor $\left(A_{1} R\right) . A T_{1} R$ receptors are expressed in the endothelium and can be activated by mechanical stimuli independently of Ang II, but it is not known if AT1Rs are linked to CYP epoxygenase activity. Although $\mathrm{AT}_{1}$ Rs are functionally coupled to TRPV4 channels in vascular SMCs (184), this has yet to be shown in endothelial cells. Another potential candidate is GPR68, a class A rhodopsin-like $\mathrm{G}_{\mathrm{q}} \mathrm{PCR}$ that is required for shear stress responses and flow-induced dilation in third-order mouse mesenteric arteries (321). Interactions between GPR68 and TRPV4 channels in the endothelium have not been demonstrated.

Although many of the studies cited above used ex vivo preparations to demonstrate that endothelial TRPV4 channels contribute to vascular regulation in response to various stimuli, these data are at odds with several in vivo studies reporting little involvement of TRPV4 channels in cardiovascular control. Separate reports demonstrated that systemic i.v. administration in mouse, rat and dog of the TRPV4 agonist GSK1016790A produces a significant reduction in mean arterial pressure (MAP) that is independent of changes in cardiac output $(204,307)$, indicative of reduced total peripheral resistance (TPR).

Administration of 4a-PDD (i.v.) in wild-type mice was also reported to reduce MAP, a response that is absent in TRPV4 ${ }^{-/-}$mice (333). These findings suggest that a loss of TRPV4 function in vivo increases TPR and consequently increases MAP. However, basal MAP was reported to be unchanged in TRPV4 ${ }^{-/}$mice compared with wild-type mice (79, 333), or slightly decreased (201). Moreover, acute or chronic (8 days) administration of selective TRPV4 antagonists (GSK2193874 or GSK2263095) in rats had no effect on MAP or heart rate (278), suggesting the lack of involvement of TRPV4 on basal blood pressure 
regulation. Although Zhang et al. reported that i.v. administration of ACh blunted the reduction in MAP observed in TRPV4 ${ }^{-/}$mice (333), Pankey et al. reported that i.v. ACh had no effect on the reduction in MAP induced by inhibition of TRPV4 channels with GSK2193974 (204). The reasons for these discrepancies are currently unknown. However, one study observed a blunted blood pressure reduction following bolus ACh administration(i.v.) in TRPV4 ${ }^{-/-}$mice, suggesting the potential importance of TRPV4 signaling in vivo (333). Collectively, these in vivo studies suggest that that TRPV4 channels in the endothelium are minimally active under basal conditions and exert only modest, localized effects on cardiovascular hemodynamics. It is possible that that inconsistencies between in vivo and ex Vivo findings may reflect restriction of the actions of TRPV4 to specific vascular beds and potential compensation for loss of channel activity by other regions in an in vivo setting, and may be addressed with the aid of cell-specific knockout animals.

TRPV3 - TRPV3 channels have a large unitary conductance ( 150-200 pS) (51) and are highly permeable to $\mathrm{Ca}^{2+}$ relative to $\mathrm{Na}^{+}\left(\mathrm{P}_{\mathrm{Ca}}: \mathrm{P}_{\mathrm{Na}}=\sim 12: 1\right)(320)$. TRPV3 is activated by innocuous heat (320) and dietary monoterpenes, including carvacrol (a derivative of oregano), eugenol (clove oil), and thymol (a compound found in thyme) (319). TRPV3 channels are expressed in the skin, and oral and nasal epithelium, and are involved in chemosensation in these tissues (319).

Earley et al. discovered that TRPV 3 channels are present in the endothelium of rat cerebral arteries and further showed that carvacrol activated TRPV3-like cation currents and increased intracellular $\mathrm{Ca}^{2+}$ levels in freshly isolated endothelial cells of isolated rat cerebral arteries, effects that were sensitive to inhibition with the nonselective TRPV3 blocker ruthenium red (76). Carvacrol application was also shown to evoke endothelium-dependent dilation of isolated cerebral arteries through a mechanism that was independent of NOS and COX activity, but sensitive to block of SK, IK, and $\mathrm{K}_{\mathrm{IR}}$ channels, suggesting the $\mathrm{Ca}^{2+}$ influx through TRPV3 evokes an EDH response (76). A follow-up study by Pires et al. demonstrated that carvacrol induced an increase the frequency of TRPV 3 sparklets in native endothelial cells of mouse cerebral pial arteries and parenchymal arterioles that was sensitive to TRPV3 blockade with isopentenyl pyrophosphate (215). The unitary amplitude of TRPV3 sparklets was greater than that of TRPV4 and TRPA1 sparklets. Carvacrol produced a robust dilation of isolated pressurized parenchymal arterioles that was sensitive to endothelium disruption, TRPV3 inhibition with isopentenyl pyrophosphate, and IK and SK channel blockade (215). It should be noted that Murphy et al. reported that carvacrol induced an endothelium-independent dilatory effect in isolated rat uterine radial arteries that was sensitive to TRPV3 inhibition, suggesting that TRPV3 is expressed in SMCs in this vascular bed (190).

The endogenous mechanisms involved in the regulation of TRPV 3 channels in the endothelium have not been identified.

TRPV1-The unitary conductance of TRPV1 is $35 \mathrm{pS}$ at $-60 \mathrm{mV}$ and $77 \mathrm{pS}$ at $+60 \mathrm{mV}$, and these channels are more permeable to $\mathrm{Ca}^{2+}$ than $\mathrm{Na}^{+}$ions $\left(\mathrm{P}_{\mathrm{Ca}}: \mathrm{P}_{\mathrm{Na}}=9.6\right)(42)$. TRPV1 channels are activated by noxious heat and capsaicin, a substance found in hot peppers (42). 
Several studies have attempted to demonstrate the involvement TRPV1 channels in endothelium-dependent vasodilation. Work from Yang et al. demonstrated that $\mathrm{Ca}^{2+}$ influx through TRPV1 channels induced by capsaicin resulted in increased phosphorylation of eNOS via protein kinase A and subsequent elevation in NO production in mouse aortic endothelial cells (325). This study also demonstrated that capsaicin caused endotheliumdependent relaxation of isolated mesenteric arteries from wild-type mice, a response that was absent in arteries from TRPV $1^{-/}$mice (325). Poblete et al. reported that the cannabinoid receptor agonist anandamide and capsaicin stimulated NO production and release in the rat mesenteric bed, an effect that was sensitive to TRPV1 inhibition (216). Surprisingly however, this response was not associated with any dilatory effects. Bratz et al. observed capsaicin-dependent dilation of coronary arteries from pigs, a response that was diminished by the TRPV1 antagonist capsazepine and by inhibition of NO production (31), supporting the concept that $\mathrm{Ca}^{2+}$ influx through TRPV1 channels stimulates eNOS activity. Similar observations have been reported for rat coronary arteries (281). Ching et al. reported that $\mathrm{Ca}^{2+}$ influx through TRPV1 channels in bovine aortic endothelial cells allows direct interaction between TRPV1 and eNOS, thereby facilitating NO production (50). The formation of this TRPV1-eNOS complex was dependent on Akt and calmodulin-dependent protein kinase II (CaMKII), such that inhibition of either prevented complex formation and subsequent NO production (50). From an in vivo perspective, capsaicin has been shown to increase myocardial blood flow in wild-type mice, an effect that was absent in TRPV1 $1^{-/}$ animals (102). This change in blood flow was not associated with a change in heart rate, indicating a direct influence of TRPV1 on vascular resistance. Capsaicin treatment has also been shown to inhibit agonist-induced constriction of human skeletal feed arteries, a response that was significantly attenuated by disruption of the endothelium (127). This report also proposed that capsaicin sensitized cells to ACh-mediated dilation, suggesting the $\mathrm{Ca}^{2+}$ entry through TRPV1 potentiates muscarinic receptor signaling-dependent relaxation. Work from the Gollasch laboratory suggested that TRPV1-dependent dilation is restricted to specific vascular beds. They observed that capsaicin produced a robust endotheliumdependent relaxation in mouse mesenteric arteries, but caused relaxation in mouse renal arteries or rat descending vasa recta only a $\sim 100$-fold greater concentrations (45).

Interestingly, TRPV1 reporter mice created using a transgenic approach showed no evidence of TRPV1 expression in endothelial cells (43). However, TRPV1 expression was detected in a subset of arteriolar SMCs, in which channel activation was found to cause vasoconstriction. Thus, a role for TRPV1 channels in endothelium-dependent vasodilation is not universally accepted by the field.

TRPC1-While several research groups have demonstrated TRPC1 expression in the endothelium, it is unclear if the TRPC1 sub-type forms homomeric channels in native cells. TRPC1 subunits have been found in heteromeric channels containing TRPC3 (259), TRPC4 (260), TRPC5 (260), TRPP1 (PKD2) (141,335), TRPV4 (100,172), and/or TRPV6 (234) subunits. TRPC 1 channels have a unitary conductance of $\sim 5 \mathrm{pS}$ and are not selective for $\mathrm{Ca}^{2+}$ versus $\mathrm{Na}^{+}$in heterologous expression systems (260).

One study showed that TRPC1 was functionally coupled to the $\mathrm{Ca}^{2+}$-sensing receptor (CaSR) in cultured HUVEC (222). siRNA-mediated TRPC1 knockdown attenuated the 
increase in intracellular $\mathrm{Ca}^{2+}$ and $\mathrm{NO}$ production induced by CaSR stimulation with spermine (222). The authors proposed that CaSR-induced NO production was mediated by TRPC1-dependent SOCE (222). Further studies by Greenburg et al. demonstrated colocalization of TRPC1 with TRPV4 in freshly isolated endothelial cells from rabbit mesenteric arteries; in these cells, CaSR stimulation induced an increase in NO production that was blocked by inhibition of either TRPC1 or TRPV4 (100). Stimulating CaSRs by increasing extracellular $\mathrm{Ca}^{2+}$ concentration resulted in relaxation of isolated rabbit mesenteric arteries, an effect that was sensitive to TRPC1 and TRPV4 inhibition. Moreover, relaxation evoked by the TRPV4 agonist GSK1016790A was blunted by inhibition of TRPC1 and NOS, but not IK (100), suggesting that CaSR-mediated vasorelaxation occurs through the TRPC1/TRPV4-dependent production of NO. Ma et al. proposed that heteromeric TRPC1/TRPV4 channels form SOCE channels in cultured aortic endothelial cells (172). However, it unknown whether this mechanism underlies the observations of Greenburg et al.

TRPC3-TRPC3 channels have a unitary conductance of $\sim 60 \mathrm{pS}$; they are equally permeable to $\mathrm{Ca}^{2+}$ and $\mathrm{Na}^{+}$ions, but are more permeable to $\mathrm{Na}^{+}$than $\mathrm{K}^{+}$(134). This channel is activated by $\mathrm{G}_{\mathrm{q}} \mathrm{PCR}$ signaling, specifically through PLC activity and the secondary messenger diacylglycerol (DAG), and may also be stimulated by elevated intracellular $\left[\mathrm{Ca}^{2+}\right]$. Several studies have suggested a potential role for TRPC3 in endothelium-dependent vasodilation. A study by Liu et al. reported that decreased TRPC 3 expression following treatment of rats (tail vein injection) with antisense oligonucleotide resulted in diminished flow- and bradykinin-induced vasodilation and attenuated the rise in endothelial intracellular $\mathrm{Ca}^{2+}$ induced by these treatments (166). Gao et al. showed that TRPC 3 is present in the endothelium and smooth muscle layers of human internal mammary artery (IMA) and demonstrated that TRPC3 channel blockade with Pyr3 modestly diminished ACh-induced relaxation of precontracted IMA rings(94). Carbachol-induced relaxation and increases in endothelial intracellular $\mathrm{Ca}^{2+}$ were also impaired in aortic rings from $\mathrm{TRPC}^{-1-}$ mice and wild-type rings treated with Pyr3 (143), further demonstrating that muscarinic-dependent relaxation may involve activation of TRPC 3 channels. A subsequent study by the Sandow laboratory demonstrated that $\sim 70 \%$ of TRPC 3 channels in the endothelium of rat mesenteric arteries are localized to MEPs, and that inhibition of these channels with Pyr3 attenuated ACh-induced endothelial cell hyperpolarization and arterial relaxation (240). A report from Kirby et al. further supported localization of TRPC3 to MEPs in distinct microdomains that also contain SK and IK channels in rat popliteal and first-order skeletal muscle arteries from the gastrocnemius muscle (138). Collectively, these data suggest that TRPC3 channel stimulation produces EDH responses following muscarinic receptor activation. Marrelli and colleagues also demonstrated that TRPC 3 channels contribute to EDH-mediated dilation of mouse posterior cerebral arteries in response to ATP, an effect that involves the activation of SK and IK channels (142). Using patch-clamp electrophysiology, they further characterized changes in freshly isolated cerebral endothelial cell membrane potential induced by TRPC3 activation and concluded that there are two components of the hyperpolarization response: an early, IK channel-dependent phase and a sustained phase that is dependent on rapid recruitment of TRPC3 channels to the plasma membrane by the SK channel (142). Interestingly, Wong et al. observed that inhibition of TRPC 3 following bradykinin 
application attenuated relaxation in isolated pig coronary arteries from males, but not females (312). The implications of this observation for other species is not clear, since many of the studies discussed here were performed in tissue collected from male rodents, while investigations on human IMAs used vessels collected from both males and females.

Collectively, the findings cited above support a mechanism whereby activation of muscarinic $\mathrm{G}_{\mathrm{q}}$ PCRs stimulates TRPC3 activity through PLC-dependent generation of DAG. TRPC3 activity, in turn, leads to increases in intracellular $\mathrm{Ca}^{2+}$ that activate SK and IK channels to cause EDH. However, at the endothelial cell resting membrane potential under physiological conditions ( - $-50 \mathrm{mV}$ ), the $\mathrm{Ca}^{2+}$ fraction of TRPC3-mediated mixed cation currents is likely to be small, arguing against direct activation of SK and IK channels by TRPC3-mediated $\mathrm{Ca}^{2+}$ influx. One possible explanation for this apparent discrepancy is that the TRPC3 subtype could constitute part of a heteromeric Pyr3-sensitive channel with higher $\mathrm{Ca}^{2+}$ permeability. Heteromeric channels consisting of TRPC1 and TRPC 3 subunits have been reported and may be involved in endothelium-dependent relaxation (143). However, the biophysical properties of such channels are unknown, and it is unclear whether these channels are sensitive to Pyr3. An alternative possibility is that $\mathrm{Na}^{+}$influx through TRPC3 channels promotes activation of the $\mathrm{Na}^{+} / \mathrm{Ca}^{2+}$ exchanger (NCX) acting in reverse mode, thereby indirectly resulting in $\mathrm{Ca}^{2+}$ influx. This hypothetical mechanism requires colocalization of the NCX and TRPC 3 to produce subcellular domains with locally elevated $\mathrm{Na}^{+}$concentrations sufficient to activate reverse-mode $\mathrm{Ca}^{2+}$ entry without causing membrane depolarization, which would diminish the electrical driving force for $\mathrm{Ca}^{2+}$ entry. Support for this hypothesis is provided by studies in HEK cell over-expression models (224) and cardiomyocytes $(68,80,220)$, which used KB-R7943, a compound that inhibits reversemode NCX activity, to demonstrate functional coupling between TRPC 3 and NCX. It should be noted that KBR7943 is known to have multiple off-target actions, including effects on other TRPC channels (147) and smooth muscle BK channels (160), raising questions about conclusions reached using this compound. However, a more recent study using cultured HUVEC demonstrated that NCX inhibition with either SEA0400 or SN-6 reduced $\mathrm{Ca}^{2+}$ influx mediated by a DAG analog (11), providing support for functional coupling between TRPC 3 and NCX within the endothelium. TRPC 3 channels functionally couple with $\mathrm{IP}_{3} \mathrm{Rs}$ on the sarcoplasmic reticulum in SMCs (316). If this complex is present in endothelial cells, it is possible that activation of TRPC 3 channels could stimulate $\mathrm{Ca}^{2+}$ release from the ER through $\mathrm{IP}_{3}$ Rs.

TRPC4-The unitary conductance of TRPC4 channels is approximately $42 \mathrm{pS}$ (232). The selectivity of channels to $\mathrm{Na}^{+}$and $\mathrm{Ca}^{2+}$ ions is not clear as $\mathrm{P}_{\mathrm{Ca}}: \mathrm{P}_{\mathrm{Na}}$ between 1.1 and 7.7 have been reported, which may be explained by possible heteromeric association with other TRPC subunits $(25,232)$. A study by Freichel et al. reported that SOCE, ACh-induced $\mathrm{Ca}^{2+}$ influx of mouse aortic endothelial cells, and relaxation of aortic rings were impaired in TRPC4 $^{-/-}$mice compared with controls (91), suggesting that TRPC4 is involved in SOCEand muscarinic receptor-dependent dilation of conduit arteries. The authors proposed that arterial relaxation is mediated through increased $\mathrm{Ca}^{2+-}$ dependent eNOS activity and NO production (92). However, the impact of this study has been diminished by subsequent reports that TRPC4 channels are not involved in endothelial SOCE $(1,110,243)$. 
TRPC5-TRPC5 channels have a unitary conductance ranging from 40 to $66 \mathrm{pS}(133,232)$ and a $\mathrm{P}_{\mathrm{Ca}}: \mathrm{P}_{\mathrm{Na}}$ between 1.8 and $9.5(132,202,232)$. Several studies have reported TRPC5 channel expression in bovine and mouse aortic endothelial cells $(159,311)$ as well as human saphenous veins, and coronary and cerebral arteries $(9,329)$. However, these studies did not evaluate the role of TRPC5 channel activity in endothelium function. TRPC5 is subject to Snitrosylation by NO donors, a modification that facilitates $\mathrm{Ca}^{2+}$ entry through TRPC5 in cultured bovine aortic endothelial cells (330). Reports from this group further suggest that TRPC5 colocalizes with caveolin-1 and eNOS, leading these authors to propose that increased activity of TRPC5 following S-nitrosylation may act as a positive feedback mechanism that serves to increase production of NO by eNOS (271). However, others have reported that TRPC5 activity in cultured bovine aortic endothelial cells is not regulated by NO-mediated nitrosylation of serine residues (311). Li et al. demonstrated that ACh-induced relaxation was unchanged in aortic rings from 6-week-old $\mathrm{TRPC}^{-/-}$mice (159), indicating that increased eNOS activity following agonist stimulation is not potentiated by TRPC5. However, this study reported that ACh-dependent relaxation of aortic segments from aged $\mathrm{TRPC}^{-1-}$ mice (60 weeks) was impaired, whereas the response to sodium nitroprusside was unaffected. The authors concluded that this differential response was attributable to increased endothelial cell senescence in the aged animals, rather than a direct effect of TRPC5 on dilatory pathways (159).

TRPP1-TRPP1 (PKD2) has a single-channel conductance of $97 \mathrm{pS}$ (140). It is more permeable to $\mathrm{Ca}^{2+}$ than $\mathrm{Na}^{+}$, but is approximately twofold or more selective for $\mathrm{K}^{+}$than $\mathrm{Ca}^{2+}$ (140). Some reports have suggested that TRPP1 forms a $\mathrm{Ca}^{2+}$-release channel in the ER membrane (146). Du et al. reported that TRPP1 is expressed in cultured rat mesenteric artery endothelial cells and forms a complex with TRPC 1 and TRPV4 that responds to shear stress (69). These authors further demonstrated that transfection of primary cultured rat mesenteric artery endothelial cells with nonfunctional pore mutants of these channels prevented increases in endothelium $\mathrm{Ca}^{2+}$ in response to flow, and lentiviral transfection of small rat mesenteric arteries with a nonfunctional TRPP1 mutant prevented flow-mediated dilation (69). Further support was provided Berrout et al., who demonstrated that stretchinduced $\mathrm{Ca}^{2+}$ influx and NO production in cultured mouse brain microvascular endothelial cells was significantly reduced following pharmacological inhibition or siRNA-mediated knockdown of either TRPC1 or TRPP1 (27). These data suggest the TRPP1, in combination with TRPC1 and TRPV4, evokes relaxation in response to flow through production of NO. It is unclear whether these complexes are mechanosensitive or are activated indirectly by a component of a separate flow-sensing element. TRPP1 complexes with TRPP2 are known to be sensitive to flow in other tissues, but TRPP1 may lose its mechanosensitive properties when expressed alone $(195,241)$. The study by Berrout et al. demonstrated that siRNAmediated knockdown of TRPP1 and TRPC1 reduced $\mathrm{Ca}^{2+}$ influx, suggesting that both TRPP1 and TRPC1 subunits, and presumably TRPV4 subunits, in these complexes contribute to mechanosensation (27).

TRPM2-TRPM2 has a unitary conductance of $58 \mathrm{pS}$ at negative membrane potentials and $76 \mathrm{pS}$ at positive potentials (230), and is equally permeable to $\mathrm{Ca}^{2+}$ and $\mathrm{Na}^{2+}$ ions $\left(\mathrm{P}_{\mathrm{Ca}}: \mathrm{P}_{\mathrm{Na}}\right.$ $=\sim 0.7-0.9)(230,317)$. TRPM 2 channels are activated by intracellular adenosine 
diphosphate ribose (213,230), arachidonic acid (107), $\mathrm{H}_{2} \mathrm{O}_{2}$ (145), and nicotinic acid adenine dinucleotide phosphate (24).

A few studies have investigated the role of TRPM2 channels in endothelium-dependent vasodilation. Chidgey et al. reported that dilation and endothelial cell $\mathrm{Ca}^{2+}$ influx in rat cremaster arterioles evoked by $\mathrm{H}_{2} \mathrm{O}_{2}$ was diminished by blocking TRPM2 channels with antibodies, and by SK and IK channel blockade, but inhibition of TRPM2 had no effect on carbachol-induced responses (49). This would suggest that ROS, but not receptor stimulation, facilitates $\mathrm{Ca}^{2+}$ entry through TRPM2 channels and evokes EDH. Iadecola and colleagues tested the hypothesis that ROS activation of TRPM2 and subsequent dilation are involved in the vascular dysfunction associated with Alzheimer's dementia. They observed that amyloid- $\beta$, a key factor in the pathogenesis of Alzheimer's disease, generated an inward current and $\mathrm{Ca}^{2+}$ influx in cultured mouse brain endothelial cells, both of which were sensitive to siRNA-mediated TRPM2 knockdown or TRPM2 inhibition with antibodies (206). The inward current was also inhibited by poly (ADP-ribose) polymerase (PARP) and PARP antagonists, implicating this enzyme in TRPM2 activation. In vivo, TRPM2 inhibition was shown to prevent cerebrovascular dysfunction in a transgenic mouse model of Alzheimer's disease as well as that associated with amyloid- $\beta$ treatment (206). Moreover, amyloid- $\beta$ had no effect on neurovascular function in TRPM $2^{-/-}$mice (206), further suggesting a pathological role for this channel in this disease.

\section{TRP channels and permeability of the vascular endothelium}

In this section, we review evidence supporting the influence of TRPV4, TRPV1, TRPC1, TRPC4, TRPC6, and TRPM2 channels on the permeability of the endothelial barrier.

TRPV4-Multiple studies have proposed an important role for endothelial TRPV4 channels in the regulation of pulmonary vascular permeability. A study from the Townsley laboratory showed that activation of TRPV4 with 4a-PDD, 5,6-EET, or 14,15-EET increased pulmonary microvascular permeability in isolated rat lungs, measured as an increase in the vascular filtration coefficient, a response that was blocked by the non-selective TRPV antagonist ruthenium red (8). Moreover, no response to 4a-PDD was observed in isolated lungs from TRPV4 ${ }^{-/}$mice, but increased permeability persisted in response to store depletion with thapsigargin and initiation of SOCE. A microscopic analysis suggested that increased permeability in response to initiation of SOCE and activation of TRPV4 differed in that TRPV4 agonists increased permeability within the alveolar septal wall by disrupting the space between endothelial and epithelial layers, whereas thapsigargin affected interendothelial junctions in extra-alveolar vessels (8). A subsequent study from this group demonstrated that TRPV4-dependent increases in microvascular permeability induced by 14,15-EET were sensitive to blockade of IK and SK channels (165), suggesting functional coupling between these components. $\mathrm{Ca}^{2+}$ influx through TRPV4 recruits matrix metalloproteinases- 2 and -9 , causing disruption of the endothelial barrier and promoting edema formation (291). A recent study has proposed that $\mathrm{H}_{2} \mathrm{O}_{2}$ facilitates $\mathrm{Ca}^{2+}$ entry through TRPV4 channels, reducing transmembrane electrical resistance and conferring increased barrier permeability in cultured mouse and human pulmonary microvascular endothelial cells (269). 
Wu et al. further explored the concept of functional specificity of $\mathrm{Ca}^{2+}$ influx pathways in the pulmonary endothelium. Although stimulation of TRPV4-mediated $\mathrm{Ca}^{2+}$ entry using $4 a-$ PDD increased permeability of isolated mouse lungs, this treatment had no effect on cell surface expression of the adhesion molecule P-selectin on pulmonary capillary endothelium (315). In contrast, $\mathrm{Ca}^{2+}$ entry through T-type $\mathrm{Ca}^{2+}$ channels promoted cell surface expression of P-selectin, but had no effect on permeability (315). Inhibition of myosin light chain kinase (MLCK) has been shown to reduce membrane-bound TRPV4 expression and intracellular $\mathrm{Ca}^{2+}$ entry following $4 \mathrm{a}-\mathrm{PDD}$ application in rat pulmonary microvascular endothelial cells (207), suggesting that MLCK regulates plasma membrane trafficking of TRPV4 channels in the pulmonary endothelium. Yin et al. demonstrated that increases in vascular pressure facilitated endothelial $\mathrm{Ca}^{2+}$ entry and alveolar liquid accumulation in isolated mouse lungs, a response that was absent in lungs from TRPV $4^{-/}$mice (327). Increasing pressure was shown to produce a corresponding increase in endothelial NO production, where a cGMP analog attenuated $\mathrm{Ca}^{2+}$ influx in response to $4 a-P D D$. The authors proposed that this increase in NO production acts through cGMP to regulate $\mathrm{Ca}^{2+}$ entry via TRPV4 channels, providing a negative feedback mechanism to regulate TRPV4mediated increases in permeability in response to increases in vascular pressure (327). Pulmonary edema induced in a rat model of heart failure was attenuated by TRPV4 blockade (278), further confirming a role for TRPV4 in increasing the permeability of the pulmonary vasculature in vivo.

TRPV1-The role of TRPV1 channels in the regulation of microvascular permeability is controversial. Thomas et al. reported that TRPV1 antagonism or genetic deletion in mice did not alter the increase in lung-wet weight induced by treatment with the endotoxin, lipopolysaccharide (LPS) (277). In support of this, Alvarez and colleagues showed that the TRPV1 agonist 4a-phorbol-12,13-didecanoate-20 homovanillate had no effect on lung permeability in isolated rat lung preparations (8). In contrast, Wang and colleagues reported that TRPV1 activation with capsaicin exerted a protective effect in vivo following lung ischemia-reperfusion injury in rabbits (296). This protection was associated with an increase in CGRP levels (296), suggesting that it is likely due to activation of TRPV1 on sensory neurons, rather than stimulation of endothelial $\mathrm{Ca}^{2+}$ influx. Moreover, although mRNA transcripts for TRPV1 channels are highly expressed in the mouse lung, expression in human lung microvascular endothelial cells is minimal (277). In addition, endothelial cells are not labeled in transgenic TRPV1 reporter mice, suggesting that the channel is not expressed in these cells (43).

TRPC1-TRPC1 channels, most likely in a heteromeric configuration, have been implicated in the control of endothelial permeability in the pulmonary vasculature. Moore et al. reported that increases in intracellular $\mathrm{Ca}^{2+}$ in cultured rat pulmonary arterial endothelial cells result in redistribution of peripheral filamentous actin and lead to changes in cell shape (189). They further proposed that TRPC1 channels may contribute to this process by acting through SOCE (189), which has been reported to increase pulmonary microvascular permeability (48). Consistent with this, Brough et al. demonstrated that SOCE is diminished in cultured human pulmonary artery endothelial cells following antisense-mediated knockdown of TRPC1 (32). Mehta el al. observed that treatment of cultured human 
pulmonary arterial endothelial cells with thrombin resulted in translocation of TRPC1 and $\mathrm{IP}_{3}$ Rs, which directly associated with RhoA; notably, inhibition of RhoA attenuated SOCE (181). A separate study demonstrated that thrombin treatment of cultured HUVEC evoked SOCE and increased permeability through induction of protein kinase $\mathrm{Ca}(\mathrm{PKCa})-$ dependent phosphorylation of TRPC1 (4). Tauseef and colleagues noted that thrombin increased the permeability of endothelial cells from wild-type mice, but not $\mathrm{TRPC}^{-/-}$mice (273). Furthermore, monolayers of cultured endothelial cell from TRPC $1^{-/-}$mice were shown to express significantly higher levels of the adheren junction molecule vascular endothelial cadherin (273). Several reports implicate sphingosine-1-phosphate, produced through sphingosine kinase 1-mediated phosphorylation, anneals adheren junctions to stabilize the endothelium barrier $(229,274)$. Tauseef et al. proposed that $\mathrm{Ca}^{2+}$ entry through TRPC1 suppresses sphingosine kinase 1, resulting in disruption of endothelial cell barrier stability (273).

TRPC4-Tiruppathi and colleagues were the first to describe a role for TRPC4 channels in the permeability of the pulmonary vasculature. Treatment of cultured mouse pulmonary endothelial cells with either thrombin or a protease-activated receptor (PAR-1) agonist resulted in a sustained increase in intracellular $\mathrm{Ca}^{2+}$, a response that was attenuated in lung endothelial cells from TRPC $4^{-/}$mice (280). This reduction in $\mathrm{Ca}^{2+}$ influx was associated with reduced actin-stress fiber formation and endothelial cell retraction. Although basal permeability did not differ between perfused lungs isolated from wild-type or TRPC4 ${ }^{-/-}$ mice, PAR-1 stimulation increased the vascular filtration coefficient of wild-type lungs, but not that of TRPC4 ${ }^{-/}$lungs (280). The authors proposed that TRPC4 is activated following intracellular store depletion and facilitates $\mathrm{Ca}^{2+}$ entry and subsequent rearrangement of the endothelium layer, a supposition confirmed in a subsequent follow up study. Disruption of the endothelial barrier by intracellular store depletion was prevented by siRNA-mediated knockdown of TRPC4 and was absent in endothelial cells from TRPC $4^{-/-}$mice (268). In cultured pulmonary artery endothelial cell, direct association between spectrin protein 4.1 and TRPC4 channels was shown to be required for SOCE (52).

Channels formed through heteromeric association of TRPC1 and TRPC4 subunits may underpin SOCE and increases in microvascular permeability in the pulmonary circulation. Channels comprised of both subunits have been identified in cultured bovine aortic endothelial cells (14). Cioffi et al. characterized the individual subunit composition of TRPC1/TRPC4 heteromeric channels using Förster Resonance Energy Transfer. They determined that these channels contained one TRPC1 subunit and at least two TRPC4 subunits (53). Furthermore, Orai1 was found to associate with TRPC4, and loss of Orai1 function was shown to improve endothelial barrier properties in cultured rat pulmonary endothelial cells (53). Additionally, TRPC1 and TRPC4 were found to colocalize with STIM1 in cultured mouse pulmonary endothelial cells, implicating this heteromeric channel in SOCE (268). However, considering the controversies surrounding TRPC channels and SOCE as previously discussed, conclusions must be approached cautiously.

TRPC6-TRPC6 channels have a unitary conductance of $\sim 30 \mathrm{pS}$, a $\mathrm{P}_{\mathrm{Ca}}: \mathrm{P}_{\mathrm{Na}}$ ratio of $\sim 5$, and are activated by the second messenger DAG following $\mathrm{G}_{\mathrm{q}} \mathrm{PCR}$ stimulation $(119,126,154)$. In 
an early study, Singh et al. reported that actin stress fiber formation and endothelial barrier dysfunction induced in human pulmonary artery endothelial cells by thrombin or a DAG analog was prevented by siRNA-mediated knockdown of TRPC6 (244). Samapati and colleagues showed that TRPC6 expression in caveoli of pulmonary endothelial cells was increased following treatment of isolated perfused rodent lungs with platelet-activating factor (PAF) (228). This study also showed that the selective TRPC6 agonist hyperforin increased endothelial $\mathrm{Ca}^{2+}$ concentration and pulmonary wet weight. Furthermore, PAF increased the intracellular $\mathrm{Ca}^{2+}$ concentration in endothelial cells as well as the vascular filtration coefficient and edema formation in isolated lungs of wild-type mice, effects that were significantly diminished in lungs from $\mathrm{TRPC}^{-/-}$mice (228). The effects of PAF and hyperforin were attenuated by NO donors and a membrane-permeable cGMP analog, whereas the increase in wet lung mass in response to hyperforin was augmented by NOS blockade. The authors proposed that NO inhibits $\mathrm{Ca}^{2+}$ entry through TRPC6 channels, but does not affect their recruitment to caveolin-rich microdomains in endothelial cells (228).

TRPM2-Although TRPM2 is expressed in the endothelium $(86,113)$, its role in regulating endothelial permeability is uncertain. Hecquet et al. provided early evidence that $\mathrm{H}_{2} \mathrm{O}_{2}$ increases intracellular $\mathrm{Ca}^{2+}$ entry and reduces transendothelial electrical conductance in cultured human pulmonary endothelial cell monolayers, a response that was sensitive to inhibition with an anti-TRPM2 blocking antibody, siRNA-mediated knockdown of TRPM2, or overexpression of a dominant-negative short TRPM2 isoform (113), suggesting TRPM2 increases permeability. However, investigations performed in vivo have provided conflicting results. In TRPM2 $2^{-1-}$ mice challenged with LPS, Di and colleagues observed an increase in pulmonary edema formation and reduced survival (64), suggesting TRPM2 maintains barrier integrity contrasting observations made in vitro. Moreover, Hardaker et al. reported no change in TRPM2-/- mice following LPS treatment (108). Although the reason for the discrepancies between these studies in vivo is not clear, it may be related to the mouse strain employed in the generation of TRPM2-deficient mice. Specifically, Di et al. created TRPM2 $^{-/-}$mice on a C57BL/6 background, whereas Hardaker et al. used a BALB/c mouse strain in generating their TRPM2-/- mice. This difference is notable because sensitivity to lung injury following LPS challenge is reported to be lower in BALB/c mice $(57,66)$. However, the precise role of TRPM2 in endothelial barrier function remains unresolved.

\section{TRP channels and angiogenesis and arteriogenesis}

TRPV1, TRPA1, TRPV4, TRPC1, TRPC3, TRPC4, TRPC5, and TRPC6 channels have been implicated in the formation of new blood vessels.

TRPV1 and TRPA1-Su et al. demonstrated that 14,15-EET increased $\mathrm{Ca}^{2+}$ influx and NO production in cultured human microvascular endothelial cells, a response that was blocked by the TRPV1 antagonist capsazepine or overexpression of inactive TRPV1 (261). In this study, application of 14,15-EET was found to increase endothelial tube formation, an effect that was abolished by capsazepine. Utilizing Matrigel plug in vivo angiogenesis assays, these authors also showed that hemoglobin content was reduced in in TRPV1-/mice and wild-type animals treated with capsazepine, indicative of reduced neovascularization (261). A subsequent study from this group further demonstrated the 
involvement of TRPV1 channels in simvastatin-induced angiogenesis, showing that $\mathrm{Ca}^{2+}$ entry through TRPV1 channels increased eNOS activity through CaMKII/Akt-dependent phosphorylation (262). Interestingly, the authors showed that the selective TRPA1 inhibitor HC-030031 diminished simvastatin-induced eNOS phosphorylation and NO production and reduced vascularization of Matrigel plugs from TRPA $1^{-/-}$mice, suggesting the involvement of pathways downstream of TRPA1 (262). A separate report from Hofmann et al. reported that TRPV1 is necessary for anandamide uptake into cultured human endothelial cells and subsequent induction of tube formation in culture, further implicating TRPV1 in angiogenesis. However, this latter study proposed a $\mathrm{Ca}^{2+}$-independent mechanism (117), differing from that hypothesized by Su et al. $(261,262)$.

TRPV4-siRNA-mediated TRPV4 channel knockdown was shown to attenuate cyclic strain-induced $\mathrm{Ca}^{2+}$ influx and bovine capillary endothelial cell cytoskeletal remodeling and reorientation, suggesting the possible involvement of TRPV4 in migration and sprouting responses associated with angiogenesis (276). The TRPV4 agonist 4a-PDD induced an increase in $\mathrm{Ca}^{2+}$ influx in cultured human brain capillary endothelial cells and promoted their proliferation, an effect that was partially attenuated by TRPV4 knockdown (112). Schierling et al. observed increased growth of the rat cerebral collateral circulation in response to 4a-PDD (233). Troidl et al. also observed increased collateral growth of the rabbit hindlimb circulation following 4a-PDD application, further implicating TRPV4 in arteriogenesis (285). Fiorio Pla et al. noted increased TRPV4 channel expression and greater subsequent $\mathrm{Ca}^{2+}$ influx in cultured endothelial cells derived from human breast carcinomas compared with human microvascular endothelial cells (87). Stimulation of TRPV4 with either arachidonic acid or 4a-PDD promoted migration of breast cancer endothelial cells, but not control endothelial cells (87). Adapala et al. provided further support for the importance of TRPV4 channels in tumor angiogenesis. Using a syngenic tumor model, Thodeti and colleagues found that TRPV4 $4^{-/}$mice exhibited an increase in tumor growth that was associated with increased vascularization and vessel diameter. In contrast, cotreatment of wild-type mice with the TRPV4 agonist GSK1016790A and the anticancer agent cisplatin reduced tumor formation by inducing vessel maturation, whereas treatment with GSK1016790A alone did not (2). Collectively, these data suggest that $\mathrm{Ca}^{2+}$ entry through TRPV4 channels has a greater impact on tumor-associated angiogenesis than on physiological angiogenesis.

TRPC1-Using an in vivo zebrafish model, Yu et al. demonstrated that knockdown of TRPC1 channels using targeted morpholino oligonucleotides disrupted angiogenic sprouting of interseg-mental vessels in larvae, an effect that was prevented by overexpression of a morpholino-resistant TRPC1 form (331). These authors further found that TRPC1 channels act downstream of VEGF-A signaling and are required for ERK signaling (331). In contrast, knockdown of TRPC1 in cultured HUVECs was shown to minimally reduce tube formation(13), whereas $\mathrm{TRPC}^{-1-}$ mice were reported to exhibit normal vascular growth (235), suggesting that TRPC1 channels have minimal effects on angiogenesis in mammals.

TRPC3-VEGF has been reported to activate TRPC3 channels in cultured human microvascular endothelial cells, suggesting a potential role for this channel in angiogenesis 
(47). Antigny et al. demonstrated that siRNA-mediated knockdown of TRPC3 reduced endothelial tube formation in human endothelial cell cultures, an effect that was associated with reduced spontaneous $\mathrm{Ca}^{2+}$ oscillations (13). Moreover, Andrikopoulos et al. recently demonstrated that VEGF signaling activates $\mathrm{Ca}^{2+}$ influx through TRPC3 channels in cultured HUVEC (11). The authors reported functional coupling of TRPC 3 channels with NCX1, and showed that inhibition or knockdown of TRPC3 reduced protein kinase C- $a$ and ERK1/2 activation, partially suppressed $\mathrm{Ca}^{2+}$ influx, and significantly attenuated in vitro tube formation in response to VEGF (11). These authors further showed that an analog of DAG induced $\mathrm{Ca}^{2+}$ - and $\mathrm{Na}^{+}$-mediated activation of ERK1/2 and promoted tube formation. Interestingly, they also reported that $\mathrm{Ca}^{2+}$ transients were sensitive to both inhibition of TRPC3 and reverse-mode NCX1, whereas $\mathrm{Na}^{+}$influx was only sensitive to TRPC3 inhibition (11). These data suggest that VEGF initiates $\mathrm{Na}^{+}$influx through TRPC3, resulting in $\mathrm{Ca}^{2+}$ influx through reverse-mode NCX1 and promotion of tube formation via ERK1/2 signaling.

TRPC4 and TRPC5-In addition to TRPC 3 channels, TRPC4 and TRPC5 channels have also been implicated in tube formation and $\mathrm{Ca}^{2+}$ oscillations in human endothelial cell cultures. In this report from Antigny et al. (13), only TRPC1 and TRPC4 were reported to be present in this immortalized endothelial cell line, and siRNA-mediated knockdown of TRPC4 was shown to significantly reduce spontaneous $\mathrm{Ca}^{2+}$ oscillations and tube formation (13). Zhu et al. reported that TRPC5 is highly expressed in human breast cancer cells following long-term chemotherapy treatment, and further demonstrated that siRNAmediated TRPC5 knockdown reduced VEGF expression, tumor growth, and vessel density in a mouse xenograft model (339). In this study, TRPC5 activity was shown to promote nuclear translocation of hypoxia-inducible factor 1- $a$ and subsequent induction of VEGF production, leading to increased tumor growth (339). Taken together, these observations suggest that TRPC4 may have a role in physiological angiogenesis, whereas TRPC5 channels are more likely involved in tumor angiogenesis.

TRPC6-It was reported that rat pulmonary microvascular endothelial cell TRPC6 channels are activated by VEGF (47), suggesting that $\mathrm{Ca}^{2+}$ influx through these channels may regulate blood vessel formation. A subsequent study from this laboratory confirmed this, showing that overexpression of TRPC6 increased the proliferation and migration of cultured microvascular endothelial cells, whereas overexpression of a dominant-negative isoform of TRPC6 reduced proliferation, migration, and sprouting (106). Moreover, Kini et al. reported in cultured human pulmonary artery endothelial cells that TRPC6 associates with PTEN (phosphatase and tensin homolog), a lipid-protein phosphatase that is required for thrombininduced migration and tube formation (137). Although these studies proposed a role for TRPC6 channels in angiogenesis based on results obtained using an in vitro approach, contrasting evidence has been provided in vivo, where gain-of-function mutations of TRPC6 in humans (310) or genetic deletion of TRPC6 in mice (65) produced no change in blood vessel structure. 


\section{TRP channels and control of the inflammatory response by the endothelium}

TRPV1, TRPV4, TRPA1, and TRPM2 have been associated with anti-inflammatory properties, whereas TRPC1, TRPC3, and TRPC6 exert pro-inflammatory affects.

TRPV1-The role of TRPV1 in neurogenic inflammation is well established. In particular, activation of TRPV1 in sensory neurons has been shown to cause the release of vasoactive neuropep-tides, including CGRP and tachykinins (e.g., substance P) and evoke a proinflammatory response. However, there is evidence that TRPV1 channels in non-neuronal tissue may have anti-inflammatory properties. Activation of TRPV1 channels is associated with increased production of $\mathrm{NO}$, which is a known anti-inflammatory mediator. This was demonstrated by Wang et al., who used cultured HUVECs to show that activation of TRPV1 channels with capsaicin not only increased eNOS phosphorylation and NO production through the phosphatidylinositol-4,5-bisphosphate 3-kinase/Akt pathway, but also produced a number of anti-inflammatory effects associated with LPS treatment, including reduced production of cytokines and chemokines, decreased expression of adhesion molecules, activation and translocation of nuclear factor- $\mathrm{\kappa B}$ (NF- $\mathrm{\kappa B})$, and increased monocyte adhesion to endothelial cells (299). These authors further reported that the anti-inflammatory effects of capsaicin were abrogated by inhibition of TRPV1 or NOS, or sequestration of $\mathrm{Ca}^{2+}$, suggesting the $\mathrm{Ca}^{2+}$ influx through TRPV1 channels promotes NO production and subsequent inhibition of the inflammatory process (299). The authors also observed that TRPV1 exerted anti-inflammatory properties in renal microvascular endothelial cells isolated from hypertensive mice (299). Lee et al. observed that a derivative of rutaecarpine, a COX-2 inhibitor, increased expression of TRPV1 and eNOS phosphorylation in cultured human aortic endothelial cells, and reduced pulmonary neutrophil infiltration in mice challenged with ovalbumin, further suggesting a role for TRPV1 channels in protection against inflammation (152). Interestingly, not only did Wilhelmsen and colleagues observe that inhibition of TRPV1 with AMG9810 augmented inflammation associated with LPS in cultured human endothelial cells, indicative of its anti-inflammatory properties, they found that AMG9810 also abrogated the reduction in inflammatory cytokines associated with endocannabinoid treatment (305). This suggests that TRPV1 is anti-inflammatory under physiological conditions, but may also attenuate anti-inflammatory mechanisms associated with other factors.

TRPV4-Although TRPV4 channels have been implicated in regulating the interendothelial integrity of the pulmonary vasculature, they do not appear to be involved in the recruitment of cytokines. $\mathrm{Ca}^{2+}$ influx mediated by EETs-activated TRPV4 channels did not affect the expression of the adhesion molecules, VCAM (vascular cell adhesion molecule), ICAM (intercellular adhesion molecule) (282), or P-selectin (315). However, in certain vascular beds, $\mathrm{Ca}^{2+}$ entry through TRPV4 channels may be associated with a reduction in inflammation. Xu et al. reported that treatment of mice with the TRPV4 channel activator GSK1016790A inhibited monocyte adhesion in cultured HUVEC and in vivo in mice treated with tumor necrosis factor-a (TNF-a) (322). Furthermore, oral administration of GSK1016790A reduced the formation of atherosclerotic plaques in $\mathrm{ApoE}^{-/-}$mice. The authors proposed that increased intracellular $\mathrm{Ca}^{2+}$ through TRPV4 channels increases eNOS activity and NO production, thereby evoking an anti-inflammatory phenotype (322). In 
contrast, ischemia/reperfusion injury in the renal microcirculation resulted in aggravated tubular damage in $\mathrm{TRPV}^{-/-}$mice, but recruitment of granulocytes and macrophages was comparable to that in wild-type mice (174), suggesting that the anti-inflammatory actions of TRPV4 channels are localized to specific regions.

TRPA1-The TRPA1 channel activator cinnamaldehyde has been reported to exert antiinflammatory affects. Liao et al. reported that treatment of cultured human endothelial cells with TNF- $a$ increased monocyte adhesion, a response that was attenuated by cinnamaldehyde (161). Moreover, cinnamaldehyde reduced the expression of cell adhesion molecules and attenuated NF- $\mathrm{KB}$ signaling in endothelial cells (161). These authors concluded that cinnamaldehyde exerted its anti-inflammatory effects by preventing the degradation of $\mathrm{I} \kappa \mathrm{Ba}$ (nuclear factor of $\kappa$ light polypeptide gene enhancer in B-cells inhibitor $a$ ), an endogenous inhibitor of NF- $\mathrm{KB}$, and subsequently inducing the protective transcription factor Nrf2 (nuclear factor erythroid-derived 2-like 2) (161). However, the antiinflammatory properties of cinnamaldehyde have yet to be associated with $\mathrm{Ca}^{2+}$ influx through TRPA1 channels. The study by Liao et al. did not confirm whether cinnamaldehyde increased endothelial cell cytosolic $\mathrm{Ca}^{2+}$. They also did not use TRPA1 antagonists on their preparations, an important consideration given that cinnamaldehyde is known to have offtarget effects.

TRPC1-TRPC1 expression has been linked to TNF-a. During the cloning of human TRPC1, Paria et al. noted four NF- $\kappa$ B binding sites in the 5'-regulatory region, and showed that treatment of cultured microvascular endothelial cell with TNF- $a$ increased TRPC1 promotor-luciferase activity and intra-cellular $\mathrm{Ca}^{2+}$ concentration following store depletion with thapsigargin (205). These changes were sensitive to NF- $\kappa B$ inhibition, leading the authors to propose that TNF- $a$ increases endothelial TRPC1 expression through NF- $\kappa B$, thereby increasing $\mathrm{Ca}^{2+}$ following intracellular store depletion (205). A separate investigation by Bodiga et al. reported that treatment of cultured HUVEC with cisplatin, an anti-cancer chemotherapeutic agent, increased the permeability and adherence of monocytes in culture, an effect that was associated with increased PKCa-mediated phosphorylation of TRPC1 channels (29). siRNA-mediated knockdown of PKCa, TRPC1, or the p65 subunit of NF- $\kappa B$ attenuated the increase in endothelial $\mathrm{Ca}^{2+}$ influx and permeability. The mechanism proposed to explain this effect was that cisplatin acted through PKCa to induce an NF- $\mathrm{kB}-$ dependent increase in TRPC1 channel expression and phosphorylation that facilitated $\mathrm{Ca}^{2+}$ influx and endothelial dysfunction (29). A follow-up study from this laboratory provided further support for this pathway(28). However, further investigations are required to determine if this mechanism operates in vivo following endogenous activation of TRPC1.

TRPC3-TRPC3 channels have been reported to exert a proinflamma-tory phenotype in macrophages and monocytes, but few studies have investigated their potential role in the endothelium. In an early study, Smedlund et al. reported that ATP-induced $\mathrm{Ca}^{2+}$ influx in cultured human coronary artery endothelial cells increased TRPC 3 expression and was essential for VCAM-1 expression and monocyte adhesion, effects that were reduced by siRNA-mediated knockdown of TRPC3 (247). A subsequent follow-up study from this laboratory reported similar observations in endothelial cells treated with TNF-a (246). The 
authors proposed that $\mathrm{Ca}^{2+}$ influx through TRPC 3 channels promoted NF- $\kappa \mathrm{B}$ activity through a calmodulin/CaMKII-dependent pathway (246). Perhaps most surprisingly was that TRPC 3 expression was increased downstream of pro-inflammatory signaling, suggesting a positive feedback mechanism that augments the inflammatory phenotype. These findings were recently confirmed in vivo in $\mathrm{ApoE}^{-/-}$mice overexpressing human TRPC3 specifically in endothelial cells. After feeding a high-fat diet for 10 weeks, atherosclerotic lesions were comparable between $\mathrm{Apo}^{-/}$and TRPV3-expressing $\mathrm{ApoE}^{-/-}$mice, but at 16 weeks, the latter mice exhibited increased lesion size, macrophage infiltration, VCAM-1 expression, and NF- $\kappa$ B activity compared with nontransgenic $\mathrm{Apo}^{-/-}$control mice $(245,248)$.

TRPC6 - TRPC6 channels have been associated with increased microvascular permeability, suggesting their possible involvement in the trafficking of leukocytes. Tauseef et al. demonstrated that treatment of cultured pulmonary endothelial cells from wild-type mice with LPS increased intracellular $\mathrm{Ca}^{2+}$ entry, an effect that was not observed in endothelial cells isolated from TRPC6 ${ }^{-/}$mice (275). In whole-animal studies, LPS increased lung permeability in association with increased leukocyte infiltration, responses that were blunted in TRPC6 $^{-1-}$ mice (275). The authors proposed that $\mathrm{Ca}^{2+}$ entry through TRPC6 channels promotes NF- $\mathrm{kB}$ activation via MLCK to evoke an inflammatory response. Webber and colleagues further proposed that TRPC6 channels mediate leukocyte transendothelial migration during an inflammatory cascade. These authors reported that TRPC6 channels colocalized with platelet/endothelial cell adhesion molecule-1 (PECAM-1) in cultured HUVECs and formed clusters following engagement of PECAM-1 (304). Buffering intracellular $\mathrm{Ca}^{2+}$ prevented leukocyte transendothelial migration, as did expression of a dominant-negative TRPC6 and silencing of TRPC6 (304). Furthermore, activation of TRPC6 in the presence of a PECAM inhibitor rescued leukocyte trans-migration, suggesting that regulation of transmigration by TRPC6 channels occurs downstream of PECAM activity (304). Using topical application of croton oil on the ear, an in vivo model of transmigration, these authors observed reduced neutrophil transendothelial migration in irradiated TRPC6 ${ }^{-/-}$ mice treated with bone marrow from wild-type or TRPC $6^{-1-}$ mice, but had no effect on trafficking (304). Collectively, these data suggest that activation of PECAM stimulates TRPC6 channel-mediated $\mathrm{Ca}^{2+}$ influx, which promotes leukocyte transmigration during an inflammatory response.

TRPM2-The increased permeability of the pulmonary vasculature in TRPM2 ${ }^{-/-}$mice challenged with LPS reported by Di and colleagues, noted above, was associated with increased expression of inflammatory cytokines, including TNF- $a$ and ilterleukin-6 (64), suggesting that TRPM2 may have anti-inflammatory properties. However, because TRPM2 channels are also expressed in leukocytes, where they contribute to inflammatory responses, it is unclear whether this effect is mediated by TRPM2 channels in the endothelium (324).

\section{TRP channels and endothelium-dependent regulation of thrombosis}

Endothelial-derived $\mathrm{NO}$ and prostacyclin have anticoagulant properties that serve to regulate platelet aggregation in vivo $(187,188)$. Although several reports have suggested that $\mathrm{Ca}^{2+}$ entry through different TRP channels is associated with increased NOS activity and NO 
production, these studies have not investigated possible associations between endothelial cell TRP channel activity and antithrombotic mechanisms.

\section{Conclusions}

TRP channels are critically important for many physiological and pathological responses within the vasculature (74). Strong evidence demonstrates an influential role of endothelial TRP channels in the regulation of endothelium-dependent dilation, vascular permeability, angiogenesis, and inflammation. These regulatory mechanisms are primarily governed through control of global changes in intracellular $\mathrm{Ca}^{2+}$ resulting from direct $\mathrm{Ca}^{2+}$ influx through TRP channels or regulation of sub-cellular $\mathrm{Ca}^{2+}$ signaling events involving intracellular $\mathrm{Ca}^{2+}$ stores. However, considerable work is still required to fully understand the mechanistic features of TRP channel signaling, including their direct interactions with signaling molecules and other TRP subtypes, and to address current discrepancies in the literature, for example the conflicting views of TRPC channels in SOCE. Nonetheless, selective pharmacological targeting of TRP channels offers a promising opportunity for potential new therapies to treat and prevent vascular diseases.

\section{Acknowledgements}

Support for this review was provided by grants from the National Heart, Lung, and Blood Institute (R01HL091905, R01HL137852, and R01HL139585), the National Institute of Neurological Disorders and Stroke (RF1110044), and the National Institute of General Medicine (P20GM130459) toS. Earley.

\section{References}

1. Abdullaev IF, Bisaillon JM, Potier M, Gonzalez JC, Motiani RK, Trebak M. Stim1 and Orai1 mediate CRAC currents and store-operated calcium entry important for endothelial cell proliferation. Circ Res 103: 1289-1299, 2008. [PubMed: 18845811]

2. Adapala RK, Thoppil RJ, Ghosh K, Cappelli HC, Dudley AC, Paruchuri S, Keshamouni V, Klagsbrun M, Meszaros JG, Chilian WM, Ingber DE, Thodeti CK. Activation of mechanosensitive ion channel TRPV4 normalizes tumor vasculature and improves cancer therapy. Oncogene 35: 314 322, 2016. [PubMed: 25867067]

3. Addison MP, Singh TU, Parida S, Choudhury S, Kasa JK, Sukumaran SV, Darzi SA, Kandasamy K, Singh V, Kumar D, Mishra SK. NO synthase inhibition attenuates EDHF-mediated relaxation induced by TRPV4 channel agonist GSK1016790A in the rat pulmonary artery: Role of TxA2. Pharmacol Rep 68: 620-626, 2016. [PubMed: 26991376]

4. Ahmmed GU, Mehta D, Vogel S, Holinstat M, Paria BC, Tiruppathi C, Malik AB. Protein kinase Calpha phosphorylates the TRPC1 channel and regulates store-operated Ca2+ entry in endothelial cells. J Biol Chem 279: 20941-20949, 2004. [PubMed: 15016832]

5. Aird WC. Endothelial cell heterogeneity. Cold Spring Harb Perspect Med 2: a006429, 2012. [PubMed: 22315715]

6. Aird WC. Phenotypic heterogeneity of the endothelium: I. Structure, function, and mechanisms. Circ Res 100: 158-173, 2007. [PubMed: 17272818]

7. Akbulut Y, Gaunt HJ, Muraki K, Ludlow MJ, Amer MS, Bruns A, Vasudev NS, Radtke L, Willot M, Hahn S, Seitz T, Ziegler S, Christmann M, Beech DJ, Waldmann H. (-)-Englerin A is a potent and selective activator of TRPC4 and TRPC5 calcium channels. Angew Chem Int Ed Engl 54: 37873791, 2015. [PubMed: 25707820]

8. Alvarez DF, King JA, Weber D, Addison E, Liedtke W, Townsley MI. Transient receptor potential vanilloid 4-mediated disruption of the alveolar septal barrier: A novel mechanism of acute lung injury. Circ Res 99: 988-995, 2006. [PubMed: 17008604] 
9. Amer MS, McKeown L, Tumova S, Liu R, Seymour VA, Wilson LA, Naylor J, Greenhalgh K, Hou B, Majeed Y, Turner P, Sedo A, O'Regan DJ, Li J, Bon RS, Porter KE, and Beech DJ. Inhibition of endothelial cell $\mathrm{Ca}(2)(+)$ entry and transient receptor potential channels by Sigma-1 receptor ligands. Br J Pharmacol 168: 1445-1455, 2013. [PubMed: 23121507]

10. Andersson DA, Gentry C, Moss S, and Bevan S. Transient receptor potential A1 is a sensory receptor for multiple products of oxidative stress. J Neurosci 28: 2485-2494, 2008. [PubMed: 18322093]

11. Andrikopoulos P, Eccles SA, Yaqoob MM. Coupling between the TRPC3 ion channel and the NCX1 transporter contributed to VEGF-induced ERK1/2 activation and angiogenesis in human primary endothelial cells. Cell Signal 37: 12-30, 2017. [PubMed: 28535874]

12. Aneiros E, Cao L, Papakosta M, Stevens EB, Phillips S, Grimm C. The biophysical and molecular basis of TRPV1 proton gating. EMBO J 30: 994-1002, 2011. [PubMed: 21285946]

13. Antigny F, Girardin N, Frieden M. Transient receptor potential canonical channels are required for in vitro endothelial tube formation. J Biol Chem 287: 5917-5927, 2012. [PubMed: 22203682]

14. Antoniotti S, Fiorio Pla A, Barral S, Scalabrino O, Munaron L, LovisoloD. Interaction between TRPC channel subunits in endothelial cells. J Recept Signal Transduct Res 26: 225-240, 2006. [PubMed: 16818374]

15. Aubdool AA, Graepel R, Kodji X, Alawi KM, Bodkin JV, Srivastava S, Gentry C, Heads R, Grant AD, Fernandes ES, Bevan S, Brain SD. TRPA1 is essential for the vascular response to environmental cold exposure. Nat Commun 5: 5732, 2014. [PubMed: 25501034]

16. Autzen HE, Myasnikov AG, Campbell MG, Asarnow D, Julius D, Cheng Y. Structure of the human TRPM4 ion channel in a lipid nanodisc. Science 359: 228-232, 2018. [PubMed: 29217581]

17. Azumaya CM, Sierra-Valdez F, Cordero-Morales JF, Nakagawa T. Cryo-EM structure of the cytoplasmic domain of murine transient receptor potential cation channel subfamily $\mathrm{C}$ member 6 (TRPC6). J Biol Chem 293: 10381-10391, 2018. [PubMed: 29752403]

18. Bagher P, Beleznai T, Kansui Y, Mitchell R, Garland CJ, Dora KA. Low intravascular pressure activates endothelial cell TRPV4 channels, local Ca2+ events, and IKCa channels, reducing arteriolar tone. Proc Natl Acad Sci USA 109: 18174-18179, 2012. [PubMed: 23071308]

19. Bandell M, Story GM, Hwang SW, Viswanath V, Eid SR, Petrus MJ, Earley TJ, Patapoutian A. Noxious cold ion channel TRPA1 is activated by pungent compounds and bradykinin. Neuron 41: 849-857, 2004. [PubMed: 15046718]

20. Bang S, Yoo S, Yang TJ, Cho H, Hwang SW. Isopentenyl pyrophosphate is a novel antinociceptive substance that inhibits TRPV3 and TRPA1 ion channels. Pain 152: 1156-1164, 2011. [PubMed: 21353389]

21. Baratchi S, Almazi JG, Darby W, Tovar-Lopez FJ, Mitchell A, McIntyre P. Shear stress mediates exocytosis of functional TRPV4 channels in endothelial cells. Cell Mol Life Sci 73: 649-666, 2016. [PubMed: 26289129]

22. Bautista DM, Jordt SE, Nikai T, Tsuruda PR, Read AJ, Poblete J, Yamoah EN, Basbaum AI, Julius D. TRPA1 mediates the inflammatory actions of environmental irritants and proalgesic agents. Cell 124: 1269-1282, 2006. [PubMed: 16564016]

23. Bautista DM, Movahed P, Hinman A, Axelsson HE, Sterner O, Hogestatt ED, Julius D, Jordt SE, Zygmunt PM. Pungent products from garlic activate the sensory ion channel TRPA1. Proc Natl Acad Sci USA 102: 12248-12252, 2005. [PubMed: 16103371]

24. Beck A, Kolisek M, Bagley LA, Fleig A, Penner R. Nicotinic acid ade-nine dinucleotide phosphate and cyclic ADP-ribose regulate TRPM2 channels in T lymphocytes. FASEB J 20: 962-964, 2006. [PubMed: 16585058]

25. Beck A, Speicher T, Stoerger C, Sell T, Dettmer V, Jusoh SA, Abdulmughni A, Cavalie A, Philipp SE, Zhu MX, Helms V, Wissenbach U, Flockerzi V. Conserved gating elements in TRPC4 and TRPC5 channels. J Biol Chem 288: 19471-19483, 2013. [PubMed: 23677990]

26. Bergdahl A, Gomez MF, Wihlborg AK, Erlinge D, Eyjolfson A, Xu SZ, Beech DJ, Dreja K, Hellstrand P. Plasticity of TRPC expression in arterial smooth muscle: Correlation with storeoperated Ca2+ entry. Am J Physiol Cell Physiol 288: C872-C880, 2005. [PubMed: 15561760]

27. Berrout J, Jin M, O'Neil RG. Critical role of TRPP2 and TRPC1 channels in stretch-induced injury of blood-brain barrier endothelial cells. Brain Res 1436: 1-12, 2012. [PubMed: 22192412] 
28. Bodiga VL, Inapurapu SP, Vemuri PK, Kudle MR, Bodiga S. Intracellular zinc status influences cisplatin-induced endothelial permeability through modulation of PKCalpha, NF-kappaB and ICAM-1 expression. Eur J Pharmacol 791: 355-368, 2016. [PubMed: 27614131]

29. Bodiga VL, Kudle MR, Bodiga S. Silencing of PKC-alpha, TRPC1 or NF-kappaB expression attenuates cisplatin-induced ICAM-1 expression and endothelial dysfunction. Biochem Pharmacol 98: 78-91, 2015. [PubMed: 26300057]

30. Bodkin JV, Thakore P, Aubdool AA, Liang L, Fernandes ES, Nandi M, Spina D, Clark JE, Aaronson PI, Shattock MJ, Brain SD. Investigating the potential role of TRPA1 in locomotion and cardiovascular control during hypertension. Pharmacol Res Perspect 2: e00052, 2014. [PubMed: 25505598]

31. Bratz IN, Dick GM, Tune JD, Edwards JM, Neeb ZP, Dincer UD, Sturek M. Impaired capsaicininduced relaxation of coronary arteries in a porcine model of the metabolic syndrome. Am J Physiol Heart Circ Physiol 294: H2489-H2496, 2008. [PubMed: 18390821]

32. Brough GH, Wu S, Cioffi D, Moore TM, Li M, Dean N, Stevens T. Contribution of endogenously expressed Trp1 to a Ca2+-selective, store-operated Ca2+ entry pathway. FASEB J 15: 1727-1738, 2001. [PubMed: 11481220]

33. Bryckaert M, Rosa JP, Denis CV, Lenting PJ. Of von Willebrand factor and platelets. Cell Mol Life Sci 72: 307-326, 2015. [PubMed: 25297919]

34. Bubolz AH, Mendoza SA, Zheng X, Zinkevich NS, Li R, Gutterman DD, Zhang DX. Activation of endothelial TRPV4 channels mediates flow-induced dilation in human coronary arterioles: Role of Ca2+ entry and mitochondrial ROS signaling. Am J Physiol Heart Circ Physiol 302: H634-642, 2012. [PubMed: 22140047]

35. Buchanan MR, Bertomeu MC, Brister SJ, Haas TA. 13-Hydroxyoctadecadienoic acid (13-HODE) metabolism and endothelial cell adhesion molecule expression: Effect on platelet vessel wall adhesion. Wien Klin Wochenschr 103: 416-421, 1991. [PubMed: 1718092]

36. Buchanan MR, Bertomeu MC, Haas TA, Orr FW Eltringham-Smith LL. Localization of 13hydroxyoctadecadienoic acid and the vitronectin receptor in human endothelial cells and endothelial cell/platelet interactions in vitro. Blood 81: 3303-3312, 1993. [PubMed: 7685202]

37. Burridge KA, Friedman MH. Environment and vascular bed origin influence differences in endothelial transcriptional profiles of coronary and iliac arteries. Am J Physiol Heart Circ Physiol 299: H837-H846, 2010. [PubMed: 20543076]

38. Busse R, Fichtner H, Luckhoff A, Kohlhardt M. Hyperpolarization and increased free calcium in acetylcholine-stimulated endothelial cells. Am J Physiol 255: H965-H969, 1988. [PubMed: 3177686]

39. Busse R, Mulsch A. Calcium-dependent nitric oxide synthesis in endothelial cytosol is mediated by calmodulin. FEBS Lett 265: 133-136, 1990. [PubMed: 1694782]

40. Campbell WB, Gebremedhin D, Pratt PF, Harder DR. Identification of epoxyeicosatrienoic acids as endothelium-derived hyperpolarizing factors. Circ Res 78: 415-423, 1996. [PubMed: 8593700]

41. Cao E, Liao M, Cheng Y, Julius D. TRPV1 structures in distinct conformations reveal activation mechanisms. Nature 504: 113-118, 2013. [PubMed: 24305161]

42. Caterina MJ, Schumacher MA, Tominaga M, Rosen TA, Levine JD, Julius D. The capsaicin receptor: A heat-activated ion channel in the pain pathway. Nature 389: 816-824, 1997. [PubMed: 9349813]

43. Cavanaugh DJ, Chesler AT, Jackson AC, Sigal YM, Yamanaka H, Grant R, O’Donnell D, Nicoll RA, Shah NM, Julius D, Basbaum AI. Trpv1 reporter mice reveal highly restricted brain distribution and functional expression in arteriolar smooth muscle cells. J Neurosci 31: 50675077, 2011. [PubMed: 21451044]

44. Chen G, Suzuki H, Weston AH. Acetylcholine releases endothelium-derived hyperpolarizing factor and EDRF from rat blood vessels. Br J Pharmacol 95: 1165-1174, 1988. [PubMed: 2851359]

45. Chen L, Kassmann M, Sendeski M, Tsvetkov D, Marko L, Michalick L, Riehle M, Liedtke WB, Kuebler WM, Harteneck C, Tepel M, Patzak A, Gollasch M. Functional transient receptor potential vanilloid 1 and transient receptor potential vanilloid 4 channels along different segments of the renal vasculature. Acta Physiol (Oxf) 213: 481-491, 2015. [PubMed: 25069877] 
46. Chen Q, She J, Zeng W, Guo J, Xu H, Bai XC, Jiang Y. Structure of mammalian endolysosomal TRPML1 channel in nanodiscs. Nature 550: 415-418, 2017. [PubMed: 29019981]

47. Cheng HW, James AF, Foster RR, Hancox JC, Bates DO. VEGF activates receptor-operated cation channels in human microvascular endothelial cells. Arterioscler Thromb Vasc Biol 26: 1768-1776, 2006. [PubMed: 16763162]

48. Chetham PM, Guldemeester HA, Mons N, Brough GH, Bridges JP, Thompson WJ, Stevens T. $\mathrm{Ca}(2+)$-inhibitable adenylyl cyclase and pulmonary microvascular permeability. Am J Physiol 273: L22-L30, 1997. [PubMed: 9252536]

49. Chidgey J, Fraser PA, Aaronson PI. Reactive oxygen species facilitate the EDH response in arterioles by potentiating intracellular endothelial $\mathrm{Ca}(2+)$ release. Free Radic Biol Med 97: 274284, 2016. [PubMed: 27320188]

50. Ching LC, Kou YR, Shyue SK, Su KH, Wei J, Cheng LC, Yu YB, Pan CC, Lee TS. Molecular mechanisms of activation of endothelial nitric oxide synthase mediated by transient receptor potential vanilloid type1. Cardiovasc Res 91: 492-501, 2011. [PubMed: 21493704]

51. Chung MK, Lee H, Mizuno A, Suzuki M, Caterina MJ. 2-aminoethoxydiphenyl borate activates and sensitizes the heat-gated ion channel TRPV3. J Neurosci 24: 5177-5182, 2004. [PubMed: 15175387]

52. Cioffi DL, Wu S, Alexeyev M, Goodman SR, Zhu MX, Stevens T. Activation of the endothelial store-operated ISOC Ca2+ channel requires interaction of protein 4.1 with TRPC4. Circ Res 97: 1164-1172, 2005. [PubMed: 16254212]

53. Cioffi DL, Wu S, Chen H, Alexeyev M, St Croix CM, Pitt BR, Uhlig S, Stevens T. Orai1 determines calcium selectivity of an endogenous TRPC heterotetramer channel. Circ Res 110: 1435-1444, 2012. [PubMed: 22534489]

54. Claesson-Welsh L Vascular permeability-the essentials. Ups J Med Sci 120: 135-143, 2015. [PubMed: 26220421]

55. Clapham DE, Montell C, Schultz G, Julius D, International Union of P. International Union of Pharmacology. XLIII. Compendium of voltage-gated ion channels: Transient receptor potential channels. Pharmacol Rev 55: 591-596, 2003. [PubMed: 14657417]

56. Correll CC, Phelps PT, Anthes JC, Umland S, Greenfeder S. Cloning and pharmacological characterization of mouse TRPV1. Neurosci Lett 370: 55-60, 2004. [PubMed: 15489017]

57. Corteling R, Wyss D, Trifilieff A. In vivo models of lung neutrophil activation. Comparison of mice and hamsters. BMC Pharmacol 2: 1, 2002. [PubMed: 11806755]

58. Cosens DJ, Manning A. Abnormal electroretinogram from a Drosophila mutant. Nature 224: 285287, 1969. [PubMed: 5344615]

59. Darby WG, Potocnik S, Ramachandran R, Hollenberg MD, Woodman OL, McIntyre P. Shear stress sensitizes TRPV4 in endothelium-dependent vasodilatation. Pharmacol Res 133: 152-159, 2018. [PubMed: 29787869]

60. Davies PF. Flow-mediated endothelial mechanotransduction. Physiol Rev 75: 519-560, 1995. [PubMed: 7624393]

61. DeHaven WI, Jones BF, Petranka JG, Smyth JT, Tomita T, Bird GS, Putney JW Jr. TRPC channels function independently of STIM1 and Orai1. J Physiol 587: 2275-2298, 2009. [PubMed: 19332491]

62. Deng X, Wang Y, Zhou Y, Soboloff J, Gill DL. STIM and Orai: Dynamic intermembrane coupling to control cellular calcium signals. J Biol Chem 284: 22501-22505, 2009. [PubMed: 19473984]

63. Deng Z, Paknejad N, Maksaev G, Sala-Rabanal M, Nichols CG, Hite RK, Yuan P. Cryo-EM and $\mathrm{X}$-ray structures of TRPV4 reveal insight into ion permeation and gating mechanisms. Nat Struct Mol Biol 25: 252-260, 2018. [PubMed: 29483651]

64. Di A, Gao XP, Qian F, Kawamura T, Han J, Hecquet C, Ye RD, Vogel SM, Malik AB. The redoxsensitive cation channel TRPM2 modulates phagocyte ROS production and inflammation. Nat Immunol 13: 29-34, 2011. [PubMed: 22101731]

65. Dietrich A, Mederos YSM, Gollasch M, Gross V, Storch U, Dubrovska G, Obst M, Yildirim E, Salanova B, Kalwa H, Essin K, Pinkenburg O, Luft FC, Gudermann T, Birnbaumer L. Increased vascular smooth muscle contractility in TRPC6-/- mice. Mol Cell Biol 25: 6980-6989, 2005. [PubMed: 16055711] 
66. Dodd-o JM, Hristopoulos ML, Welsh-Servinsky LE, Tankersley CG, Pearse DB. Strain-specific differences in sensitivity to ischemiareperfusion lung injury in mice. J Appl Physiol (1985) 100: 1590-1595, 2006. [PubMed: 16439514]

67. Doerner JF, Hatt H, Ramsey IS. Voltage- and temperature-dependent activation of TRPV3 channels is potentiated by receptor-mediated PI(4,5)P2 hydrolysis. J Gen Physiol 137: 271-288, 2011. [PubMed: 21321070]

68. Doleschal B, Primessnig U, Wolkart G, Wolf S, Schernthaner M, Lichtenegger M, Glasnov TN, Kappe CO, Mayer B, Antoons G, Heinzel F, Poteser M, Groschner K. TRPC3 contributes to regulation of cardiac contractility and arrhythmogenesis by dynamic interaction with NCX1. Cardiovasc Res 106: 163-173, 2015. [PubMed: 25631581]

69. Du J, Ma X, Shen B, Huang Y, Birnbaumer L, Yao X. TRPV4, TRPC1, and TRPP2 assemble to form a flow-sensitive heteromeric channel. FASEB J 28: 4677-4685, 2014. [PubMed: 25114176]

70. Duan J, Li J, Zeng B, Chen GL, Peng X, Zhang Y, Wang J, Clapham DE, Li Z, Zhang J. Structure of the mouse TRPC4 ion channel. Nat Commun 9: 3102, 2018. [PubMed: 30082700]

71. Duan J, Li Z, Li J, Hulse RE, Santa-Cruz A, Valinsky WC, Abiria SA, Krapivinsky G, Zhang J, Clapham DE. Structure of the mammalian TRPM7, a magnesium channel required during embryonic development. Proc Natl Acad Sci USA 115: E8201-E8210, 2018. [PubMed: 30108148]

72. Duan J, Li Z, Li J, Santa-Cruz A, Sanchez-Martinez S, Zhang J, Clapham DE. Structure of fulllength human TRPM4. Proc Natl Acad Sci USA 115: 2377-2382, 2018. [PubMed: 29463718]

73. Earley S TRPA1 channels in the vasculature. Br J Pharmacol 167: 13-22, 2012. [PubMed: 22563804]

74. Earley S, Brayden JE. Transient receptor potential channels in the vasculature. Physiol Rev 95: 645-690, 2015. [PubMed: 25834234]

75. Earley S, Gonzales AL, Crnich R. Endothelium-dependent cerebral artery dilation mediated by TRPA1 and Ca2+-Activated K+ channels. Circ Res 104: 987-994, 2009. [PubMed: 19299646]

76. Earley S, Gonzales AL, Garcia ZI. A dietary agonist of transient receptor potential cation channel V3 elicits endothelium-dependent vasodilation. Mol Pharmacol 77: 612-620, 2010. [PubMed: 20086034]

77. Earley S, Heppner TJ, Nelson MT, Brayden JE. TRPV4 forms a novel Ca2+ signaling complex with ryanodine receptors and BKCa channels. Circ Res 97: 1270-1279, 2005. [PubMed: 16269659]

78. Earley S, Pastuszyn A, Walker BR. Cytochrome p-450 epoxygenase products contribute to attenuated vasoconstriction after chronic hypoxia. Am J Physiol Heart Circ Physiol 285: H127136, 2003. [PubMed: 12623785]

79. Earley S, Pauyo T, Drapp R, Tavares MJ, Liedtke W, Brayden JE. TRPV4-dependent dilation of peripheral resistance arteries influences arterial pressure. Am J Physiol Heart Circ Physiol 297: H1096-H1102, 2009. [PubMed: 19617407]

80. Eder P, Probst D, Rosker C, Poteser M, Wolinski H, Kohlwein SD, Romanin C, Groschner K. Phospholipase C-dependent control of cardiac calcium homeostasis involves a TRPC3-NCX1 signaling complex. Cardiovasc Res 73: 111-119, 2007. [PubMed: 17129578]

81. Edwards G, Dora KA, Gardener MJ, Garland CJ, Weston AH. K+ is an endothelium-derived hyperpolarizing factor in rat arteries. Nature 396: 269-272, 1998. [PubMed: 9834033]

82. Edwards G, Feletou M, Weston AH. Endothelium-derived hyperpolar-ising factors and associated pathways: A synopsis. Pflugers Arch 459: 863-879, 2010. [PubMed: 20383718]

83. Ellinsworth DC, Earley S, Murphy TV, Sandow SL. Endothelial control of vasodilation: Integration of myoendothelial microdomain signalling and modulation by epoxyeicosatrienoic acids. Pflugers Arch 466: 389-405, 2014. [PubMed: 23748495]

84. Everaerts W, Zhen X, Ghosh D, Vriens J, Gevaert T, Gilbert JP, Hayward NJ, McNamara CR, Xue F, Moran MM, Strassmaier T, Uykal E, Owsianik G, Vennekens R, De Ridder D, Nilius B, Fanger CM, Voets T. Inhibition of the cation channel TRPV4 improves bladder function in mice and rats with cyclophosphamide-induced cystitis. Proc Natl Acad Sci USA 107: 19084-19089, 2010. [PubMed: 20956320] 
85. Fan C, Choi W, Sun W, Du J, Lu W. Structure of the human lipid-gated cation channel TRPC3. Elife 7: pii: e36852, 2018. [PubMed: 29726814]

86. Fantozzi I, Zhang S, Platoshyn O, Remillard CV, Cowling RT, Yuan JX. Hypoxia increases AP-1 binding activity by enhancing capacitative $\mathrm{Ca} 2+$ entry in human pulmonary artery endothelial cells. Am J Physiol Lung Cell Mol Physiol 285: L1233-L1245, 2003. [PubMed: 12909593]

87. Fiorio Pla A, Ong HL, Cheng KT, Brossa A, Bussolati B, Lockwich T, Paria B, Munaron L, Ambudkar IS. TRPV4 mediates tumor-derived endothelial cell migration via arachidonic acidactivated actin remodeling. Oncogene 31: 200-212, 2012. [PubMed: 21685934]

88. Fisslthaler B, Popp R, Kiss L, Potente M, Harder DR, Fleming I, Busse R. Cytochrome P450 2C is an EDHF synthase in coronary arteries. Nature 401: 493-497, 1999. [PubMed: 10519554]

89. Flockerzi V, Nilius B. TRPs: Truly remarkable proteins. Handb Exp Pharmacol 222: 1-12, 2014. [PubMed: 24756700]

90. Folkman J, D'Amore PA. Blood vessel formation: What is its molecular basis? Cell 87: 11531155, 1996. [PubMed: 8980221]

91. Freichel M, Suh SH, Pfeifer A, Schweig U, Trost C, Weissgerber P, Biel M, Philipp S, Freise D, Droogmans G, Hofmann F, Flockerzi V, Nilius B. Lack of an endothelial store-operated Ca2+ current impairs agonist-dependent vasorelaxation in TRP4-/- mice. Nat Cell Biol 3: 121-127, 2001. [PubMed: 11175743]

92. Freichel M, Vennekens R, Olausson J, Hoffmann M, Muller C, Stolz S, Scheunemann J, Weissgerber P, Flockerzi V. Functional role of TRPC proteins in vivo: Lessons from TRPCdeficient mouse models. Biochem Biophys Res Commun 322: 1352-1358, 2004. [PubMed: 15336983]

93. Furchgott RF, Zawadzki JV. The obligatory role of endothelial cells in the relaxation of arterial smooth muscle by acetylcholine. Nature 288: 373-376, 1980. [PubMed: 6253831]

94. Gao G, Bai XY, Xuan C, Liu XC, Jing WB, Novakovic A, Yang Q, He GW. Role of TRPC3 channel in human internal mammary artery. Arch Med Res 43: 431-437, 2012. [PubMed: 22960861]

95. Garland CJ, Hiley CR, Dora KA. EDHF: Spreading the influence of the endothelium. Br J Pharmacol 164: 839-852, 2011. [PubMed: 21133895]

96. Gee KR, Brown KA, Chen WN, Bishop-Stewart J, Gray D, Johnson I. Chemical and physiological characterization of fluo-4 Ca(2+)-indicator dyes. Cell Calcium 27: 97-106, 2000. [PubMed: 10756976]

97. Gees M, Colsoul B, Nilius B. The role of transient receptor potential cation channels in $\mathrm{Ca} 2+$ signaling. Cold Spring Harb Perspect Biol 2: a003962, 2010. [PubMed: 20861159]

98. Goedicke-Fritz S, Kaistha A, Kacik M, Markert S, Hofmeister A, Busch C, Banfer S, Jacob R, Grgic I, Hoyer J. Evidence for functional and dynamic microcompartmentation of Cav-1/TRPV4/ $\mathrm{K}(\mathrm{Ca})$ in caveolae of endothelial cells. Eur J Cell Biol 94: 391-400, 2015. [PubMed: 26116074]

99. Gomis A, Soriano S, Belmonte C, Viana F. Hypoosmotic- and pressure-induced membrane stretch activate TRPC5 channels. J Physiol 586: 5633-5649, 2008. [PubMed: 18832422]

100. Greenberg HZE, Carlton-Carew SRE, Khan DM, Zargaran AK, Jahan KS, Vanessa Ho WS, Albert AP. Heteromeric TRPV4/TRPC1 channels mediate calcium-sensing receptor-induced nitric oxide production and vasorelaxation in rabbit mesenteric arteries. Vascul Pharmacol96-98: 53-62, 2017.

101. Grieben M, Pike AC, Shintre CA, Venturi E, El-Ajouz S, Tessitore A, Shrestha L, Mukhopadhyay S, Mahajan P, Chalk R, Burgess-Brown NA, Sitsapesan R, Huiskonen JT, Carpenter EP. Structure of the polycystic kidney disease TRP channel Polycystin-2 (PC2). Nat Struct Mol Biol 24: 114122, 2017. [PubMed: 27991905]

102. Guarini G, Ohanyan VA, Kmetz JG, DelloStritto DJ, Thoppil RJ, Thodeti CK, Meszaros JG, Damron DS, Bratz IN. Disruption of TRPV1-mediated coupling of coronary blood flow to cardiac metabolism in diabetic mice: Role of nitric oxide and BK channels. Am J Physiol Heart Circ Physiol 303: H216-223, 2012. [PubMed: 22610171]

103. Guo J, She J, Zeng W, Chen Q, Bai XC, Jiang Y. Structures of the calcium-activated, nonselective cation channel TRPM4. Nature 552: 205-209, 2017. [PubMed: 29211714] 
104. Hafner S, Burg F, Kannler M, Urban N, Mayer P, Dietrich A, Trauner D, Broichhagen J, Schaefer M. A (+)-Larixol congener with high affinity and subtype selectivity toward TRPC6. ChemMedChem 13: 1028-1035, 2018. [PubMed: 29522264]

105. Halaszovich CR, Zitt C, Jungling E, Luckhoff A. Inhibition of TRP3 channels by lanthanides. Block from the cytosolic side of the plasma membrane. J Biol Chem 275: 37423-37428, 2000. [PubMed: 10970899]

106. Hamdollah Zadeh MA, Glass CA, Magnussen A, Hancox JC, Bates DO. VEGF-mediated elevated intracellular calcium and angiogenesis in human microvascular endothelial cells in vitro are inhibited by dominant negative TRPC6. Microcirculation 15: 605-614, 2008. [PubMed: 18800249]

107. Hara Y, Wakamori M, Ishii M, Maeno E, Nishida M, Yoshida T, Yamada H, Shimizu S, Mori E, Kudoh J, Shimizu N, Kurose H, Okada Y, Imoto K, Mori Y. LTRPC2 Ca2+-permeable channel activated by changes in redox status confers susceptibility to cell death. Mol Cell 9: 163-173, 2002. [PubMed: 11804595]

108. Hardaker L, Bahra P, de Billy BC, Freeman M, Kupfer N, Wyss D, Trifilieff A. The ion channel transient receptor potential melastatin-2 does not play a role in inflammatory mouse models of chronic obstructive pulmonary diseases. Respir Res 13: 30, 2012. [PubMed: 22475739]

109. Harraz OF, Longden TA, Hill-Eubanks D, Nelson MT. PIP2 depletion promotes TRPV4 channel activity in mouse brain capillary endothelial cells. Elife 7: pii: e38689, 2018. [PubMed: 30084828]

110. Hartmann J, Dragicevic E, Adelsberger H, Henning HA, Sumser M, Abramowitz J, Blum R, Dietrich A, Freichel M, Flockerzi V, Birnbaumer L, Konnerth A. TRPC3 channels are required for synaptic transmission and motor coordination. Neuron 59: 392-398, 2008. [PubMed: 18701065]

111. Hartmannsgruber V, Heyken WT, Kacik M, Kaistha A, Grgic I, Harteneck C, Liedtke W, Hoyer J, Kohler R. Arterial response to shear stress critically depends on endothelial TRPV4 expression. PloS One 2: e827, 2007. [PubMed: 17786199]

112. Hatano N, Suzuki H, Itoh Y, Muraki K. TRPV4 partially participates in proliferation of human brain capillary endothelial cells. Life Sci 92: 317-324, 2013. [PubMed: 23333822]

113. Hecquet CM, Ahmmed GU, Vogel SM, Malik AB. Role of TRPM2 channel in mediating H2O2induced $\mathrm{Ca} 2+$ entry and endothelial hyper-permeability. Circ Res 102: 347-355, 2008. [PubMed: 18048770]

114. Hill-Eubanks DC, Gonzales AL, Sonkusare SK, Nelson MT. Vascular TRP channels: Performing under pressure and going with the flow. Physiology (Bethesda) 29: 343-360, 2014. [PubMed: 25180264]

115. Hill K, McNulty S, Randall AD. Inhibition of TRPM2 channels by the antifungal agents clotrimazole and econazole. Naunyn Schmiedebergs Arch Pharmacol 370: 227-237, 2004. [PubMed: 15549272]

116. Hirschi M, Herzik MA Jr, Wie J, Suo Y, Borschel WF, Ren D, Lander GC, Lee SY. Cryo-electron microscopy structure of the lysosomal calcium-permeable channel TRPML3. Nature 550: 411414, 2017. [PubMed: 29019979]

117. Hofmann NA, Barth S, Waldeck-Weiermair M, Klec C, Strunk D, Malli R, Graier WF. TRPV1 mediates cellular uptake of anandamide and thus promotes endothelial cell proliferation and network-formation. Biol Open 3: 1164-1172, 2014. [PubMed: 25395667]

118. Hofmann T, Chubanov V, Gudermann T, Montell C. TRPM5 is a voltage-modulated and Ca(2+)activated monovalent selective cation channel. Curr Biol 13: 1153-1158, 2003. [PubMed: 12842017]

119. Hofmann T, Obukhov AG, Schaefer M, Harteneck C, Gudermann T, Schultz G. Direct activation of human TRPC6 and TRPC3 channels by diacylglycerol. Nature 397: 259-263, 1999. [PubMed: 9930701]

120. Hong K, Cope EL, DeLalio LJ, Marziano C, Isakson BE, Sonkusare SK. TRPV4 (transient receptor potential vanilloid 4) channel-dependent negative feedback mechanism regulates $\mathrm{Gq}$ protein-coupled receptor-induced vasoconstriction. Arterioscler Thromb Vasc Biol 38: 542-554, 2018. [PubMed: 29301784] 
121. Hu G, Place AT, Minshall RD. Regulation of endothelial permeability by Src kinase signaling: Vascular leakage versus transcellular transport of drugs and macromolecules. Chem Biol Interact 171: 177-189, 2008. [PubMed: 17897637]

122. Hughes TET, Lodowski DT, Huynh KW, Yazici A, Del Rosario J, Kapoor A, Basak S, Samanta A, Han X, Chakrapani S, Zhou ZH, Filizola M, Rohacs T, Han S, Moiseenkova-Bell VY. Structural basis of TRPV5 channel inhibition by econazole revealed by cryo-EM. Nat Struct Mol Biol 25: 53-60, 2018. [PubMed: 29323279]

123. Hutchinson PJ, Palmer RM, Moncada S. Comparative pharmacology of EDRF and nitric oxide on vascular strips. Eur J Pharmacol 141: 445-451, 1987. [PubMed: 3499329]

124. Huynh KW, Cohen MR, Jiang J, Samanta A, Lodowski DT, Zhou ZH, Moiseenkova-Bell VY. Structure of the full-length TRPV2 channel by cryo-EM. Nat Commun 7: 11130, 2016. [PubMed: 27021073]

125. Ignarro LJ, Buga GM, Wood KS, Byrns RE, Chaudhuri G. Endothelium-derived relaxing factor produced and released from artery and vein is nitric oxide. Proc Natl Acad Sci USA 84: 92659269, 1987. [PubMed: 2827174]

126. Inoue R, Okada T, Onoue H, Hara Y, Shimizu S, Naitoh S, Ito Y, Mori Y. The transient receptor potential protein homologue TRP6 is the essential component of vascular alpha(1)-adrenoceptoractivated $\mathrm{Ca}(2+)$-permeable cation channel. Circ Res 88: 325-332, 2001. [PubMed: 11179201]

127. Ives SJ, Park SY, Kwon OS, Gifford JR, Andtbacka RHI, Hyngstrom JR, Richardson RS. TRPV1 channels in human skeletal muscle feed arteries: Implications for vascular function. Exp Physiol 102: 1245-1258, 2017. [PubMed: 28681979]

128. Iwasaki Y, Tanabe M, Kobata K, Watanabe T. TRPA1 agonistsallyl isothiocyanate and cinnamaldehyde-induce adrenaline secretion. Biosci Biotechnol Biochem 72: 2608-2614, 2008. [PubMed: 18838811]

129. Jaffe EA, Hoyer LW, Nachman RL. Synthesis of von Willebrand factor by cultured human endothelial cells. Proc Natl Acad Sci USA 71: 1906-1909, 1974. [PubMed: 4209883]

130. Ji G, Feldman ME, Deng KY, Greene KS, Wilson J, Lee JC, Johnston RC, Rishniw M, Tallini Y, Zhang J, Wier WG, Blaustein MP, Xin HB, Nakai J, Kotlikoff MI. Ca2+-sensing transgenic mice: Postsynaptic signaling in smooth muscle. J Biol Chem 279: 21461-21468, 2004. [PubMed: 14990564]

131. Jordt SE, Bautista DM, Chuang HH, McKemy DD, Zygmunt PM, Hogestatt ED, Meng ID, Julius D. Mustard oils and cannabinoids excite sensory nerve fibres through the TRP channel ANKTM1. Nature 427: 260-265, 2004. [PubMed: 14712238]

132. Jung S, Muhle A, Schaefer M, Strotmann R, Schultz G, Plant TD. Lanthanides potentiate TRPC5 currents by an action at extracellular sites close to the pore mouth. J Biol Chem 278: 3562-3571, 2003. [PubMed: 12456670]

133. Kaczmarek JS, Riccio A, Clapham DE. Calpain cleaves and activates the TRPC5 channel to participate in semaphorin 3A-induced neuronal growth cone collapse. Proc Natl Acad Sci USA 109: 7888-7892, 2012. [PubMed: 22547824]

134. Kamouchi M, Philipp S, Flockerzi V, Wissenbach U, Mamin A, Raeymaekers L, Eggermont J, Droogmans G, Nilius B. Properties of heterologously expressed hTRP3 channels in bovine pulmonary artery endothelial cells. J Physiol 518(Pt 2): 345-358, 1999. [PubMed: 10381584]

135. Karashima Y, Prenen J, Talavera K, Janssens A, Voets T, Nilius B. Agonist-induced changes in $\mathrm{Ca}(2+)$ permeation through the nociceptor cation channel TRPA1. Biophys J 98: 773-783, 2010. [PubMed: 20197030]

136. Ke SK, Chen L, Duan HB, Tu YR. Opposing actions of TRPV4 channel activation in the lung vasculature. Respir Physiol Neurobiol 219: 43-50, 2015. [PubMed: 26282788]

137. Kini V, Chavez A, Mehta D. A new role for PTEN in regulating transient receptor potential canonical channel 6-mediated Ca2+ entry, endothelial permeability, and angiogenesis. J Biol Chem 285: 33082-33091, 2010. [PubMed: 20705603]

138. Kirby BS, Bruhl A, Sullivan MN, Francis M, Dinenno FA, Earley S. Robust internal elastic lamina fenestration in skeletal muscle arteries. PLoS One 8: e54849, 2013. [PubMed: 23359815]

139. Kiyonaka S, Kato K, Nishida M, Mio K, Numaga T, Sawaguchi Y, Yoshida T, Wakamori M, Mori E, Numata T, Ishii M, Takemoto H, Ojida A, Watanabe K, Uemura A, Kurose H, Morii T, 
Kobayashi T, Sato Y, Sato C, Hamachi I, Mori Y. Selective and direct inhibition of TRPC3 channels underlies biological activities of a pyrazole compound. Proc Natl Acad Sci USA 106: 5400-5405, 2009. [PubMed: 19289841]

140. Kleene SJ, Kleene NK. The native TRPP2-dependent channel of murine renal primary cilia. Am J Physiol Renal Physiol 312: F96-F108, 2017. [PubMed: 27760766]

141. Kobori T, Smith GD, Sandford R, Edwardson JM. The transient receptor potential channels TRPP2 and TRPC1 form a heterotetramer with a 2:2 stoichiometry and an alternating subunit arrangement. J Biol Chem 284: 35507-35513, 2009. [PubMed: 19850920]

142. Kochukov MY, Balasubramanian A, Abramowitz J, Birnbaumer L, Marrelli SP. Activation of endothelial transient receptor potential $\mathrm{c} 3$ channel is required for small conductance calciumactivated potassium channel activation and sustained endothelial hyperpolarization and vasodilation of cerebral artery. J Am Heart Assoc 3: pii: e000913, 2014. [PubMed: 25142058]

143. Kochukov MY, Balasubramanian A, Noel RC, Marrelli SP. Role of TRPC1 and TRPC3 channels in contraction and relaxation of mouse thoracic aorta. J Vasc Res 50: 11-20, 2013. [PubMed: 23095462]

144. Kohler R, Heyken WT, Heinau P, Schubert R, Si H, Kacik M, Busch C, Grgic I, Maier T, Hoyer J. Evidence for a functional role of endothelial transient receptor potential V4 in shear stressinduced vasodilatation. Arterioscler Thromb Vasc Biol 26: 1495-1502, 2006. [PubMed: 16675722]

145. Kolisek M, Beck A, Fleig A, Penner R. Cyclic ADP-ribose and hydrogen peroxide synergize with ADP-ribose in the activation of TRPM2 channels. Mol Cell 18: 61-69, 2005. [PubMed: 15808509]

146. Koulen P, Cai Y, Geng L, Maeda Y, Nishimura S, Witzgall R, Ehrlich BE, Somlo S. Polycystin-2 is an intracellular calcium release channel. Nat Cell Biol 4: 191-197, 2002. [PubMed: 11854751]

147. Kraft $\mathrm{R}$ The $\mathrm{Na}+\mathrm{Ca} 2+$ exchange inhibitor KB-R7943 potently blocks TRPC channels. Biochem Biophys Res Commun 361: 230-236, 2007. [PubMed: 17658472]

148. Lacorre DA, Baekkevold ES, Garrido I, Brandtzaeg P, Haraldsen G, Amalric F, Girard JP. Plasticity of endothelial cells: Rapid dedifferentiation of freshly isolated high endothelial venule endothelial cells outside the lymphoid tissue microenvironment. Blood 103: 4164-4172, 2004. [PubMed: 14976058]

149. Launay P, Fleig A, Perraud AL, Scharenberg AM, Penner R, Kinet JP. TRPM4 is a Ca2+activated nonselective cation channel mediating cell membrane depolarization. Cell 109: 397407, 2002. [PubMed: 12015988]

150. Ledoux J, Bonev AD, Nelson MT. Ca2+-activated K+ channels in murine endothelial cells: Block by intracellular calcium and magnesium. J Gen Physiol 131: 125-135, 2008. [PubMed: 18195387]

151. Ledoux J, Werner ME, Brayden JE, Nelson MT. Calcium-activated potassium channels and the regulation of vascular tone. Physiology (Bethesda) 21: 69-78, 2006. [PubMed: 16443824]

152. Lee CM, Gu JA, Rau TG, Wang C, Yen CH, Huang SH, Lin FY, Lin CM, Huang ST. Synthetic fluororutaecarpine inhibits inflammatory stimuli and activates endothelial transient receptor potential vanilloid-type 1. Molecules 22: pii: E656, 2017. [PubMed: 28422079]

153. Lee MD, Wilson C, Saunter CD, Kennedy C, Girkin JM, McCarron JG. Spatially structured cell populations process multiple sensory signals in parallel in intact vascular endothelium. Sci Signal 11: pii: eaar4411, 2018. [PubMed: 30563865]

154. Lemonnier L, Trebak M, Putney JW Jr. Complex regulation of the TRPC3, 6 and 7 channel subfamily by diacylglycerol and phosphatidylinositol-4,5-bisphosphate. Cell Calcium 43: 506514, 2008. [PubMed: 17942152]

155. Leuner K, Kazanski V, Muller M, Essin K, Henke B, Gollasch M, Harteneck C, Muller WE. Hyperforin-a key constituent of St. John's wort specifically activates TRPC6 channels. FASEB J 21: 4101-4111, 2007. [PubMed: 17666455]

156. Li M, Jiang J, Yue L. Functional characterization of homo- and heteromeric channel kinases TRPM6 and TRPM7. J Gen Physiol 127: 525-537, 2006. [PubMed: 16636202] 
157. Li M, Zhang WK, Benvin NM, Zhou X, Su D, Li H, Wang S, Michailidis IE, Tong L, Li X, Yang J. Structural basis of dual $\mathrm{Ca}(2+) / \mathrm{pH}$ regulation of the endolysosomal TRPML1 channel. Nat Struct Mol Biol 24: 205-213, 2017. [PubMed: 28112729]

158. Li S, Seitz R, Lisanti MP. Phosphorylation of caveolin by src tyrosine kinases. The alpha-isoform of caveolin is selectively phosphorylated by v-Src in vivo. J Biol Chem 271: 3863-3868, 1996. [PubMed: 8632005]

159. Li Z, Guo G, Wang H, Si X, Zhou G, Xiong Y, Li S, Dai R, Yang C. TRPC5 channel modulates endothelial cells senescence. Eur J Pharmacol 802: 27-35, 2017. [PubMed: 28237267]

160. Liang GH, Kim JA, Seol GH, Choi S, Suh SH. The $\mathrm{Na}(+) / \mathrm{Ca}(2+)$ exchanger inhibitor KB-R7943 activates large-conductance $\mathrm{Ca}(2+)$-activated $\mathrm{K}(+)$ channels in endothelial and vascular smooth muscle cells. Eur J Pharmacol 582: 35-41, 2008. [PubMed: 18237728]

161. Liao BC, Hsieh CW, Liu YC, Tzeng TT, Sun YW, Wung BS. Cinnamaldehyde inhibits the tumor necrosis factor-alpha-induced expression of cell adhesion molecules in endothelial cells by suppressing NF-kappaB activation: Effects upon IkappaB and Nrf2. Toxicol Appl Pharmacol 229: 161-171, 2008. [PubMed: 18304597]

162. Liao M, Cao E, Julius D, Cheng Y. Single particle electron cryo-microscopy of a mammalian ion channel. Curr Opin Struct Biol 27: 1-7, 2014. [PubMed: 24681231]

163. Liao M, Cao E, Julius D, Cheng Y. Structure of the TRPV1 ion channel determined by electron cryo-microscopy. Nature 504: 107-112, 2013. [PubMed: 24305160]

164. Liedtke W, Choe Y, Marti-Renom MA, Bell AM, Denis CS, Sali A, Hudspeth AJ, Friedman JM, Heller S. Vanilloid receptor-related osmotically activated channel (VR-OAC), a candidate vertebrate osmoreceptor. Cell 103: 525-535, 2000. [PubMed: 11081638]

165. Lin MT, Jian MY, Taylor MS, Cioffi DL, Yap FC, Liedtke W, Townsley MI. Functional coupling of TRPV4, IK, and SK channels contributes to $\mathrm{Ca}(2+)$-dependent endothelial injury in rodent lung. Pulm Circ 5: 279-290, 2015. [PubMed: 26064452]

166. Liu CL, Huang Y, Ngai CY, Leung YK, Yao XQ. TRPC3 is involved in flow- and bradykinininduced vasodilation in rat small mesenteric arteries. Acta Pharmacol Sin 27: 981-990, 2006. [PubMed: 16867248]

167. Long SB, Campbell EB, Mackinnon R. Crystal structure of a mammalian voltage-dependent Shaker family K+ channel. Science 309: 897-903, 2005. [PubMed: 16002581]

168. Longden TA, Dabertrand F, Koide M, Gonzales AL, Tykocki NR, Brayden JE, Hill-Eubanks D, Nelson MT. Capillary K(+)-sensing initiates retrograde hyperpolarization to increase local cerebral blood flow. Nat Neurosci 20: 717-726, 2017. [PubMed: 28319610]

169. Loot AE, Popp R, Fisslthaler B, Vriens J, Nilius B, Fleming I. Role of cytochrome P450dependent transient receptor potential V4 activation in flow-induced vasodilatation. Cardiovasc Res 80: 445-452, 2008. [PubMed: 18682435]

170. Lu T, Wang XL, Chai Q, Sun X, Sieck GC, Katusic ZS, Lee HC. Role of the endothelial caveolae microdomain in shear stress-mediated coronary vasorelaxation. J Biol Chem 292: 19013-19023, 2017. [PubMed: 28924052]

171. Lucas P, Ukhanov K, Leinders-Zufall T, Zufall F. A diacylglycerol-gated cation channel in vomeronasal neuron dendrites is impaired in TRPC2 mutant mice: Mechanism of pheromone transduction. Neuron 40: 551-561, 2003. [PubMed: 14642279]

172. Ma X, Cheng KT, Wong CO, O’Neil RG, Birnbaumer L, Ambudkar IS, Yao X. Heteromeric TRPV4-C1 channels contribute to store-operated $\mathrm{Ca}(2+)$ entry in vascular endothelial cells. Cell Calcium 50: 502-509, 2011. [PubMed: 21930300]

173. Macpherson LJ, Geierstanger BH, Viswanath V, Bandell M, Eid SR, Hwang S, Patapoutian A. The pungency of garlic: Activation of TRPA1 and TRPV1 in response to allicin. Curr Biol 15: 929-934, 2005. [PubMed: 15916949]

174. Mannaa M, Marko L, Balogh A, Vigolo E, N'Diaye G, Kassmann M, Michalick L, Weichelt U, Schmidt-Ott KM, Liedtke WB, Huang Y, Muller DN, Kuebler WM, Gollasch M. Transient receptor potential vanilloid 4 channel deficiency aggravates tubular damage after acute renal ischaemia reperfusion. Sci Rep 8: 4878, 2018. [PubMed: 29559678]

175. Marchenko SM, Sage SO. Electrical properties of resting and acetylcholine-stimulated endothelium in intact rat aorta. J Physiol 462: 735-751, 1993. [PubMed: 8331598] 
176. Maroto R, Raso A, Wood TG, Kurosky A, Martinac B, Hamill OP. TRPC1 forms the stretchactivated cation channel in vertebrate cells. Nat Cell Biol 7: 179-185, 2005. [PubMed: $15665854]$

177. Marrelli SP, O’Neil RG, Brown RC, Bryan RM Jr. PLA2 and TRPV4 channels regulate endothelial calcium in cerebral arteries. Am J Physiol Heart Circ Physiol 292: H1390-1397, 2007. [PubMed: 17071727]

178. Marziano C, Hong K, Cope EL, Kotlikoff MI, Isakson BE, Sonkusare SK. Nitric oxide-dependent feedback loop regulates transient receptor potential vanilloid 4 (TRPV4) channel cooperativity and endothelial function in small pulmonary arteries. J Am Heart Assoc 6: pii: e007157, 2017. [PubMed: 29275372]

179. McIntyre P, McLatchie LM, Chambers A, Phillips E, Clarke M, Savidge J, Toms C, Peacock M, Shah K, Winter J, Weerasakera N, Webb M, Rang HP, Bevan S, James IF. Pharmacological differences between the human and rat vanilloid receptor 1 (VR1). Br J Pharmacol 132: 10841094, 2001. [PubMed: 11226139]

180. McNamara CR, Mandel-Brehm J, Bautista DM, Siemens J, Deranian KL, Zhao M, Hayward NJ, Chong JA, Julius D, Moran MM, Fanger CM. TRPA1 mediates formalin-induced pain. Proc Natl Acad Sci USA 104: 13525-13530, 2007. [PubMed: 17686976]

181. Mehta D, Ahmmed GU, Paria BC, Holinstat M, Voyno-Yasenetskaya T, Tiruppathi C, Minshall $\mathrm{RD}$, Malik AB. RhoA interaction with inositol 1,4,5-trisphosphate receptor and transient receptor potential channel-1 regulates $\mathrm{Ca} 2+$ entry. Role in signaling increased endothelial permeability. $\mathrm{J}$ Biol Chem 278: 33492-33500, 2003. [PubMed: 12766172]

182. Mehta D, Malik AB. Signaling mechanisms regulating endothelial permeability. Physiol Rev 86: 279-367, 2006. [PubMed: 16371600]

183. Mendoza SA, Fang J, Gutterman DD, Wilcox DA, Bubolz AH, Li R, Suzuki M, Zhang DX. TRPV4-mediated endothelial Ca2+ influx and vasodilation in response to shear stress. Am J Physiol Heart Circ Physiol 298: H466-H476, 2010. [PubMed: 19966050]

184. Mercado J, Baylie R, Navedo MF, Yuan C, Scott JD, Nelson MT, Brayden JE, Santana LF. Local control of TRPV4 channels by AKAP150-targeted PKC in arterial smooth muscle. J Gen Physiol 143: 559-575, 2014. [PubMed: 24778429]

185. Miller M, Shi J, Zhu Y, Kustov M, Tian JB, Stevens A, Wu M, Xu J, Long S, Yang P, Zholos AV, Salovich JM, Weaver CD, Hopkins CR, Lindsley CW, McManus O, Li M, Zhu MX. Identification of ML204, a novel potent antagonist that selectively modulates native TRPC4/C5 ion channels. J Biol Chem 286: 33436-33446, 2011. [PubMed: 21795696]

186. Moncada S, Gryglewski R, Bunting S, Vane JR. An enzyme isolated from arteries transforms prostaglandin endoperoxides to an unstable substance that inhibits platelet aggregation. Nature 263: 663-665, 1976. [PubMed: 802670]

187. Moncada S, Higgs A. The L-arginine-nitric oxide pathway. N Engl J Med 329: 2002-2012, 1993. [PubMed: 7504210]

188. Moncada S, Vane JR. The role of prostacyclin in vascular tissue. Fed Proc 38: 66-71, 1979. [PubMed: 215463]

189. Moore TM, Brough GH, Babal P, Kelly JJ, Li M, Stevens T. Store-operated calcium entry promotes shape change in pulmonary endothelial cells expressing Trp1. Am J Physiol 275: L574-582, 1998. [PubMed: 9728053]

190. Murphy TV, Kanagarajah A, Toemoe S, Bertrand PP, Grayson TH, Britton FC, Leader L, Senadheera S, Sandow SL. TRPV3 expression and vasodilator function in isolated uterine radial arteries from non-pregnant and pregnant rats. Vascul Pharmacol 83: 66-77, 2016. [PubMed: 27073026]

191. Murugappa S, Kunapuli SP. The role of ADP receptors in platelet function. Front Biosci 11: 1977-1986, 2006. [PubMed: 16368572]

192. Nagata K, Duggan A, Kumar G, Garcia-Anoveros J. Nociceptor and hair cell transducer properties of TRPA1, a channel for pain and hearing. J Neurosci 25: 4052-4061, 2005. [PubMed: 15843607] 
193. Naik JS, Osmond JM, Walker BR, Kanagy NL. Hydrogen sulfide-induced vasodilation mediated by endothelial TRPV4 channels. Am J Physiol Heart Circ Physiol 311: H1437-H1444, 2016. [PubMed: 27765747]

194. Naik JS, Walker BR. Endothelial-dependent dilation following chronic hypoxia involves TRPV4mediated activation of endothelial BK channels. Pflugers Arch 470: 633-648, 2018. [PubMed: 29380056]

195. Nauli SM, Alenghat FJ, Luo Y, Williams E, Vassilev P, Li X, Elia AE, Lu W, Brown EM, Quinn SJ, Ingber DE, Zhou J. Polycystins 1 and 2 mediate mechanosensation in the primary cilium of kidney cells. Nat Genet 33: 129-137, 2003. [PubMed: 12514735]

196. Nilius B, Droogmans G, Wondergem R. Transient receptor potential channels in endothelium: Solving the calcium entry puzzle? Endothelium 10: 5-15, 2003. [PubMed: 12699072]

197. Nilius B, Flockerzi V. What do we really know and what do we need to know: Some controversies, perspectives, and surprises. Handb Exp Pharmacol 223: 1239-1280, 2014. [PubMed: 24961986]

198. Nilius B, Prenen J, Droogmans G, Voets T, Vennekens R, Freichel M, Wissenbach U, Flockerzi V. Voltage dependence of the Ca2+-activated cation channel TRPM4. J Biol Chem 278: 3081330820, 2003. [PubMed: 12799367]

199. Nilius B, Prenen J, Janssens A, Voets T, Droogmans G. Decavanadate modulates gating of TRPM4 cation channels. J Physiol 560: 753-765, 2004. [PubMed: 15331675]

200. Nilius B, Vennekens R, Prenen J, Hoenderop JGJ, Bindels RJM, Droog-mans G. Whole-cell and single channel monovalent cation currents through the novel rabbit epithelial $\mathrm{Ca}(2+)$ channel ECaC. J Physiol 527: 239-248, 2000. [PubMed: 10970426]

201. Nishijima Y, Zheng X, Lund H, Suzuki M, Mattson DL, Zhang DX. Characterization of blood pressure and endothelial function in TRPV4-deficient mice with 1-NAME- and angiotensin IIinduced hypertension. Physiol Rep 2: e00199, 2014. [PubMed: 24744878]

202. Okada T, Shimizu S, Wakamori M, Maeda A, Kurosaki T, Takada N, Imoto K, Mori Y. Molecular cloning and functional characterization of a novel receptor-activated TRP Ca2+ channel from mouse brain. J Biol Chem 273: 10279-10287, 1998. [PubMed: 9553080]

203. Olson ST, Bjork I. Regulation of thrombin activity by antithrombin and heparin. Semin Thromb Hemost 20: 373-409, 1994. [PubMed: 7899869]

204. Pankey EA, Kassan M, Choi SK, Matrougui K, Nossaman BD, Hyman AL, Kadowitz PJ. Vasodilator responses to acetylcholine are not mediated by the activation of soluble guanylate cyclase or Trpv4 channels in the rat. Am J Physiol Heart Circ Physiol 306: H1495-H1506, 2014. [PubMed: 24658016]

205. Paria BC, Malik AB, Kwiatek AM, Rahman A, May MJ, Ghosh S, Tiruppathi C. Tumor necrosis factor-alpha induces nuclear factor-kappaB-dependent TRPC1 expression in endothelial cells. J Biol Chem 278: 37195-37203, 2003. [PubMed: 12855710]

206. Park L, Wang G, Moore J, Girouard H, Zhou P, Anrather J, IadecolaC. The key role of transient receptor potential melastatin-2 channels in amyloid-beta-induced neurovascular dysfunction. Nat Commun 5: 5318, 2014. [PubMed: 25351853]

207. Parker JC, Hashizumi M, Kelly SV, Francis M, Mouner M, Meyer AL, Townsley MI, Wu S, Cioffi DL, Taylor MS. TRPV4 calcium entry and surface expression attenuated by inhibition of myosin light chain kinase in rat pulmonary microvascular endothelial cells. Physiol Rep 1: e00121, 2013. [PubMed: 24303188]

208. Paulsen CE, Armache JP, Gao Y, Cheng Y, Julius D. Structure of the TRPA1 ion channel suggests regulatory mechanisms. Nature 525: 552, 2015.

209. Paustian PW, Chapnick BM, Feigen LP, Hyman AL, Kadowitz PJ. Effects of 13, 14dehydroprostacyclin methyl ester on the feline intestinal vascular bed. Prostaglandins 14: 11411152, 1977. [PubMed: 341229]

210. Pearson JD. Endothelial cell function and thrombosis. Baillieres Best Pract Res Clin Haematol 12: 329-341, 1999. [PubMed: 10856973]

211. Peier AM, Reeve AJ, Andersson DA, Moqrich A, Earley TJ, Hergarden AC, Story GM, Colley S, Hogenesch JB, McIntyre P, Bevan S, Patapoutian A. A heat-sensitive TRP channel expressed in keratinocytes. Science 296: 2046-2049, 2002. [PubMed: 12016205] 
212. Pelucchi B, Aguiari G, Pignatelli A, Manzati E, Witzgall R, Del Senno L, Belluzzi O. Nonspecific cation current associated with native polycystin-2 in HEK-293 cells. J Am Soc Nephrol 17: 388397, 2006. [PubMed: 16396967]

213. Perraud AL, Fleig A, Dunn CA, Bagley LA, Launay P, Schmitz C, Stokes AJ, Zhu Q, Bessman MJ, Penner R, Kinet JP, Scharenberg AM. ADP-ribose gating of the calcium-permeable LTRPC2 channel revealed by Nudix motif homology. Nature 411: 595-599, 2001. [PubMed: 11385575]

214. Pires PW, Earley S. Neuroprotective effects of TRPA1 channels in the cerebral endothelium following ischemic stroke. Elife 7: pii: e35316, 2018. [PubMed: 30239332]

215. Pires PW, Sullivan MN, Pritchard HA, Robinson JJ, Earley S. Unitary TRPV3 channel Ca2+ influx events elicit endothelium-dependent dilation of cerebral parenchymal arterioles. Am J Physiol Heart Circ Physiol 309: H2031-H2041, 2015. [PubMed: 26453324]

216. Poblete IM, Orliac ML, Briones R, Adler-Graschinsky E, Huidobro-Toro JP. Anandamide elicits an acute release of nitric oxide through endothelial TRPV1 receptor activation in the rat arterial mesenteric bed. J Physiol 568: 539-551, 2005. [PubMed: 16081483]

217. Potier M, Trebak M. New developments in the signaling mechanisms of the store-operated calcium entry pathway. Pflugers Arch 457: 405-415, 2008. [PubMed: 18536932]

218. Pozsgai G, Bodkin JV, Graepel R, Bevan S, Andersson DA, Brain SD. Evidence for the pathophysiological relevance of TRPA1 receptors in the cardiovascular system in vivo. Cardiovasc Res 87: 760-768, 2010. [PubMed: 20442136]

219. Prawitt D, Monteilh-Zoller MK, Brixel L, Spangenberg C, Zabel B, Fleig A, Penner R. TRPM5 is a transient $\mathrm{Ca} 2+-$ activated cation channel responding to rapid changes in $[\mathrm{Ca} 2+]$ i. Proc Natl Acad Sci USA 100: 15166-15171, 2003. [PubMed: 14634208]

220. Qi Z, Wong CK, Suen CH, Wang J, Long C, Sauer H, Yao X, Tsang SY. TRPC3 regulates the automaticity of embryonic stem cell-derived cardiomyocytes. Int J Cardiol 203: 169-181, 2016. [PubMed: 26512833]

221. Qian X, Francis M, Solodushko V, Earley S, Taylor MS. Recruitment of dynamic endothelial Ca2+ signals by the TRPA1 channel activator AITC in rat cerebral arteries. Microcirculation 20: 138-148, 2013. [PubMed: 22928941]

222. Qu YY, Wang LM, Zhong H, Liu YM, Tang N, Zhu LP, He F, Hu QH. TRPC1 stimulates calciumsensing receptorinduced storeoperated $\mathrm{Ca} 2+$ entry and nitric oxide production in endothelial cells. Mol Med Rep 16: 4613-4619, 2017. [PubMed: 28791397]

223. Radomski MW, Palmer RM, Moncada S. The anti-aggregating properties of vascular endothelium: Interactions between prostacyclin and nitric oxide. Br J Pharmacol 92: 639-646, 1987. [PubMed: 3322462]

224. Rosker C, Graziani A, Lukas M, Eder P, Zhu MX, Romanin C, Groschner K. Ca(2+) signaling by TRPC 3 involves $\mathrm{Na}(+)$ entry and local coupling to the $\mathrm{Na}(+) / \mathrm{Ca}(2+)$ exchanger. $\mathrm{J}$ Biol Chem 279: 13696-13704, 2004. [PubMed: 14736881]

225. Rubaiy HN, Ludlow MJ, Henrot M, Gaunt HJ, Miteva K, Cheung SY, Tanahashi Y, Hamzah N, Musialowski KE, Blythe NM, Appleby HL, Bailey MA, McKeown L, Taylor R, Foster R, Waldmann H, Nussbaumer P, Christmann M, Bon RS, Muraki K, Beech DJ. Pico-molar, selective, and subtype-specific small-molecule inhibition of TRPC1/2/5 channels. J Biol Chem 292: 8158-8173, 2017. [PubMed: 28325835]

226. Sadler JE. Thrombomodulin structure and function. Thromb Haemost 78: 392-395, 1997. [PubMed: 9198185]

227. Saliez J, Bouzin C, Rath G, Ghisdal P, Desjardins F, Rezzani R, Rodella LF, Vriens J, Nilius B, Feron O, Balligand JL, Dessy C. Role of cave-olar compartmentation in endothelium-derived hyperpolarizing factor-mediated relaxation: $\mathrm{Ca} 2+$ signals and gap junction function are regulated by caveolin in endothelial cells. Circulation 117: 1065-1074, 2008. [PubMed: 18268148]

228. Samapati R, Yang Y, Yin J, Stoerger C, Arenz C, Dietrich A, Gudermann T, Adam D, Wu S, Freichel M, Flockerzi V, Uhlig S, Kuebler WM. Lung endothelial Ca2+ and permeability response to platelet-activating factor is mediated by acid sphingomyelinase and transient receptor potential classical 6. Am J Respir Crit Care Med 185: 160-170, 2012. [PubMed: 22246702]

229. Sammani S, Moreno-Vinasco L, Mirzapoiazova T, Singleton PA, Chiang ET, Evenoski CL, Wang T, Mathew B, Husain A, Moitra J, Sun X, Nunez L, Jacobson JR, Dudek SM, Natarajan V, Garcia 
JG. Differential effects of sphingosine 1-phosphate receptors on airway and vascular barrier function in the murine lung. Am J Respir Cell Mol Biol 43: 394-402, 2010. [PubMed: 19749179]

230. Sano Y, Inamura K, Miyake A, Mochizuki S, Yokoi H, Matsushime H, Furuichi K. Immunocyte Ca2+ influx system mediated by LTRPC2. Science 293: 1327-1330, 2001. [PubMed: 11509734]

231. Saotome K, Singh AK, Yelshanskaya MV, Sobolevsky AI. Crystal structure of the epithelial calcium channel TRPV6. Nature 534: 506-511, 2016. [PubMed: 27296226]

232. Schaefer M, Plant TD, Obukhov AG, Hofmann T, Gudermann T, Schultz G. Receptor-mediated regulation of the nonselective cation channels TRPC4 and TRPC5. J Biol Chem 275: 1751717526, 2000. [PubMed: 10837492]

233. Schierling W, Troidl K, Apfelbeck H, Troidl C, Kasprzak PM, Schaper W, Schmitz-Rixen T. Cerebral arteriogenesis is enhanced by pharmacological as well as fluid-shear-stress activation of the Trpv4 calcium channel. Eur J Vasc Endovasc Surg 41: 589-596, 2011. [PubMed: 21316269]

234. Schindl R, Fritsch R, Jardin I, Frischauf I, Kahr H, Muik M, Riedl MC, Groschner K, Romanin C. Canonical transient receptor potential (TRPC) 1 acts as a negative regulator for vanilloid TRPV6mediated Ca2+ influx. J Biol Chem 287: 35612-35620, 2012. [PubMed: 22932896]

235. Schmidt K, Dubrovska G, Nielsen G, Fesus G, Uhrenholt TR, Hansen PB, Gudermann T, Dietrich A, Gollasch M, de Wit C, Kohler R. Amplification of EDHF-type vasodilatations in TRPC1deficient mice. Br J Pharmacol 161: 1722-1733, 2010. [PubMed: 20718731]

236. Schmiege P, Fine M, Blobel G, Li X. Human TRPML1 channel structures in open and closed conformations. Nature 550: 366-370, 2017. [PubMed: 29019983]

237. Schubert W, Frank PG, Razani B, Park DS, Chow CW, Lisanti MP. Caveolae-deficient endothelial cells show defects in the uptake and transport of albumin in vivo. J Biol Chem 276: 4861948622, 2001. [PubMed: 11689550]

238. Semtner M, Schaefer M, Pinkenburg O, Plant TD. Potentiation of TRPC5 by protons. J Biol Chem 282: 33868-33878, 2007. [PubMed: 17884814]

239. Senadheera S, Bertrand PP, Grayson TH, Leader L, Murphy TV, Sandow SL. Pregnancy-induced remodelling and enhanced endothelium-derived hyperpolarization-type vasodilator activity in rat uterine radial artery: Transient receptor potential vanilloid type 4 channels, caveolae and myoendothelial gap junctions. J Anat 223: 677-686, 2013. [PubMed: 24128141]

240. Senadheera S, Kim Y, Grayson TH, Toemoe S, Kochukov MY, Abramowitz J, Housley GD, Bertrand RL, Chadha PS, Bertrand PP, Murphy TV, Tare M, Birnbaumer L, Marrelli SP, Sandow SL. Transient receptor potential canonical type 3 channels facilitate endothelium-derived hyperpolarization-mediated resistance artery vasodilator activity. Cardiovasc Res 95: 439-447, 2012. [PubMed: 22721989]

241. Sharif-Naeini R, Folgering JH, Bichet D, Duprat F, Lauritzen I, Arhatte M, Jodar M, Dedman A, Chatelain FC, Schulte U, Retailleau K, Loufrani L, Patel A, Sachs F, Delmas P, Peters DJ, Honore E. Polycystin-1 and -2 dosage regulates pressure sensing. Cell 139: 587-596, 2009. [PubMed: 19879844]

242. Shen PS, Yang X, DeCaen PG, Liu X, Bulkley D, Clapham DE, Cao E. The structure of the polycystic kidney disease channel PKD2 in lipid nanodiscs. Cell 167: 763-773 e711, 2016. [PubMed: 27768895]

243. Shinde AV, Motiani RK, Zhang X, Abdullaev IF, Adam AP, Gonzalez-Cobos JC, Zhang W, Matrougui K, Vincent PA, Trebak M. STIM1 controls endothelial barrier function independently of Orai1 and Ca2+ entry. Sci Signal 6: ra18, 2013. [PubMed: 23512989]

244. Singh I, Knezevic N, Ahmmed GU, Kini V, Malik AB, Mehta D. Galphaq-TRPC6-mediated $\mathrm{Ca} 2+$ entry induces RhoA activation and resultant endothelial cell shape change in response to thrombin. J Biol Chem 282: 7833-7843, 2007. [PubMed: 17197445]

245. Smedlund K, Dube P, Vazquez G. Early steatohepatitis in hyperlipidemic mice with endothelialspecific gain of TRPC3 function precedes changes in aortic atherosclerosis. Physiol Genomics 48: 644-649, 2016. [PubMed: 27449657]

246. Smedlund K, Tano JY, Vazquez G. The constitutive function of native TRPC3 channels modulates vascular cell adhesion molecule-1 expression in coronary endothelial cells through nuclear factor kappaB signaling. Circ Res 106: 1479-1488, 2010. [PubMed: 20360250] 
247. Smedlund K, Vazquez G. Involvement of native TRPC3 proteins in ATP-dependent expression of VCAM-1 and monocyte adherence in coronary artery endothelial cells. Arterioscler Thromb Vasc Biol 28: 2049-2055, 2008. [PubMed: 18787184]

248. Smedlund KB, Birnbaumer L, Vazquez G. Increased size and cellularity of advanced atherosclerotic lesions in mice with endothelial overexpression of the human TRPC3 channel. Proc Natl Acad Sci USA 112: E2201-E2206, 2015. [PubMed: 25870279]

249. Smyth JT, Dehaven WI, Jones BF, Mercer JC, Trebak M, Vazquez G, Putney JW Jr. Emerging perspectives in store-operated Ca2+ entry: Roles of Orai, Stim and TRP. Biochim Biophys Acta 1763: 1147-1160, 2006. [PubMed: 17034882]

250. Smyth JT, Hwang SY, Tomita T, DeHaven WI, Mercer JC, Putney JW. Activation and regulation of store-operated calcium entry. J Cell Mol Med 14: 2337-2349, 2010. [PubMed: 20807283]

251. Soboloff J, Rothberg BS, Madesh M, Gill DL. STIM proteins: Dynamic calcium signal transducers. Nat Rev Mol Cell Biol 13: 549-565, 2012. [PubMed: 22914293]

252. Song K, Wang H, Kamm GB, Pohle J, Reis FC, Heppenstall P, Wende H, Siemens J. The TRPM2 channel is a hypothalamic heat sensor that limits fever and can drive hypothermia. Science 353: 1393-1398, 2016. [PubMed: 27562954]

253. Sonkusare SK, Bonev AD, Ledoux J, Liedtke W, Kotlikoff MI, Heppner TJ, Hill-Eubanks DC, Nelson MT. Elementary Ca2+ signals through endothelial TRPV4 channels regulate vascular function. Science 336: 597-601, 2012. [PubMed: 22556255]

254. Sonkusare SK, Dalsgaard T, Bonev AD, Hill-Eubanks DC, Kotlikoff MI, Scott JD, Santana LF, Nelson MT. AKAP150-dependent cooperative TRPV4 channel gating is central to endotheliumdependent vasodilation and is disrupted in hypertension. Sci Signal 7: ra66, 2014. [PubMed: 25005230]

255. Spassova MA, Hewavitharana T, Xu W, Soboloff J, Gill DL. A common mechanism underlies stretch activation and receptor activation of TRPC6 channels. Proc Natl Acad Sci USA 103: 16586-16591, 2006. [PubMed: 17056714]

256. Storch U, Forst AL, Philipp M, Gudermann T, Mederos y Schnitzler M. Transient receptor potential channel 1 (TRPC1) reduces calcium permeability in heteromeric channel complexes. J Biol Chem 287: 3530-3540, 2012. [PubMed: 22157757]

257. Story GM, Peier AM, Reeve AJ, Eid SR, Mosbacher J, Hricik TR, Earley TJ, Hergarden AC, Andersson DA, Hwang SW, McIntyre P, Jegla T, Bevan S, Patapoutian A. ANKTM1, a TRP-like channel expressed in nociceptive neurons, is activated by cold temperatures. Cell 112: 819-829, 2003. [PubMed: 12654248]

258. Strotmann R, Harteneck C, Nunnenmacher K, Schultz G, Plant TD. OTRPC4, a nonselective cation channel that confers sensitivity to extra-cellular osmolarity. Nat Cell Biol 2: 695-702, 2000. [PubMed: 11025659]

259. Strubing C, Krapivinsky G, Krapivinsky L, Clapham DE. Formation of novel TRPC channels by complex subunit interactions in embryonic brain. J Biol Chem 278: 39014-39019, 2003. [PubMed: 12857742]

260. Strubing C, Krapivinsky G, Krapivinsky L, Clapham DE. TRPC1 and TRPC5 form a novel cation channel in mammalian brain. Neuron 29: 645-655, 2001. [PubMed: 11301024]

261. Su KH, Lee KI, Shyue SK, Chen HY, Wei J, Lee TS. Implication of transient receptor potential vanilloid type 1 in 14,15-epoxyeicosatrienoic acid-induced angiogenesis. Int J Biol Sci 10: 990996, 2014. [PubMed: 25210497]

262. Su KH, Lin SJ, Wei J, Lee KI, Zhao JF, Shyue SK, Lee TS. The essential role of transient receptor potential vanilloid 1 in simvastatin-induced activation of endothelial nitric oxide synthase and angiogenesis. Acta Physiol (Oxf) 212: 191-204, 2014. [PubMed: 25183024]

263. Su Q, Hu F, Liu Y, Ge X, Mei C, Yu S, Shen A, Zhou Q, Yan C, Lei J, Zhang Y, Liu X, Wang T. Cryo-EM structure of the polycystic kidney disease-like channel PKD2L1. Nat Commun 9: 1192, 2018. [PubMed: 29567962]

264. Sukumaran SV, Singh TU, Parida S, Narasimha Reddy Ch E, Thangamalai R, Kandasamy K, Singh V, Mishra SK. TRPV4 channel activation leads to endothelium-dependent relaxation mediated by nitric oxide and endothelium-derived hyperpolarizing factor in rat pulmonary artery. Pharmacol Res 78: 18-27, 2013. [PubMed: 24075884] 
265. Sullivan MN, Earley S. TRP channel $\mathrm{Ca}(2+)$ sparklets: Fundamental signals underlying endothelium-dependent hyperpolarization. Am J Physiol Cell Physiol 305: C999-C1008, 2013. [PubMed: 24025865]

266. Sullivan MN, Francis M, Pitts NL, Taylor MS, Earley S. Optical recording reveals novel properties of GSK1016790A-induced vanilloid transient receptor potential channel TRPV4 activity in primary human endothelial cells. Mol Pharmacol 82: 464-472, 2012. [PubMed: 22689561]

267. Sullivan MN, Gonzales AL, Pires PW, Bruhl A, Leo MD, Li W, Oulidi A, Boop FA, Feng Y, Jaggar JH, Welsh DG, Earley S. Localized TRPA1 channel Ca2+ signals stimulated by reactive oxygen species promote cerebral artery dilation. Sci Signal 8: ra2, 2015. [PubMed: 25564678]

268. Sundivakkam PC, Freichel M, Singh V, Yuan JP, Vogel SM, Flockerzi V, Malik AB, Tiruppathi C. The $\mathrm{Ca}(2+)$ sensor stromal interaction molecule 1 (STIM1) is necessary and sufficient for the store-operated $\mathrm{Ca}(2+)$ entry function of transient receptor potential canonical (TRPC) 1 and 4 channels in endothelial cells. Mol Pharmacol 81: 510-526, 2012. [PubMed: 22210847]

269. Suresh K, Servinsky L, Reyes J, Baksh S, Undem C, Caterina M, Pearse DB, Shimoda LA. Hydrogen peroxide-induced calcium influx in lung microvascular endothelial cells involves TRPV4. Am J Physiol Lung Cell Mol Physiol 309: L1467-L1477, 2015. [PubMed: 26453519]

270. Tajada S, Moreno CM, O’Dwyer S, Woods S, Sato D, Navedo MF, Santana LF. Distance constraints on activation of TRPV4 channels by AKAP150-bound PKCalpha in arterial myocytes. J Gen Physiol 149: 639-659, 2017. [PubMed: 28507079]

271. Takahashi N, Kozai D, Mori Y. TRP channels: Sensors and transducers of gasotransmitter signals. Front Physiol 3: 324, 2012. [PubMed: 22934072]

272. Tang Q, Guo W, Zheng L, Wu JX, Liu M, Zhou X, Zhang X, Chen L. Structure of the receptoractivated human TRPC6 and TRPC3 ion channels. Cell Res 28: 746-755, 2018. [PubMed: 29700422]

273. Tauseef M, Farazuddin M, Sukriti S, Rajput C, Meyer JO, Ramasamy SK, Mehta D. Transient receptor potential channel 1 maintains adherens junction plasticity by suppressing sphingosine kinase 1 expression to induce endothelial hyperpermeability. FASEB J 30: 102-110, 2016. [PubMed: 26316271]

274. Tauseef M, Kini V, Knezevic N, Brannan M, Ramchandaran R, Fyrst H, Saba J, Vogel SM, Malik $\mathrm{AB}$, Mehta $\mathrm{D}$. Activation of sphingosine kinase-1 reverses the increase in lung vascular permeability through sphingosine-1-phosphate receptor signaling in endothelial cells. Circ Res 103: 1164-1172, 2008. [PubMed: 18849324]

275. Tauseef M, Knezevic N, Chava KR, Smith M, Sukriti S, Gianaris N, Obukhov AG, Vogel SM, Schraufnagel DE, Dietrich A, Birnbaumer L, Malik AB, Mehta D. TLR4 activation of TRPC6dependent calcium signaling mediates endotoxin-induced lung vascular permeability and inflammation. J Exp Med 209: 1953-1968, 2012. [PubMed: 23045603]

276. Thodeti CK, Matthews B, Ravi A, Mammoto A, Ghosh K, Bracha AL, Ingber DE. TRPV4 channels mediate cyclic strain-induced endothelial cell reorientation through integrin-to-integrin signaling. Circ Res 104: 1123-1130, 2009. [PubMed: 19359599]

277. Thomas KC, Roberts JK, Deering-Rice CE, Romero EG, Dull RO, Lee J, Yost GS, Reilly CA. Contributions of TRPV1, endovanilloids, and endoplasmic reticulum stress in lung cell death in vitro and lung injury. Am J Physiol Lung Cell Mol Physiol 302: L111-119, 2012. [PubMed: 21949157]

278. Thorneloe KS, Cheung M, Bao W, Alsaid H, Lenhard S, Jian MY, Costell M, Maniscalco-Hauk K, Krawiec JA, Olzinski A, Gordon E, Lozinskaya I, Elefante L, Qin P, Matasic DS, James C, Tunstead J, Donovan B, Kallal L, Waszkiewicz A, Vaidya K, Davenport EA, Larkin J, Burgert M, Casillas LN, Marquis RW, Ye G, Eidam HS, Goodman KB, Toomey JR, Roethke TJ, Jucker BM, Schnackenberg CG, Townsley MI, Lepore JJ, Willette RN. An orally active TRPV4 channel blocker prevents and resolves pulmonary edema induced by heart failure. Sci Transl Med 4: 159ra148, 2012.

279. Thorneloe KS, Sulpizio AC, Lin Z, Figueroa DJ, Clouse AK, McCafferty GP, Chendrimada TP, Lashinger ES, Gordon E, Evans L, Misajet BA, Demarini DJ, Nation JH, Casillas LN, Marquis RW, Votta BJ, Sheardown SA, Xu X, Brooks DP, Laping NJ, Westfall TD. N-((1S)-1-\{[4-((2S)-2$\{[(2,4$-dichlorophenyl)sulfonyl $]$ amino $\}-3$-hydroxypropanoyl)-1-piperazinyl $]$ carbonyl $\}-3$ - 
methylbutyl)-1-benzothiophene-2-carboxamide (GSK1016790A), a novel and potent transient receptor potential vanilloid 4 channel agonist induces urinary bladder contraction and hyperactivity: Part I. J Pharmacol Exp Ther 326: 432-442, 2008. [PubMed: 18499743]

280. Tiruppathi C, Freichel M, Vogel SM, Paria BC, Mehta D, Flockerzi V, Malik AB. Impairment of store-operated $\mathrm{Ca} 2+$ entry in TRPC4(-/-) mice interferes with increase in lung microvascular permeability. Circ Res 91: 70-76, 2002. [PubMed: 12114324]

281. Torres-Narvaez JC, Mondragon Ldel V, Varela Lopez E, Perez-Torres I, Diaz Juarez JA, Suarez J, Hernandez GP. Role of the transient receptor potential vanilloid type 1 receptor and stretchactivated ion channels in nitric oxide release from endothelial cells of the aorta and heart in rats. Exp Clin Cardiol 17: 89-94, 2012. [PubMed: 23620694]

282. Townsley MI, Morisseau C, Hammock B, King JA. Impact of epoxyeicosatrienoic acids in lung ischemia-reperfusion injury. Microcirculation 17: 137-146, 2010. [PubMed: 20163540]

283. Tran QK, Watanabe H. Calcium signalling in the endothelium. Handb Exp Pharmacol 145-187, 2006. [PubMed: 16999219]

284. Trebak M STIM1/Orai1, ICRAC, and endothelial SOC. Circ Res 104: e56-57, 2009. [PubMed: 19423858]

285. Troidl C, Troidl K, Schierling W, Cai WJ, Nef H, Mollmann H, Kostin S, Schimanski S, Hammer L, Elsasser A, Schmitz-Rixen T, Schaper W. Trpv4 induces collateral vessel growth during regeneration of the arterial circulation. J Cell Mol Med 13: 2613-2621, 2009. [PubMed: 19017361]

286. Uchida K 4-Hydroxy-2-nonenal: A product and mediator of oxidative stress. Prog Lipid Res 42: 318-343, 2003. [PubMed: 12689622]

287. Venkatachalam K, Montell C. TRP channels. Annu Rev Biochem 76: 387-417, 2007. [PubMed: 17579562]

288. Vennekens R, Hoenderop JG, Prenen J, Stuiver M, Willems PH, Droogmans G, Nilius B, Bindels RJ. Permeation and gating properties of the novel epithelial $\mathrm{Ca}(2+)$ channel. J Biol Chem 275: 3963-3969, 2000. [PubMed: 10660551]

289. Verhamme P, Hoylaerts MF. The pivotal role of the endothelium in haemostasis and thrombosis. Acta Clin Belg 61: 213-219, 2006. [PubMed: 17240734]

290. Vig M, Peinelt C, Beck A, Koomoa DL, Rabah D, Koblan-Huberson M, Kraft S, Turner H, Fleig A, Penner R, Kinet JP. CRACM1 is a plasma membrane protein essential for store-operated Ca2+ entry. Science 312: 1220-1223, 2006. [PubMed: 16645049]

291. Villalta PC, Rocic P, Townsley MI. Role of MMP2 and MMP9 in TRPV4-induced lung injury. Am J Physiol Lung Cell Mol Physiol 307: L652-L659, 2014. [PubMed: 25150065]

292. Vinayagam D, Mager T, Apelbaum A, Bothe A, Merino F, Hofnagel O, Gatsogiannis C, Raunser S. Electron cryo-microscopy structure of the canonical TRPC4 ion channel. Elife 7: pii: e36615, 2018. [PubMed: 29717981]

293. Vincent F, Acevedo A, Nguyen MT, Dourado M, DeFalco J, Gustafson A, Spiro P, Emerling DE, Kelly MG, Duncton MA. Identification and characterization of novel TRPV4 modulators. Biochem Biophys Res Commun 389: 490-494, 2009. [PubMed: 19737537]

294. Vriens J, Owsianik G, Fisslthaler B, Suzuki M, Janssens A, Voets T, Morisseau C, Hammock BD, Fleming I, Busse R, Nilius B. Modulation of the Ca2 permeable cation channel TRPV4 by cytochrome P450 epoxygenases in vascular endothelium. Circ Res 97: 908-915, 2005. [PubMed: 16179585]

295. Walker RL, Hume JR, Horowitz B. Differential expression and alternative splicing of TRP channel genes in smooth muscles. Am J Physiol Cell Physiol 280: C1184-C1192, 2001. [PubMed: 11287332]

296. Wang M, Ji P, Wang R, Zhao L, Xia Z. TRPV1 agonist capsaicin attenuates lung ischemiareperfusion injury in rabbits. J Surg Res 173: 153-160, 2012. [PubMed: 20950828]

297. Wang SQ, Song LS, Lakatta EG, Cheng H. Ca2+ signalling between single L-type Ca2+ channels and ryanodine receptors in heart cells. Nature 410: 592-596, 2001. [PubMed: 11279498]

298. Wang X, Lau F, Li L, Yoshikawa A, van Breemen C. Acetylcholine-sensitive intracellular Ca2+ store in fresh endothelial cells and evidence for ryanodine receptors. Circ Res 77: 37-42, 1995. [PubMed: 7788880] 
299. Wang Y, Cui L, Xu H, Liu S, Zhu F, Yan F, Shen S, Zhu M. TRPV1 agonism inhibits endothelial cell inflammation via activation of eNOS/NO pathway. Atherosclerosis 260: 13-19, 2017. [PubMed: 28324760]

300. Wang Y, Deng X, Zhou Y, Hendron E, Mancarella S, Ritchie MF, Tang XD, Baba Y, Kurosaki T, Mori Y, Soboloff J, Gill DL. STIM protein coupling in the activation of Orai channels. Proc Natl Acad Sci USA 106: 7391-7396, 2009. [PubMed: 19376967]

301. Watanabe H, Davis JB, Smart D, Jerman JC, Smith GD, Hayes P, Vriens J, Cairns W, Wissenbach U, Prenen J, Flockerzi V, Droogmans G, Benham CD, Nilius B. Activation of TRPV4 channels (hVRL-2/mTRP12) by phorbol derivatives. J Biol Chem 277: 13569-13577, 2002. [PubMed: 11827975]

302. Watanabe H, Vriens J, Prenen J, Droogmans G, Voets T, Nilius B. Anandamide and arachidonic acid use epoxyeicosatrienoic acids to activate TRPV4 channels. Nature 424: 434-438, 2003. [PubMed: 12879072]

303. Watanabe H, Vriens J, Suh SH, Benham CD, Droogmans G, Nilius B. Heat-evoked activation of TRPV4 channels in a HEK293 cell expression system and in native mouse aorta endothelial cells. J Biol Chem 277: 47044-47051, 2002. [PubMed: 12354759]

304. Weber EW, Han F, Tauseef M, Birnbaumer L, Mehta D, Muller WA. TRPC6 is the endothelial calcium channel that regulates leukocyte transendothelial migration during the inflammatory response. J Exp Med 212: 1883-1899, 2015. [PubMed: 26392222]

305. Wilhelmsen K, Khakpour S, Tran A, Sheehan K, Schumacher M, Xu F, Hellman J. The endocannabinoid/endovanilloid $\mathrm{N}$-arachidonoyl dopamine (NADA) and synthetic cannabinoid WIN55,212-2 abate the inflammatory activation of human endothelial cells. J Biol Chem 289: 13079-13100, 2014. [PubMed: 24644287]

306. Wilkes M, Madej MG, Kreuter L, Rhinow D, Heinz V, De Sanctis S, Ruppel S, Richter RM, Joos F, Grieben M, Pike AC, Huiskonen JT, Carpenter EP, Kuhlbrandt W, Witzgall R, Ziegler C. Molecular insights into lipid-assisted $\mathrm{Ca}(2+)$ regulation of the TRP channel Polycystin-2. Nat Struct Mol Biol 24: 123-130, 2017. [PubMed: 28092368]

307. Willette RN, Bao W, Nerurkar S, Yue TL, Doe CP, Stankus G, Turner GH, Ju H, Thomas H, Fishman CE, Sulpizio A, Behm DJ, Hoffman S, Lin Z, Lozinskaya I, Casillas LN, Lin M, Trout RE, Votta BJ, Thorneloe K, Lashinger ES, Figueroa DJ, Marquis R, Xu X. Systemic activation of the transient receptor potential vanilloid subtype 4 channel causes endothelial failure and circulatory collapse: Part 2. J Pharmacol Exp Ther 326: 443-452, 2008. [PubMed: 18499744]

308. Wilson PD. Polycystic kidney disease: New understanding in the pathogenesis. Int J Biochem Cell Biol 36: 1868-1873, 2004. [PubMed: 15203099]

309. Winkler PA, Huang Y, Sun W, Du J, Lu W. Electron cryo-microscopy structure of a human TRPM4 channel. Nature 552: 200-204, 2017. [PubMed: 29211723]

310. Winn MP, Conlon PJ, Lynn KL, Farrington MK, Creazzo T, Hawkins AF, Daskalakis N, Kwan SY, Ebersviller S, Burchette JL, Pericak-Vance MA, Howell DN, Vance JM, Rosenberg PB. A mutation in the TRPC6 cation channel causes familial focal segmental glomerulosclerosis. Science 308: 1801-1804, 2005. [PubMed: 15879175]

311. Wong CO, Sukumar P, Beech DJ, Yao X. Nitric oxide lacks direct effect on TRPC5 channels but suppresses endogenous TRPC5-containing channels in endothelial cells. Pflugers Arch 460: 121130, 2010. [PubMed: 20390293]

312. Wong PS, Roberts RE, Randall MD. Sex differences in the role of transient receptor potential (TRP) channels in endothelium-dependent vasorelaxation in porcine isolated coronary arteries. Eur J Pharmacol 750: 108-117, 2015. [PubMed: 25620134]

313. Woodfin A, Voisin MB, Nourshargh S. Recent developments and complexities in neutrophil transmigration. Curr Opin Hematol 17: 9-17, 2010. [PubMed: 19864945]

314. Wu S, Cioffi EA, Alvarez D, Sayner SL, Chen H, Cioffi DL, King J, Creighton JR, Townsley M, Goodman SR, Stevens T. Essential role of a Ca2+-selective, store-operated current (ISOC) in endothelial cell permeability: Determinants of the vascular leak site. Circ Res 96: 856-863, 2005. [PubMed: 15790951]

315. Wu S, Jian MY, Xu YC, Zhou C, Al-Mehdi AB, Liedtke W, Shin HS, Townsley MI. Ca2+ entry via alpha1G and TRPV4 channels differentially regulates surface expression of P-selectin and 
barrier integrity in pulmonary capillary endothelium. Am J Physiol Lung Cell Mol Physiol 297: L650-L657, 2009. [PubMed: 19617313]

316. Xi Q, Adebiyi A, Zhao G, Chapman KE, Waters CM, Hassid A, Jaggar JH. IP3 constricts cerebral arteries via IP3 receptor-mediated TRPC3 channel activation and independently of sarcoplasmic reticulum Ca2+ release. Circ Res 102: 1118-1126, 2008. [PubMed: 18388325]

317. Xia R, Mei ZZ, Mao HJ, Yang W, Dong L, Bradley H, Beech DJ, Jiang LH. Identification of pore residues engaged in determining divalent cationic permeation in transient receptor potential melastatin subtype channel 2. J Biol Chem 283: 27426-27432, 2008. [PubMed: 18687688]

318. Xu F, Satoh E, Iijima T. Protein kinase C-mediated Ca2+ entry in HEK 293 cells transiently expressing human TRPV4. Br J Pharmacol 140: 413-421, 2003. [PubMed: 12970074]

319. Xu H, Delling M, Jun JC, Clapham DE. Oregano, thyme and clove-derived flavors and skin sensitizers activate specific TRP channels. Nat Neurosci 9: 628-635, 2006. [PubMed: 16617338]

320. Xu H, Ramsey IS, Kotecha SA, Moran MM, Chong JA, Lawson D, Ge P, Lilly J, Silos-Santiago I, Xie Y, DiStefano PS, Curtis R, Clapham DE. TRPV3 is a calcium-permeable temperaturesensitive cation channel. Nature 418: 181-186, 2002. [PubMed: 12077604]

321. Xu J, Mathur J, Vessieres E, Hammack S, Nonomura K, Favre J, Grimaud L, Petrus M, Francisco A, Li J, Lee V, Xiang FL, Mainquist JK, Cahalan SM, Orth AP, Walker JR, Ma S, Lukacs V, Bordone L, Bandell M, Laffitte B, Xu Y, Chien S, Henrion D, Patapoutian A. GPR68 senses flow and is essential for vascular physiology. Cell 173: 762-775e716, 2018. [PubMed: 29677517]

322. Xu S, Liu B, Yin M, Koroleva M, Mastrangelo M, Ture S, Morrell CN, Zhang DX, Fisher EA, Jin ZG. A novel TRPV4-specific agonist inhibits monocyte adhesion and atherosclerosis. Oncotarget 7: 37622-37635, 2016. [PubMed: 27191895]

323. Yamaguchi H, Matsushita M, Nairn AC, Kuriyan J. Crystal structure of the atypical protein kinase domain of a TRP channel with phosphotransferase activity. Mol Cell 7: 1047-1057, 2001. [PubMed: 11389851]

324. Yamamoto S, Shimizu S, Kiyonaka S, Takahashi N, Wajima T, Hara Y, Negoro T, Hiroi T, Kiuchi Y, Okada T, Kaneko S, Lange I, Fleig A, Penner R, Nishi M, Takeshima H, Mori Y. TRPM2mediated $\mathrm{Ca} 2+$ influx induces chemokine production in monocytes that aggravates inflammatory neutrophil infiltration. Nat Med 14: 738-747, 2008. [PubMed: 18542050]

325. Yang D, Luo Z, Ma S, Wong WT, Ma L, Zhong J, He H, Zhao Z, Cao T, Yan Z, Liu D, Arendshorst WJ, Huang Y, Tepel M, Zhu Z. Activation of TRPV1 by dietary capsaicin improves endothelium-dependent vasorelaxation and prevents hypertension. Cell Metab 12: 130-141, 2010. [PubMed: 20674858]

326. Yildirim E, Dietrich A, Birnbaumer L. The mouse C-type transient receptor potential 2 (TRPC2) channel: Alternative splicing and calmodulin binding to its $\mathrm{N}$ terminus. Proc Natl Acad Sci USA 100: 2220-2225, 2003. [PubMed: 12601176]

327. Yin J, Hoffmann J, Kaestle SM, Neye N, Wang L, Baeurle J, Liedtke W, Wu S, Kuppe H, Pries AR, Kuebler WM. Negative-feedback loop attenuates hydrostatic lung edema via a cGMPdependent regulation of transient receptor potential vanilloid 4. Circ Res 102: 966-974, 2008. [PubMed: 18323527]

328. Yin Y, Wu M, Zubcevic L, Borschel WF, Lander GC, Lee SY. Structure of the cold- and mentholsensing ion channel TRPM8. Science 359: 237-241, 2018. [PubMed: 29217583]

329. Yip H, Chan WY, Leung PC, Kwan HY, Liu C, Huang Y, Michel V, Yew DT, Yao X. Expression of TRPC homologs in endothelial cells and smooth muscle layers of human arteries. Histochem Cell Biol 122: 553-561, 2004. [PubMed: 15538613]

330. Yoshida T, Inoue R, Morii T, Takahashi N, Yamamoto S, Hara Y, Tominaga M, Shimizu S, Sato Y, Mori Y. Nitric oxide activates TRP channels by cysteine S-nitrosylation. Nat Chem Biol 2: 596607, 2006. [PubMed: 16998480]

331. Yu PC, Gu SY, Bu JW, Du JL. TRPC1 is essential for in vivo angio-genesis in zebrafish. Circ Res 106: 1221-1232, 2010. [PubMed: 20185799]

332. Yue L, Peng J-B, Hediger MA, Clapham DE. CaT1 manifests the pore properties of the calciumrelease-activated calcium channel. Nature 410: 705-709, 2001. [PubMed: 11287959]

333. Zhang DX, Mendoza SA, Bubolz AH, Mizuno A, Ge ZD, Li R, Warltier DC, Suzuki M, Gutterman DD. Transient receptor potential vanilloid type 4-deficient mice exhibit impaired 
endothelium-dependent relaxation induced by acetylcholine in vitro and in vivo. Hypertension 53: 532-538, 2009. [PubMed: 19188524]

334. Zhang J, Burridge KA, Friedman MH. In vivo differences between endothelial transcriptional profiles of coronary and iliac arteries revealed by microarray analysis. Am J Physiol Heart Circ Physiol 295: H1556-H1561, 2008. [PubMed: 18689496]

335. Zhang P, Luo Y, Chasan B, Gonzalez-Perrett S, Montalbetti N, Timpanaro GA, Cantero Mdel R, Ramos AJ, Goldmann WH, Zhou J, Cantiello HF. The multimeric structure of polycystin-2 (TRPP2): structural-functional correlates of homo- and hetero-multimers with TRPC1. Hum Mol Genet 18: 1238-1251, 2009. [PubMed: 19193631]

336. Zhang S, Li N, Zeng W, Gao N, Yang M. Cryo-EM structures of the mammalian endo-lysosomal TRPML1 channel elucidate the combined regulation mechanism. Protein Cell 8: 834-847, 2017. [PubMed: 28936784]

337. Zhang Z, Toth B, Szollosi A, Chen J, Csanady L. Structure of a TRPM2 channel in complex with $\mathrm{Ca}(2+)$ explains unique gating regulation. Elife 7: pii: e36409, 2018. [PubMed: 29745897]

338. Zheng W, Yang X, Hu R, Cai R, Hofmann L, Wang Z, Hu Q, Liu X, Bulkey D, Yu Y, Tang J, Flockerzi V, Cao Y, Cao E, Chen XZ. Hydrophobic pore gates regulate ion permeation in polycystic kidney disease 2 and 2L1 channels. Nat Commun 9: 2302, 2018. [PubMed: 29899465]

339. Zhu Y, Pan Q, Meng H, Jiang Y, Mao A, Wang T, Hua D, Yao X, Jin J, Ma X. Enhancement of vascular endothelial growth factor release in long-term drug-treated breast cancer via transient receptor potential channel 5-Ca(2+)-hypoxia-inducible factor 1alpha pathway. Pharmacol Res 93: 36-42, 2015. [PubMed: 25579062]

340. Zitt C, Zobel A, Obukhov AG, Harteneck C, Kalkbrenner F, Luckhoff A, Schultz G. Cloning and functional expression of a human $\mathrm{Ca} 2+-$ permeable cation channel activated by calcium store depletion. Neuron 16: 1189-1196, 1996. [PubMed: 8663995]

341. Zubcevic L, Herzik MA Jr., Chung BC, Liu Z, Lander GC, Lee SY. Cryo-electron microscopy structure of the TRPV2 ion channel. Nat Struct Mol Biol 23: 180-186, 2016. [PubMed: 26779611] 


\section{Didactic Synopsis}

\section{Major teaching points}

1. The primary function of the vascular endothelium involves:

a. Regulating vascular tone

b. Maintaining the vascular barrier

c. Angiogenesis

d. Control of the inflammatory response

e. Antithrombosis

2. Understand that $\mathrm{Ca}^{2+}$ is key signaling messenger in mediating a physiological response

3. Differences in structural and biophysical properties of TRP channels

4. $\mathrm{Ca}^{2+}$ influx through TRP channels are important in maintaining normal endothelium function 


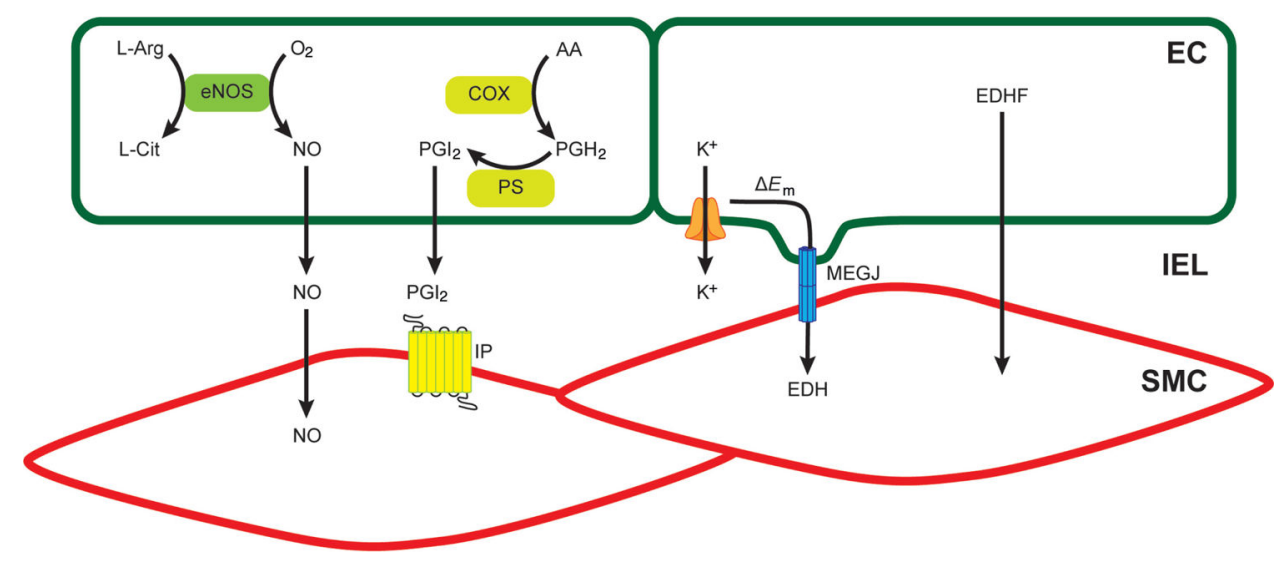

Figure 1.

Mechanism of endothelium-dependent dilation. Upon agonist stimulation, endothelial nitric oxide synthase (eNOS) activity increases to generate nitric oxide (NO). NO diffuses across the internal elastic lamina (IEL) to relax the underlying smooth muscle cells (SMC). Arachidonic acid (AA) metabolism by cyclooxygenase (COX) enzymes to produce prostaglandin $\mathrm{H}_{2}\left(\mathrm{PGH}_{2}\right)$. In turn, this is converted to prostacyclin $\left(\mathrm{PGI}_{2}\right)$ by prostacyclin synthase (PS), and mediates relaxation through the prostacyclin receptor (IP). Endothelial cell plasma membrane hyperpolarization generated by $\mathrm{K}^{+}$efflux $\left(\Delta E_{\mathrm{m}}\right)$ spreads through myoendothelial gap junctions (MEGJ) to promote endothelium-dependent hyperpolarization $(\mathrm{EDH})$ and relaxation. Several other factors, collectively termed as endothelium-derived hyperpolarizing factor (EDHF), hyperpolarizes smooth muscle cells to evoke relaxation. 
Table 1

\begin{tabular}{|c|c|c|c|c|c|}
\hline \multirow{3}{*}{ 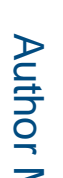 } & \multicolumn{5}{|c|}{ Function of Endothelial TRP Channels Summary } \\
\hline & TRP & Vasodilation & Permeability & Vessel formation & Inflammation \\
\hline & TRPA1 & $\uparrow$ & & $\uparrow$ & $\downarrow$ \\
\hline 及 & TRPV1 & $\uparrow$ & $\downarrow$ & $\uparrow$ & $\downarrow$ \\
\hline$\supseteq$ & TRPV3 & $\uparrow$ & & & \\
\hline 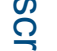 & TRPV4 & $\uparrow$ & $\uparrow$ & $\uparrow$ & $\downarrow$ \\
\hline$\overline{\mathrm{O}}$ & TRPC1 & $\uparrow$ & $\uparrow$ & $\uparrow$ & $\uparrow$ \\
\hline & TRPC3 & $\uparrow$ & & $\uparrow$ & $\uparrow$ \\
\hline & TRPC4 & $\uparrow$ & $\uparrow$ & $\uparrow$ & \\
\hline & TRPC5 & $\uparrow$ & & $\uparrow$ & \\
\hline & TRPC6 & & $\uparrow$ & $\uparrow$ & $\uparrow$ \\
\hline & TRPM2 & $\uparrow$ & $\uparrow \downarrow$ & & $\downarrow$ \\
\hline$D$ & TRPP1 & $\uparrow$ & & & \\
\hline
\end{tabular}

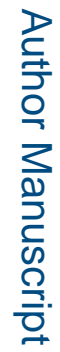

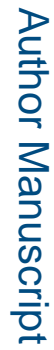

Compr Physiol. Author manuscript; available in PMC 2019 December 12. 


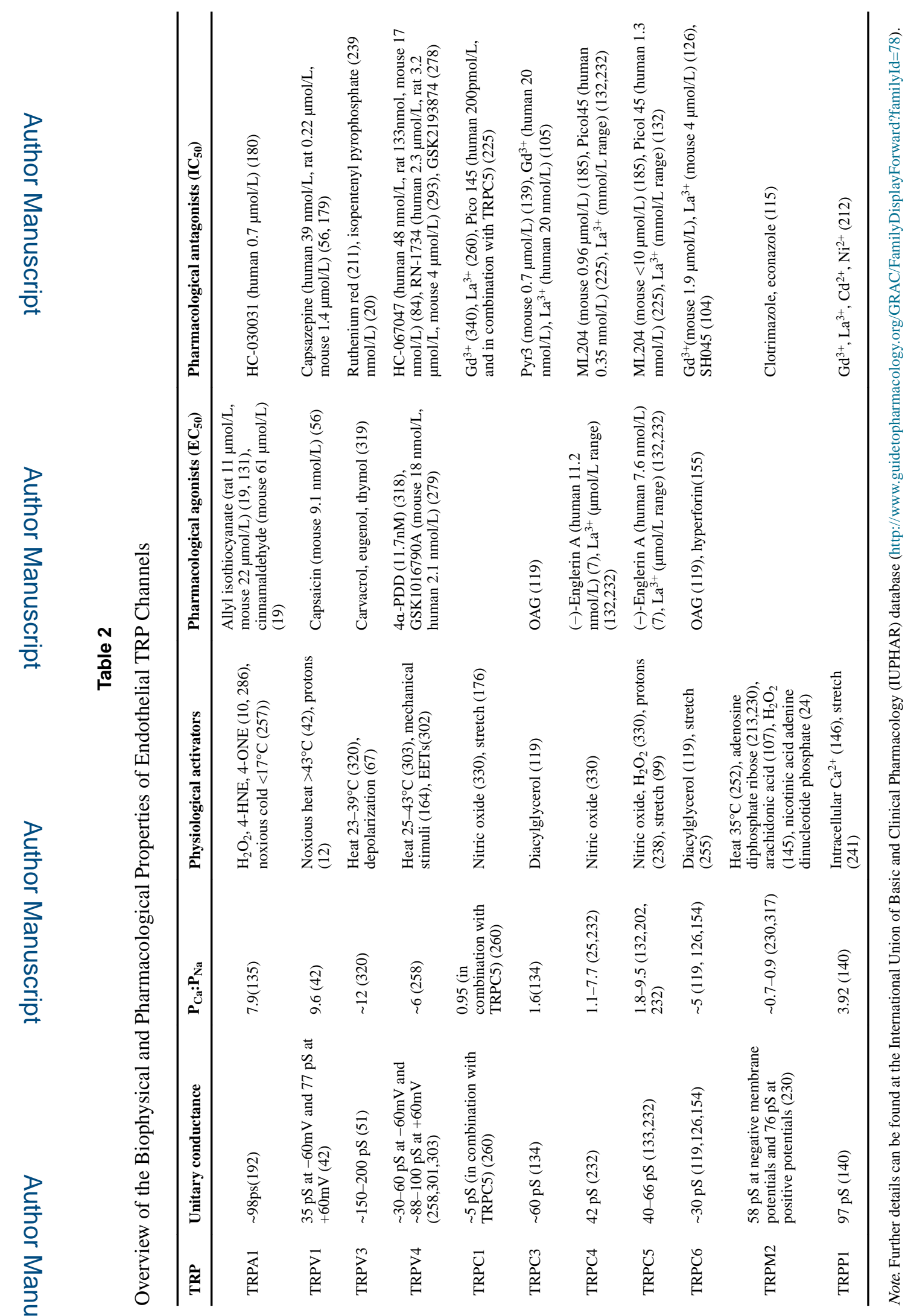

Compr Physiol. Author manuscript; available in PMC 2019 December 12. 